PERCY JAVIER IGEI KANESHIRO

PROPOSTA DE UM PROCEDIMENTO PARA A MODELAGEM DE SISTEMAS DE CONTROLE DE EDIFÍCIOS INTELIGENTES UTILIZANDO A REDE DE PETRI COLORIDA

Tese apresentada à Escola Politécnica da Universidade de São Paulo para obtenção do título de Doutor em Engenharia 
PERCY JAVIER IGEI KANESHIRO

\section{PROPOSTA DE UM PROCEDIMENTO PARA A MODELAGEM DE SISTEMAS DE CONTROLE DE EDIFÍCIOS INTELIGENTES UTILIZANDO A REDE DE PETRI COLORIDA}

Tese apresentada à Escola Politécnica da Universidade São Paulo para obtenção do título de Doutor em Engenharia

Área de concentração:

Engenharia de Computação e Sistemas

Digitais

Orientador:

Prof. Dr. Carlos Eduardo Cugnasca 
Este exemplar foi revisado e alterado em relação à versão original, sob responsabilidade única do autor e com a anuência de seu orientador.

São Paulo, 26 de setembro 2011

Assinatura do autor

Assinatura do orientador

Igei Kaneshiro, Percy Javier

Proposta de um procedimento para modelagem de sistemas de controle de edifícios inteligentes utilizando a rede de Petri colorida / P. J. Igei Kaneshiro. - ed.-ver. - São Paulo, 2011.

$116 \mathrm{p}$.

Tese (Doutorado) - Escola Politécnica da Universidade de São Paulo. Departamento de Engenharia de Computação e Sistemas Digitais.

1. Edifícios inteligentes 2. Automação predial (Simulação; Modelagem) 3. Redes de Petri I. Universidade de São Paulo. Escola Politécnica. Departamento de Engenharia de Computação e Sistemas Digitais II. t. 
À minha esposa, Midori. Aos meus queridos pais Yoichi e Michan. Aos meus queridos sogros Paulo e Rosa. 


\section{AGRADECIMENTOS}

Ao meu orientador, Prof. Dr. Carlos Eduardo Cugnasca, minha eterna gratidão pelo voto de confiança, pela constante orientação e por tudo o que aprendi com ele ao longo desses anos.

Aos Profs. Drs. Paulo Eigi Miyagi e Fabrício Junqueira pelas inúmeras e valiosas contribuições para o desenvolvimento deste trabalho.

Aos professores e alunos do Laboratório de Automação Agrícola (LAA) e do Laboratório de Automação de Sistemas (LAS), sou grato pelo apoio e pela amizade.

Aos meus colegas e amigos da Poli e do ITA, José, Mauricio, Juan, Roy, Marcosiris, Caio e Juan Carlos, sou grato pela grande amizade, assim como pelas inúmeras discussões criativas.

Ao Conselho Nacional de Desenvolvimento Científico e Tecnológico (CNPq), expresso minha gratidão pela concessão da bolsa de doutorado e pelo apoio financeiro para a realização deste trabalho.

Finalmente, gostaria de agradecer a todos aqueles que contribuíram direta ou indiretamente para a realização deste trabalho. 


\section{RESUMO}

Os avanços tecnológicos das últimas décadas têm motivado o desenvolvimento dos edifícios inteligentes, visando à criação de ambientes mais confortáveis e seguros para os ocupantes, economicamente vantajosos para os proprietários e ambientalmente corretos. Considerando-se que nestes ambientes emergem novas formas de interação entre os usuários e os sistemas prediais, as quais não são adequadamente tratadas por técnicas convencionais de modelagem, torna-se necessário o estudo de novas soluções que abordem essas interações. Assim, este trabalho apresenta a proposta de uma abordagem sistemática para modelar e simular os sistemas de controle de edifícios inteligentes. Considera-se o sistema de controle como um sistema orientado por eventos discretos, no qual a comunicação entre os dispositivos que o constituem é realizada por meio da troca assíncrona de mensagens. Nesta abordagem, é utilizada a rede de Petri colorida para especificar as funcionalidades do edifício inteligente e a interação entre os dispositivos que constituem o seu sistema de controle. Assim, fornece-se um procedimento estruturado para desenvolver modelos que facilita a especificação do algoritmo de controle dos subsistemas do edifício inteligente. Para avaliar as principais características do procedimento proposto, foi apresentado um exemplo de aplicação que aborda a integração das funcionalidades de um sistema de telefonia distribuído e um sistema de vigilância predial. A abordagem de modelagem possibilitou a identificação das funcionalidades dos dispositivos inteligentes que integram 0 sistema de controle em diferentes níveis de abstração e as interações que ocorrem durante o seu funcionamento. A realização deste trabalho contribui para o aprimoramento de novas abordagens para o desenvolvimento de sistemas de controle com arquiteturas heterárquicas. Estes sistemas são constituídos por dispositivos inteligentes colaborativos, que possuem um elevado grau de autonomia.

Palavras-chave: Edifício Inteligente, computação pervasiva, rede de Petri colorida, publish/subscribe, modelagem, simulação. 


\section{ABSTRACT}

Technological advances in recent decades have motivated the development of intelligent buildings, aimed at creating environments more productive for the occupants, economically advantageous for the owners and environmentally correct. New ways of interaction between users and the buildings systems are emerging from these kinds of systems, which are not adequately treated by conventional modeling techniques. In this sense, it is necessary the study of new approaches which address these new functionalities. Thus, this work presents a proposal for a systematic approach to model and simulate the control system of the intelligent buildings. The control system is considered to be a discrete event system, where the communication between the devices that integrate it is oriented by means of asynchronous messages exchange. This approach uses the colored Petri nets in order to specify the functionalities of the building system and their devices interactions. The approach provides a structured procedure to develop models that facilitate the algorithm specification of the control system. In order to verify the main characteristics of the proposed procedure, it is presented an example that is a control system that integrates a distributed telephony system and a surveillance building system. The approach proposed enabled the identification of the main functionalities and interactions of the intelligent devices constituting the control system. The achievement of this thesis contributes to the development of new approaches to develop heterarchical control system architectures. This kind of system architectures is constituted by collaborative intelligent devices that have a high degree of autonomy.

Keywords: Intelligent buildings, pervasive computing, colored Petri nets, publish/subscribe, modeling, simulation. 


\section{LISTA DE ILUSTRAÇÕES}

Figura 2.1 - (a) Sistema de Informação e (b) Sistema Produtivo (extraído de

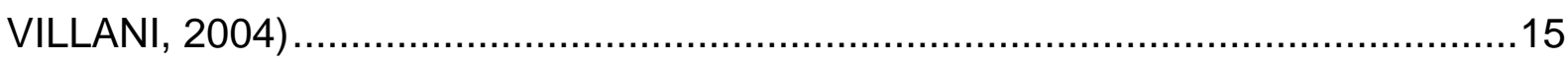

Figura 2.2 - Diagrama conceitual de um sistema de controle (MIYAGI, 1996) ..........16

Figura 2.4 - Evolução das arquiteturas de controle (Trentesaux (2009)) .................20

Figura 2.5 - Estrutura geral de funcionamento do El ...........................................23

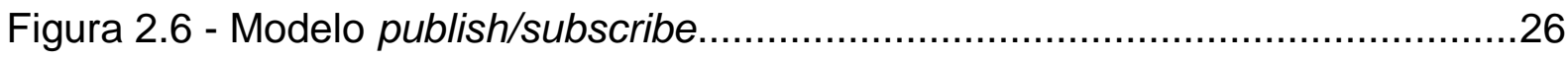

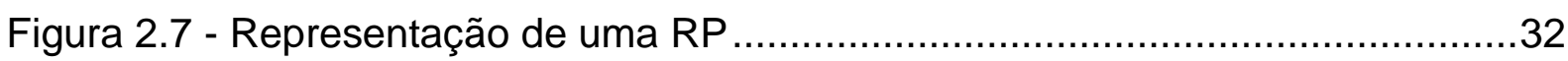

Figura 2.8 - Rede da Figura 2.6 após o disparo de T1 ..........................................

Figura 2.9 - Estrutura simplificada de um sistema de segurança predial .................36

Figura 2.10 - Modelo simplificado da especificação do sistema de segurança ..........37

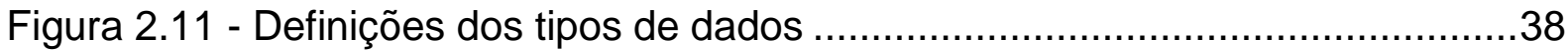

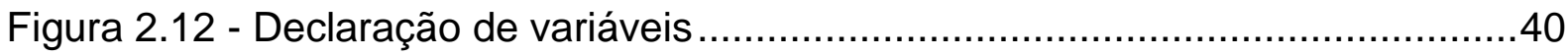

Figura 2.13 - Modelo hierárquico do sistema de segurança....................................41

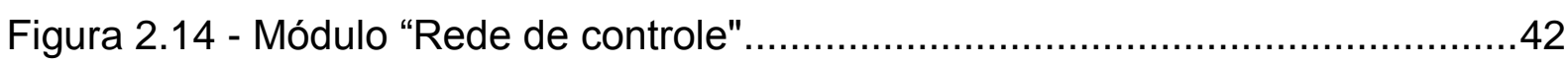

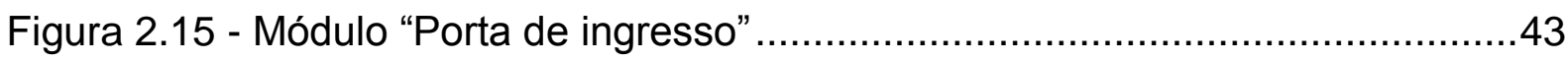

Figura 2.16 - Sistema de segurança para duas salas ..............................................4

Figura 2.17 - Módulo do Sistema de alerta ........................................................4

Figura 2.18 - Definições dos novos tipos de dados............................................... 45

Figura 2.19 - Modelo do sistema de segurança com múltiplas salas .......................46

Figura 2.20 - Chegada de uma marca ao módulo do Sistema de alerta ...................46

Figura 2.21 - Módulo de alerta depois que a transição "Acionar alerta" é disparada......47

Figura 2.22 - Framework de um sistema predial (Adaptado de Arakaki (2004)) .......49

Figura 2.23 - Esquema de um projeto de software (DEBONI, 2003)........................51

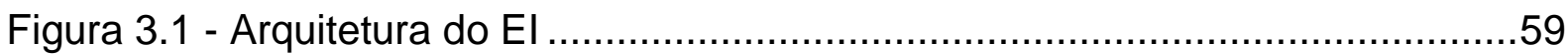

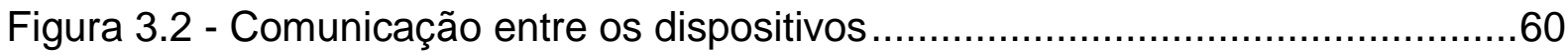

Figura 3.3 - Representação interna dos dispositivos de controle ..............................60

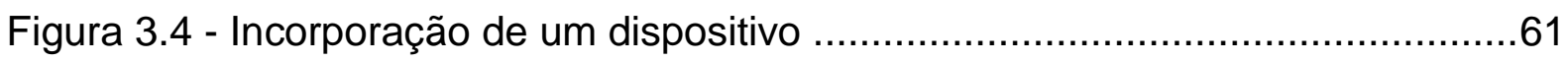

Figura 3.5 - Procedimento de modelagem proposto para o sistema de controle ......63

Figura 3.6 - Definição dos requisitos do sistema de controle predial .......................63

Figura 3.7 - Visão sistemática das estratégias de controle ......................................65 
Figura 3.8 - Visão sistemática da interação entre os dispositivos .66

Figura 3.9 - Saída de um dado do produtor .67

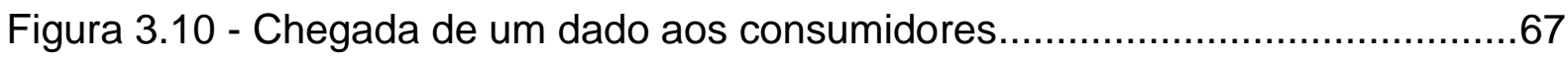

Figura 3.11 - Construção de componentes ........................................................68

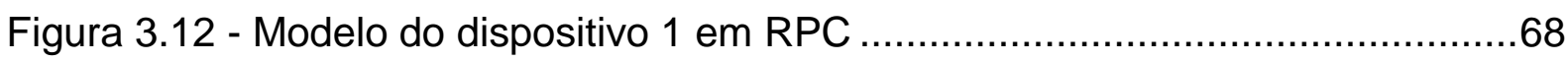

Figura 3.13 - Dinâmica do funcionamento do sistema de controle...........................69

Figura 3.14 - Substituição de transição "Processos" ..................................................70

Figura 3.15 - Modelo com "n" sensores.........................................................

Figura 3.16 - Modelo parametrizado de "n" sensores ............................................72

Figura 4.1- Diagrama do sistema de controle do El ...........................................78

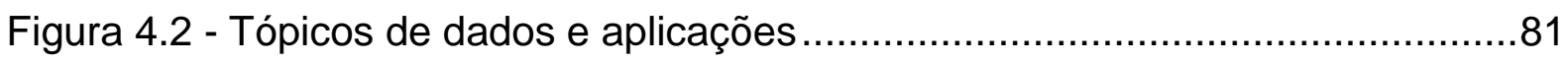

Figura 4.3 - Substituição de transição "Usuários nas salas".........................................83

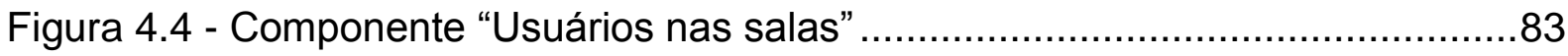

Figura 4.5 - Substituição de transição "Chamadas telefônicas".......................................84

Figura 4.6 - Componente "Chamadas telefônicas" ................................................. 84

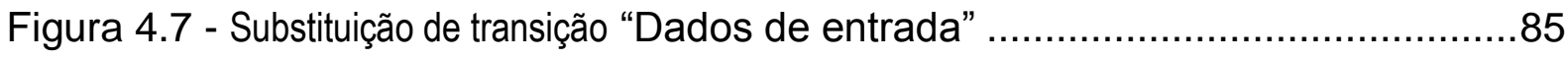

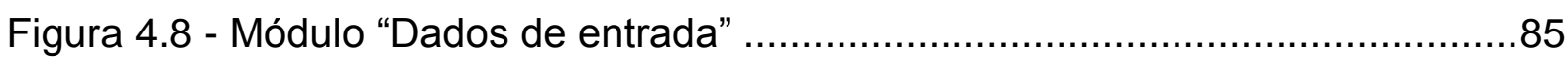

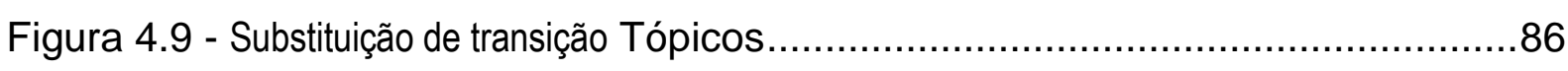

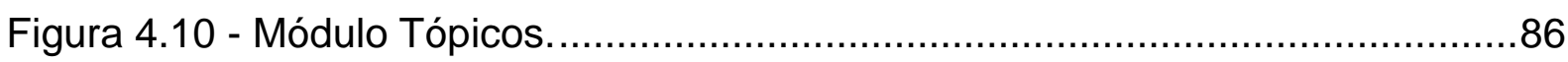

Figura 4.11 - Substituição de transição "Filtro Ramal 1" .............................................87

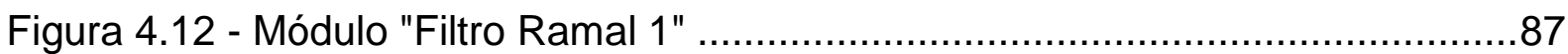

Figura 4.13 - Substituição de transição "Ramal 1" .......................................................8

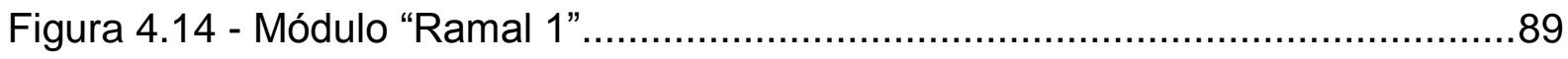

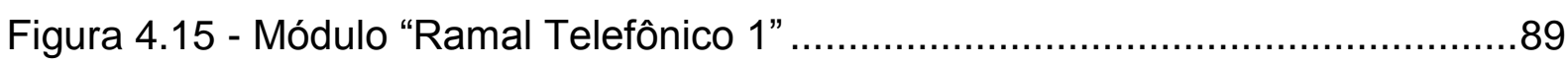

Figura 4.16 - Substituição de transição "Ramal Telefônico sala 1"...................................89

Figura 4.17 - Modelo de funcionamento do sistema de controle ..............................90

Figura 4.18 - Módulo Processos........................................................................

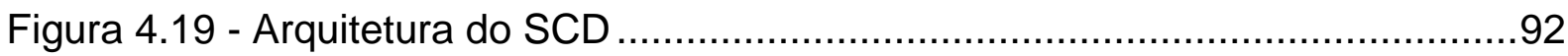

Figura 4.20 - Substituição de transição "Processos" .....................................................92

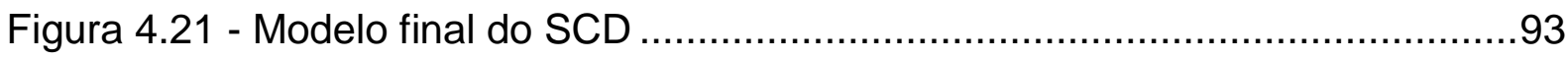




\section{LISTA DE QUADROS}

Quadro 1 - Interpretações típicas de lugares e transições (MURATA, 1989) .................29

Quadro 2 - Descrição das atividades dos dispositivos....................................... 80 


\section{LISTA DE ABREVIATURAS E SIGLAS}

$\begin{array}{ll}\text { ANP } & \text { Analytic Network Process } \\ \text { BMS } & \text { Building Management System } \\ \text { CLP } & \text { Controlador Lógico Programável } \\ \text { DSBC } & \text { Desenvolvimento de Software Baseado em Componentes } \\ \text { EI } & \text { Edifício Inteligente } \\ \text { HVAC } & \text { Ventilação e Ar Condicionado } \\ \text { In } & \text { Porta de entrada } \\ \text { MFG } & \text { Mark Flow Graph } \\ \text { Out } & \text { Porta de saída } \\ \text { PFS } & \text { Production Flow Schema } \\ \text { P/S } & \text { Publish/Subscribe } \\ \text { Q } & \text { Questão } \\ \text { R } & \text { Resposta } \\ \text { RP } & \text { Rede de Petri } \\ \text { RPC } & \text { Rede de Petri Colorida } \\ \text { SCD } & \text { Sistema de Comunicação Distribuído } \\ \text { SED } & \text { Sistemas a Eventos Discretos } \\ \text { SP } & \text { Sistema Produtivo } \\ \text { SVP } & \text { Sistema de Vigilância Predial }\end{array}$




\section{LISTA DE PALAVRAS RESERVADAS}

Rede de Petri (Fonte: Arial Narrow)

- $\operatorname{Arco}(\mathrm{s})$

- Lugar (es)

- Transição (ões)

- Substituição de transição (ões)

- Marca (as) (colorida (s))

- Marcação

- Disparo (s)

- Pré (pós) condição (ões)

- Estado (s)

- Substituição de transição (ões)

- Variável (s)

- Inscrição do arco (s)

- Socket (s)

- Expressão de guarda (s)

Paradigma Publish/Subscribe (Fonte: Arial Negrito)

- Tópico

- Produtores

- Consumidores 


\section{SUMÁRIO}

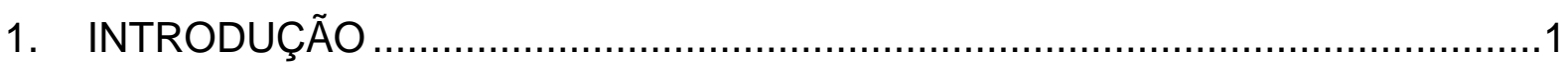

1.1 OBJETIVO

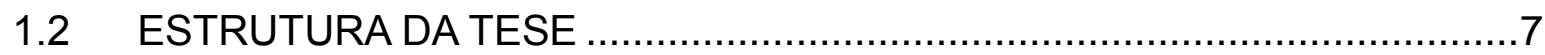

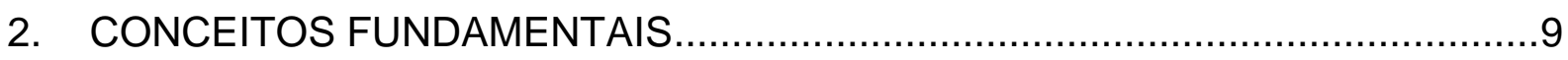

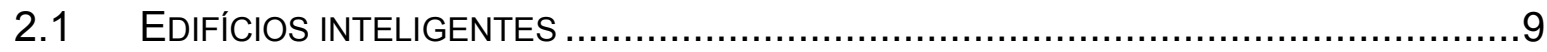

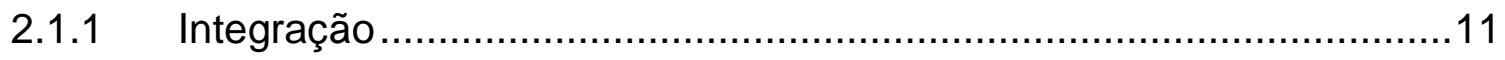

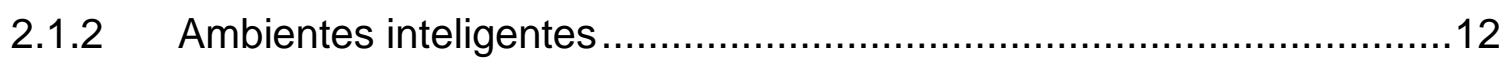

2.1.3 Classificação do edifício inteligente como sistema produtivo ...............14

2.1.4 Diagrama conceitual do sistema de controle ...................................15

2.1.5 Arquitetura do sistema de controle ............................................16

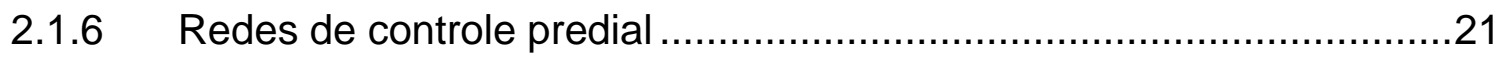

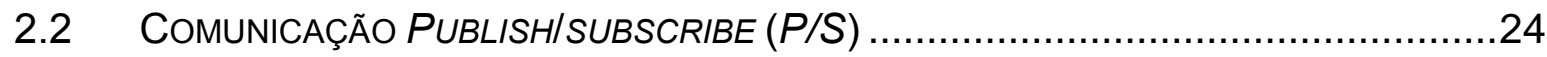

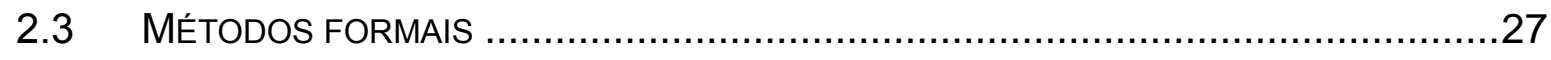

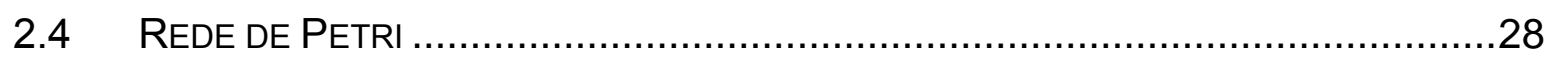

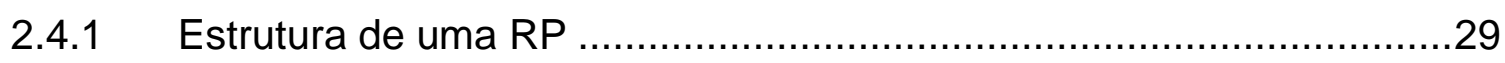

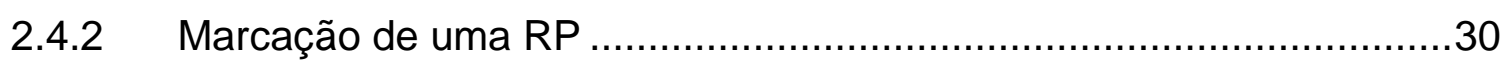

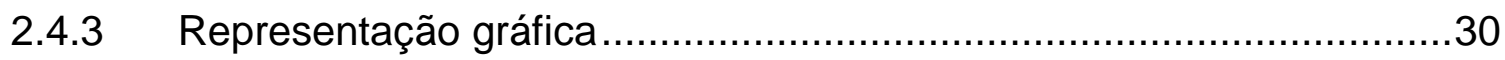

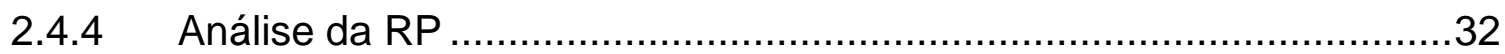

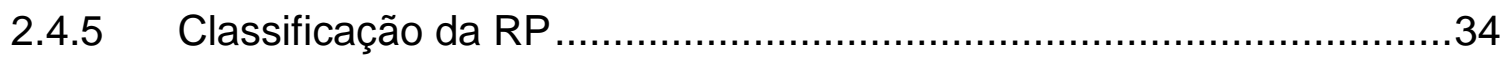

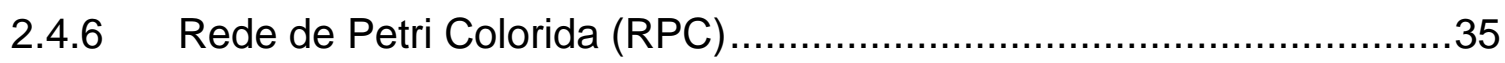

2.5 DESENVOLVIMENTO DE SOFTWARE BASEADO EM COMPONENTES ......................47

2.6 ABORDAGENS PARA ESPECIFICAÇÃO DOS ElS...........................................52

2.7 CONSIDERAÇÕES FINAIS DO PRESENTE CAPITULO .........................................56

3. PROCEDIMENTO DE MODELAGEM PROPOSTO......................................58

3.1 DESCRIÇÃO DA ARQUITETURA DE CONTROLE HETERARQUICA ..........................58

3.2 CARACTERÍSTICAS DA ARQUITETURA DE CONTROLE HETERARQUICA ..................61

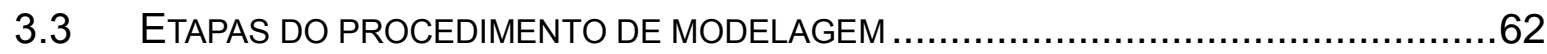

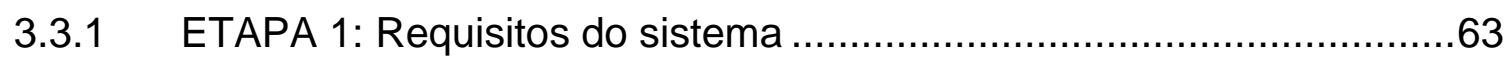

3.3.2 ETAPA 2: Especificação das estratégias a serem modeladas ............64

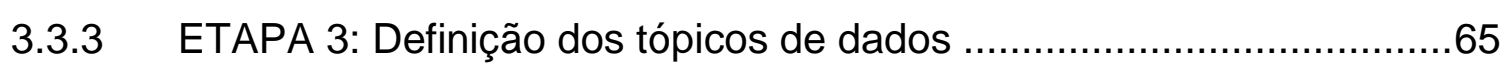

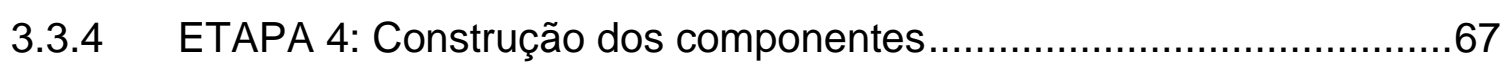


3.3.5 ETAPA 5: Modelagem estrutural do sistema de controle...................69

3.3.6 ETAPA 6: Análise dos modelos .............................................72

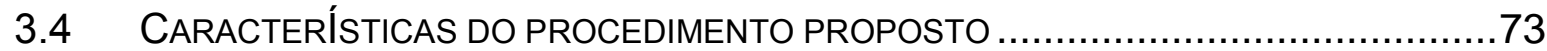

3.5 CONSIDERAÇÕES FINAIS DO PRESENTE CAPÍTULO ................................... 74

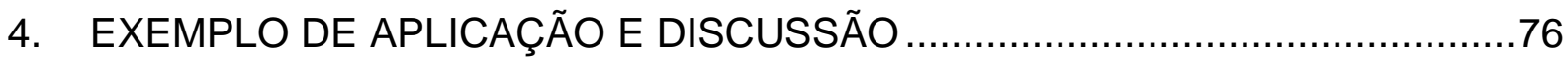

4.1 ETAPA 1: REQUISITOS DO SISTEMA DE CONTROLE PREDIAL..........................77

4.2 ETAPA 2: ESPECIFICAÇÃO DAS ESTRATÉGIAS A SEREM MODELADAS ..................79

4.3 ETAPA 3: DEFINIÇÃO DOS TÓPICOS ....................................................... 81

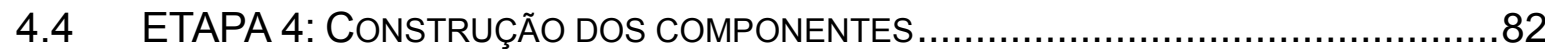

4.5 ETAPA 5: MOdELAGEM ESTRUTURAL DO SISTEMA DE CONTROLE .....................90

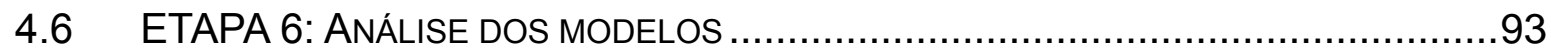

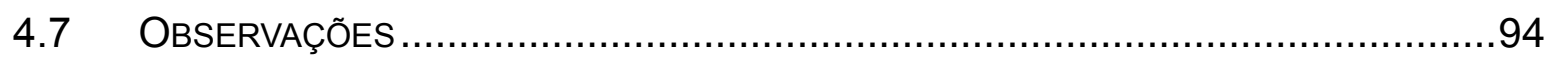

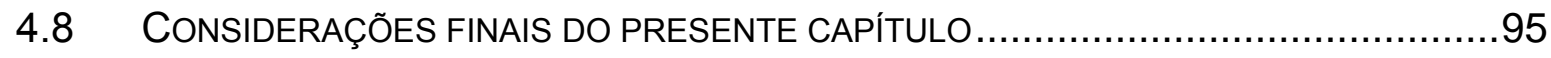

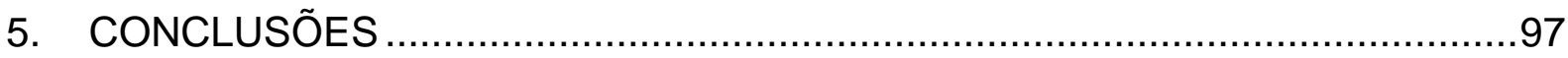

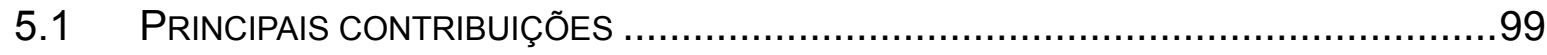

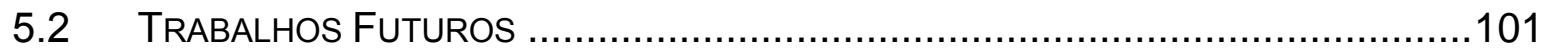

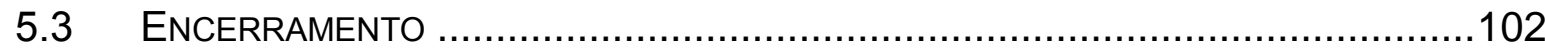




\section{INTRODUÇÃO}

Durante as últimas décadas, o desenvolvimento dos edifícios inteligentes (Els) tem sido significativo, em razão da constante evolução tecnológica nas áreas de microeletrônica, redes de comunicação e paradigmas de controle (FLAX, 1991; GRONBAEK; KROGH; KYNG, 2001; LIU; YAO, 2010). Estes avanços tecnológicos têm possibilitado o aprimoramento das características do El em termos de redução do consumo energético, conforto e segurança dos usuários, e redução do impacto ambiental durante sua construção e funcionamento (JABLONSKI; KLEMPOUS; LICZNERSKI, 2004).

O projeto dos Els deve considerar a absorção de novas tecnologias para incrementar suas funcionalidades e adaptar-se às necessidades dos usuários, procurando manter um ambiente produtivo ao longo de todo seu ciclo de vida e evitar a obsolescência prematura (BASTIDAS, 2005). Pesquisadores preveem que, nas próximas décadas, ocorrerá um aumento radical na qualidade e quantidade dos Els devido ao desenvolvimento da computação pervasiva (ABAWAJY, 2009). Os novos Els são constituídos por dispositivos mecatrônicos de diferentes características em termos de capacidade de hardware, sistema operacional e conectividade de rede de comunicação (cabeadas e sem fio) com foco nas aplicações prediais. Assim, torna-se possível a integração dos sistemas prediais do El com uma grande quantidade de dispositivos que o usuário utiliza cotidianamente, tais como: PDA, TV, rádio, telefone celular, entre outros.

Um dos atuais desafios na comunidade científica relacionado ao desenvolvimento dos Els é a criação de soluções que abordem as complexas interações entre a grande quantidade e variedade de dispositivos que integram o sistema de controle (AUGUSTIN et al. 2006; BETTINI, 2009; CHEN et al., 2003; LEE et al., 2006). Isto se deve a que os dispositivos executam múltiplas atividades concorrentemente, fazendo uso de um intenso compartilhamento de um mesmo conjunto de recursos, tais como: salas, infraestrutura, água, eletricidade e redes de comunicação, entre 
outros (ARAKAKI, 2004).

Do ponto de vista do controle local dos dispositivos de controle, o seu funcionamento pode ser facilmente representado por um conjunto de atividades sequenciais. No entanto, os sistemas de controle são constituídos por um conjunto de componentes que atuam cooperativamente, compartilhando os mesmos recursos, informações, ou ambos. Nesse contexto, a execução simultânea das atividades desses dispositivos gera um alto grau de dificuldade para representar o seu comportamento global, caracterizando assim, um sistema complexo (MATSUSAKI; SANTOS FILHO, 2006; NAKAMOTO, 2008; SOMMERVILLE, 2007).

A complexidade é uma característica do sistema em que a representação do comportamento global não pode se dar de modo estritamente sequencial, mesmo conhecendo-se o comportamento individual de cada um dos componentes (NAKAMOTO, 2008). Nos sistemas de controle dos Els, a complexidade tem sua origem no comportamento concorrente e não determinístico dos seus componentes durante a realização das atividades de controle (ARAKAKI, 2004; BASTIDAS; MIYAGI; PINA, 2006). Como exemplo, citam-se alguns processos concorrentes realizados pelo sistema de controle durante uma ocorrência de incêndio (KANESHIRO, 2006):

a) evacuação e sinalização das rotas de emergência;

b) posicionamento dos elevadores em andares específicos;

c) ativação do sistema de extinção de incêndio;

d) pressurização dos compartimentos das escadas de emergência.

A execução destes processos é influenciada por alguns fatores, tais como: localização dos ocupantes, tipos de equipamento de combate a incêndio e velocidade de propagação do fogo, entre outros. Assim, o comportamento dinâmico do sistema de controle pode atingir um número elevado de estados em função desses fatores. Por outro lado, o compartilhamento de um mesmo recurso (materiais, informações, ou ambos) pode levar o sistema a evoluir para um estado indesejável denominado autotravamento (deadlock). Esse estado é caracterizado quando o fluxo dos processos é permanentemente impedido, como resultado de 
uma falta de recursos (MATSUSAKI; SANTOS FILHO, 2006).

O travamento de um processo nos sistemas de controle dos Els pode ocorrer, por exemplo, durante a falta de recursos suficientes para suprir as necessidades de conforto ou segurança por causa de uma especificação ou implementação inadequada do sistema de controle. Assim, estes sistemas devem ser projetados de tal forma que situações indesejáveis sejam evitadas (ARAKAKI, 2004; JORGENSEN; TJELL; FERNANDES, 2009; SILVA, 2008; VILLANI, 2004).

O projeto dos sistemas de controle não é uma tarefa trivial. Desconsiderar algumas interações importantes entre os componentes pode ocasionar erros de especificação ou funcionamentos inadequados, colocando em risco a integridade dos ocupantes e das próprias instalações. Sendo assim, é importante que a lógica de controle dos Els seja rigorosamente especificada e verificada antes de sua implementação para garantir que o sistema de controle esteja livre de possíveis erros ou especificações inadequadas.

O projeto dos sistemas de controle dos Els pode ser facilitado por meio da utilização de diversos tipos de modelos, sejam estes físicos, matemáticos, computacionais etc. O modelo do sistema de controle é uma abstração do sistema, na qual são representados seus principais componentes bem como a maneira como eles interagem (JUNQUEIRA; MIYAGI, 2009).

O processo de modelagem e simulação do sistema de controle desempenha um papel fundamental na concepção dos Els, uma vez que possibilitam sua análise, aprimoramento e validação em diferentes etapas anteriores à implementação, reduzindo significativamente possíveis erros de projeto (MIYAGl et al., 2002). A modelagem dos sistemas de controle dos Els consiste na construção de modelos que representam sistemas de controle reais ou hipotéticos, com a finalidade de realizar experimentos para: a) explicar o seu comportamento; b) construir teorias ou hipóteses que consideram o comportamento observado; c) projetar novos sistemas com funcionalidades aprimoradas e d) descrever comportamentos futuros ou efeitos produzidos ao mudarem os parâmetros de funcionamento do sistema (JUNQUEIRA; MIYAGI, 2009). 
O comportamento dinâmico dos dispositivos que constituem o sistema de controle do El é definido por meio de mudanças de estados discretos, resultante da ocorrência de eventos instantâneos. Esse tipo de sistema pode ser considerado um Sistema a Eventos Discretos (SED), para o qual têm sido desenvolvidas várias técnicas de descrição, como a rede de Petri, cadeias de Markov, teoria das filas, máquinas de estados etc. (MURATA, 1989; RAMADGE; WONHAM, 1989).

Por outro lado, as variáveis ambientais monitoradas pelos sensores (variáveis contínuas), tais como temperatura, umidade e nível de oxigênio (VILLANI; MIYAGI; VALETTE, 2007), indicam que conceitos de sistemas híbridos e incertezas também são importantes na modelagem dos sistemas de controle dos Els. O sistema híbrido é caracterizado como aquele no qual coexistem e interagem variáveis de estado de natureza discreta e contínua (VILLANI, 2004). Entretanto, do ponto de vista macroscópico e com foco nas atividades que o sistema de controle realiza, considera-se que a visão do sistema de controle como um SED é suficiente, já que o foco está em valores e níveis específicos (discretos) das variáveis (que podem até ser contínuas). Assim, os estados e atividades dos componentes são definidos em função de uma comparação qualitativa de grandezas do tipo: igual a, maior que, menor que, entre outras (KANESHIRO, 2006).

Entre as técnicas de descrição para SEDs, uma de comprovada eficiência é a rede de Petri (RP), pois esta possui regras básicas simples, sua representação gráfica não exige um profundo conhecimento de teorias matemáticas e há possibilidade de derivação em programas de controle (JENSEN; KRISTENSEN, 2009). Devido a estas características, a RP e suas extensões têm sido aplicadas a uma grande variedade de sistemas, incluindo sistemas de controle para Els, sistemas de comunicações, sistemas militares, sistemas de processamento de informação e sistemas de manufatura, entre outros (JENSEN; KRISTENSEN, 2009; ZHOU; DICESARE, 1993).

Em relação aos Els, alguns trabalhos propõem a utilização da RP e suas derivações, como o Production Flow Schema (PFS) e o Mark Flow Graph (MFG), para a modelagem de alguns sistemas prediais do El (MIYAGl et al., 2002). Em Bastidas (1999), foi desenvolvido um procedimento para modelar o sistema de controle 
hierárquico de um conjunto de elevadores. Kaneshiro (2006) apresentou uma sistemática para modelar e simular um sistema de proteção contra incêndios na qual a lógica de controle é distribuída hierarquicamente. Esses trabalhos utilizaram uma abordagem top-down, na qual os sistemas de controle foram abordados em diferentes níveis de abstração. Inicialmente, um modelo conceitual é obtido com o PFS e o seu refinamento para modelos funcionais, por meio do MFG. Em Arakaki (2004) e Silva (2008) foram propostos procedimentos de modelagem de sistemas de controle de Els com uma arquitetura hierárquica. Estas propostas consideraram a detecção e o tratamento de falhas durante o funcionamento do sistema. Nesses trabalhos, foram utilizadas extensões da RP que não possuem diferenciação nas suas marcas limitando a sua aplicação nos desenvolvimento dos sistemas complexos e de grande porte, como os sistemas de controle dos Els.

Alguns trabalhos têm sido desenvolvidos utilizando a rede de Petri colorida (RPC) para modelar os sistemas de controle dos Els. Em Bastidas (2005), foi proposto um procedimento para modelar sistemas distribuídos abertos para Els baseado na RPC para descrever a arquitetura hierárquica dos sistemas de controle. Em Jorgensen (2002), foi proposto um sistema de controle para monitorar as necessidades dos pacientes e fornecer ferramentas adequadas aos médicos e enfermeiros para 0 cuidado dos pacientes. A RPC foi utilizada para validar as características do sistema de controle. Esses trabalhos permitem o desenvolvimento estruturado dos modelos que constituem o sistema de controle, facilitando o direcionamento do processo de modelagem e o aprimoramento das especificações dos sistemas prediais.

Em relação aos procedimentos para especificar sistemas de controle dos Els com arquiteturas hierárquicas, uma das limitações encontradas é que uma possível modificação do sistema, como a alteração de um processo ou atividade, requer que o componente do nível superior de controle seja modificado, e, consequentemente, os componentes do nível inferior também tenham que sofrer alteração, afetando toda a arquitetura do sistema de controle (MATSUSAKI, 2004; NAKAMOTO, 2008). Esta limitação, no entanto, pode ser melhorada por meio da utilização de um procedimento para especificar os sistemas de controle considerando uma arquitetura heterárquica, na qual é desconsidera qualquer nível de hierarquia entre os dispositivos que constituem o sistema. Para o desenvolvimento do sistema de 
controle, propõe-se um procedimento sistemático para a caracterização dos dispositivos que constituem o sistema de controle, apoiados em modelos desenvolvidos em RPC. A abordagem considera que a colaboração entre os dispositivos é realizada por meio da troca assíncrona e desacoplada das mensagens e na aplicação da RPC como linguagem formal de especificação e análise do sistema.

Com esta abordagem, procura-se desenvolver os modelos dos dispositivos que conformam o sistema de controle. A simulação destes modelos procura identificar certas condições indesejáveis do sistema, como a presença de estados nos quais o sistema fica bloqueado (deadlock), ou a detecção de erros de especificação de projeto ou de sua implementação, prevenindo problemas em fases posteriores do projeto.

\subsection{OBJETIVO}

O objetivo deste trabalho é propor um procedimento sistemático para especificar os sistemas de controle heterárquicos dos Els utilizando a RPC.

Dentro do objetivo apresentado, as principais metas deste trabalho podem ser sintetizadas em dois pontos:

1) Desenvolvimento de uma arquitetura de controle heterárquica na qual se consideram conceitos de comunicação assíncrona e componentização. A colaboração entre os dispositivos inteligentes é realizada por meio do paradigma de comunicação publish/subscribe (apresentado no capítulo 2.2).

2) Desenvolvimento de uma sistemática baseada em RPC para a construção dos modelos que representam as funcionalidades e as interações dos dispositivos que integram o sistema de controle heterárquico.

Assim, o presente trabalho visa contribuir para o desenvolvimento de uma nova 
abordagem para o projeto dos Els, explorando conceitos de distribuição heterárquica de controle, componentização e reuso dos modelos em RPC. A abordagem sistemática de modelagem visa: (i) determinar o conjunto de atividades que os dispositivos que constituem o sistema de controle realizam e o conjunto de dados necessários para estabelecer o controle colaborativo, (ii) desenvolver os modelos dos dispositivos e da rede de controle com um nível de abstração adequado que permita implementar sua lógica de controle, (iii) analisar o modelo do sistema de controle para determinar se a lógica de controle é atendida pelos dispositivos que integram o sistema de controle.

\subsection{ESTRUTURA DA TESE}

Esta tese está estruturada da seguinte forma:

Capítulo 2: Revisão bibliográfica. Neste capítulo, apresentam-se os principais conceitos envolvidos neste trabalho. Inicialmente, é apresentado o conceito do edifício inteligente. Em seguida, expõe-se o paradigma de comunicação publish/subscribe para estabelecer a comunicação entre os dispositivos inteligentes. Apresenta-se ainda a definição da RPC e suas principais características, seguidas de uma abordagem baseada em componentes para o desenvolvimento do software de controle. Finalmente, são apresentados alguns trabalhos relacionados ao desenvolvimento de sistemas de controle para El.

Capítulo 3: Procedimento de modelagem proposto. Neste capítulo, inicialmente é desenvolvida uma arquitetura heterárquica para o sistema de controle. Nessa arquitetura, são descritos os componentes que constituem o sistema de controle do El, os quais possuem um mesmo nível hierárquico. Definida a arquitetura do sistema de controle, é proposta uma sistemática que permita modelar as especificações do sistema de controle do El, baseadas na arquitetura heterárquica.

Capítulo 4: Exemplo de aplicação. Neste capítulo, é apresentado um exemplo de aplicação que consiste na integração de dois sistemas prediais. A integração do 
sistema de telefonia ao sistema de segurança predial, visando a aproveitar as funcionalidades dos dispositivos de ambos os sistemas. Por meio deste exemplo, as principais características do procedimento proposto são apresentadas.

Capítulo 5: Conclusões. Este capítulo apresenta os principais resultados, as contribuições desta pesquisa e as limitações encontradas. Adicionalmente, indicamse possíveis pontos de investigação futura a fim de dar continuidade a este trabalho. 


\section{CONCEITOS FUNDAMENTAIS}

O objetivo deste capítulo é apresentar os conceitos básicos envolvidos neste trabalho. Inicialmente, são apresentadas as definições e as principais características dos Els. Em seguida, aborda-se a computação pervasiva dentro do contexto das aplicações relacionadas à criação de novas funcionalidades nos Els. Descreve-se ainda o paradigma de comunicação utilizado nas aplicações da rede de controle predial. Finalmente, expõe-se uma breve recapitulação da rede de Petri, considerando as vantagens da rede de Petri colorida como ferramenta de modelagem para os Els.

\subsection{EDIFÍCIOS INTELIGENTES}

A procura por um ambiente físico no qual uma organização possa melhorar a produtividade dos seus usuários, a eficiência na utilização dos recursos energéticos e reduzir o impacto ambiental durante o seu projeto e funcionamento, tem estimulado o desenvolvimento dos edifícios inteligentes (FLAX, 1991). Os Els são projetados para satisfazer as necessidades de seus usuários, tais como: controle ambiental, mobilidade, comunicação, proteção contra incêndios e segurança. As principais características que diferenciam um edifício inteligente dos edifícios convencionais é a integração dos serviços oferecidos pelos sistemas prediais e a capacidade de adaptação às necessidades do ambiente e dos usuários (LU; CLEMENTS CROOME; VILJANEN, 2009). O edifício inteligente é um sistema que disponibiliza serviços aos usuários (LIU; YAO, 2010; VILLANI; MIYAGI; VALETTE, 2007). Os usuários podem especificar parâmetros ambientais na forma de requisitos para seu ambiente, como temperatura, umidade e iluminação. $O$ edifício fornece serviços que são entregues na forma de ações físicas (regular o termostato, fechar uma janela etc.) ou como informação (alertar a ocorrência de um incêndio, mostrar um dado em um display etc.). 
Existem na literatura diversas definições dos Els (ELLIOTT, 2009; FLAX, 1991; GRONBAEK; KROGH; KYNG, 2001), porém, não há consenso sobre uma definição exata do que poderia ser chamado El, já que estes estão em constante evolução. As primeiras definições estavam centradas em aspectos meramente tecnológicos e não sugeriam nenhuma interação com os usuários. Entretanto, uma abordagem baseada unicamente nesses aspectos pode tornar prematuramente obsoletos os Els (WONG; LI; WANG, 2005). Segundo Bastidas (2005), o El deve ser flexível para se adaptar facilmente a qualquer modificação em termos de uso, infraestrutura, recursos externos e funcionalidades, entre outras características, fornecendo uma plataforma sobre a qual podem ser implementadas novas tecnologias a um mínimo custo e sem interrupção considerável das atividades produtivas. Os principais sistemas que compõem o El são (WANG; XIE, 2002; WONG; LI; WANG, 2005):

- $\quad$ sistema de iluminação: garante a iluminação adequada e eficiente nos ambientes do edifício. A iluminação e os níveis de contraste nos ambientes têm um impacto direto no bem-estar, na motivação e na produtividade dos moradores do prédio;

- $\quad$ sistema de comunicação de voz e dados: permite o desenvolvimento das atividades cotidianas dos seus ocupantes. Voz e dados no contexto de comunicação predial incluem: serviços de voz (telefonia, interfones), sonorização em diferentes ambientes (elevadores, corredores etc.), videoconferências, acesso à internet e bases de dados, entre outros;

- ventilação e ar condicionado (HVAC): desempenham um papel importante no controle das condições ambientais internas para oferecer um nível de conforto adequado aos moradores;

- $\quad$ segurança: constituído por três subsistemas (controle de acesso, intrusão e vigilância) que trabalham de forma sincronizada, preservam a segurança dos usuários e o patrimônio do prédio;

- transporte vertical: esse sistema é constituído pelo conjunto de elevadores e escadas rolantes;

- $\quad$ sistema contra incêndio: a operação desse sistema está condicionada a normas e regulamentos. Em situações de emergência, é possível se comunicar com outros sistemas prediais para realizar atividades de forma integrada. 


\subsubsection{Integração}

A integração nos sistemas prediais é uma característica primordial para os Els atingirem seus objetivos e oferecerem uma maior confiabilidade e robustez no controle dos sistemas, com um menor custo de funcionamento quando comparados aos edifícios convencionais (CLARK; MEHTA, 1997). Segundo diversos autores, a capacidade de integração dos serviços oferecidos e a capacidade de adaptação às necessidades dos seus usuários são os principais requisitos que definem os Els (FLAX, 1991; MIYAGI et al., 2002; WONG; LI; WANG, 2005). Uma situação de emergência é o exemplo mais comum de como a integração dos sistemas prediais pode ser benéfica para garantir a segurança dos usuários.

Alguns exemplos de integração do sistema contra incêndio com os outros sistemas prediais são (KANESHIRO, 2006):

- sistema de transporte vertical: permitindo a operação em modo de emergência. Esse modo de operação permite que os elevadores sejam deslocados imediatamente até o andar térreo para que possam, então, ser utilizados pela brigada de bombeiros;

- sistema de segurança: permitindo a localização das pessoas dentro do prédio. A equipe de resgate poderia ter conhecimento prévio de onde procurar os ocupantes em uma eventual evacuação, reduzindo-se assim, o risco de ingressar em áreas perigosas desnecessariamente. Adicionalmente, o sistema de segurança destrava as portas do edifício, facilitando a evacuação de seus ocupantes;

- sistema de ar condicionado: em caso de incêndio, o sistema evita que a fumaça se propague a outras áreas do prédio.

A integração dos sistemas prediais tem sido realizada por abordagens centralizadas, inspiradas na área da automação industrial. Segundo Jablonski, Klempous e Licznerski (2004), essa abordagem contempla três níveis. O nível superior, ou Building Management System (BMS), gerencia as funções do edifício como um todo e supervisiona os sistemas prediais. No segundo nível hierárquico (subordinado ao 
$B M S$ ), estão os sistemas prediais do $\mathrm{El}$, tais como o sistema contra incêndio, HVAC, segurança etc. que interagem por meio do BMS. Finalmente, o último nível é constituído por sensores, atuadores e dispositivos de propósito simples dedicados a monitorar e controlar o ambiente físico do prédio.

Nos últimos anos, o paradigma de concepção dos sistemas de controle dos Els vem sendo modificado com a substituição gradual das arquiteturas centralizadas e proprietárias por arquiteturas abertas e distribuídas, em razão do aumento da capacidade computacional e de comunicação dos dispositivos eletrônicos (HUR; KIM; PARK, 2006; WONG; LI, 2009; XIE; PU; MOORE, 1998). Uma das vantagens das arquiteturas distribuídas em relação às centralizadas é o aumento da confiabilidade na construção dos sistemas prediais. Em um sistema centralizado, se - BMS deixa de funcionar, todo o sistema permanece inoperante; já em uma arquitetura distribuída, mesmo havendo alguma falha em um sistema predial, os outros sistemas continuarão funcionando, ainda que com alguma degradação (ARAKAKI, 2004). Por outro lado, o uso de tecnologias abertas possibilita a construção de sistemas utilizando componentes de diferentes fabricantes, em função das características que melhor atendam as necessidades, tanto do ponto de vista técnico como do econômico (BASTIDAS; MIYAGI; PINA, 2006; CUNHA, 2008).

\subsubsection{Ambientes inteligentes}

Em função dos avanços tecnológicos ao longo do tempo, Sharples, Callaghan e Clarke (1999) classificaram os Els em 3 gerações:

- a primeira geração consistia em sistemas prediais independentes. Esses sistemas eram relativamente sofisticados, mas não tinham a capacidade de integração com os outros sistemas prediais;

- a segunda geração considerava a integração dos sistemas prediais por meio de redes de controle;

- a terceira geração de El tem a capacidade de aprender e se adaptar às necessidades dos ocupantes, além das capacidades de integração com os 
outros sistemas prediais.

Este trabalho está focado na terceira geração de El, cujos avanços tecnológicos em diversas áreas têm possibilitado o seu maior desenvolvimento (ABAWAJY, 2009; GRONBAEK; KROGH; KYNG, 2001). Esses avanços tecnológicos podem ser agrupados em (COOK; AUGUSTO; JAKKULA, 2009):

(i) dispositivos inteligentes: sensores, controladores, dispositivos com identificação por radiofrequência (RFID);

(ii) comunicação móvel sem fio: redes de comunicação de curta distância, como infravermelho, redes LANs, rede de sensores sem fio, rede de celulares;

(iii) paradigmas da computação: distribuída, ponto a ponto, computação em grid, computação pervasiva ${ }^{1}$, computação móvel;

(iv) middlewares: tecnologia de agentes, interfaces múltiplas de homemmáquina.

Adicionalmente, os desenvolvimentos tecnológicos nas áreas de robótica e inteligência artificial têm contribuído para o avanço do estado da arte dos Els (COOK; AUGUSTO; JAKKULA, 2009).

O El envolve aplicações sensíveis ao contexto, ou seja, aplicações que se adaptam a um conjunto de parâmetros, tais como: estado da conexão, tipos de dispositivos, entorno do usuário etc. (COOK; AUGUSTO; JAKKULA, 2009; RIES, 2007). sistema de controle do El é constituído por dispositivos inteligentes que adquirem e processam informações de um determinado ambiente físico e das atividades dos usuários com o objetivo de tomar diferentes decisões e agir segundo as diferentes situações ou contextos apresentados de maneira imperceptível para o usuário (GRONBAEK; KROGH; KYNG, 2001; GU; PUNG; ZHANG, 2005; PREKOP; BURNETT, 2003; SOMMERVILLE, 2007). O tipo de necessidade varia em função

\footnotetext{
${ }^{1}$ A computação pervasiva visa a fornecer acesso computacional de maneira invisível e onipresente (WEISER, 1991) aos usuários das aplicações. O termo "invisível" é utilizado para especificar a independência do conhecimento da tecnologia por parte do usuário para desfrutar dos seus benefícios, e o termo "onipresença" é utilizado para a definição da amplitude da disponibilidade da tecnologia de informação para o usuário.
} 
das próprias características dos usuários e do ambiente considerado. Algumas dessas necessidades podem ser: garantir a segurança dos ocupantes, reduzir os custos de manutenção predial, otimizar recursos físicos e energéticos e automatizar diversas tarefas cotidianas (HELAL et al., 2005; RIES, 2007; SILVA, 2008).

\subsubsection{Classificação do edifício inteligente como sistema produtivo}

A função principal de um Sistema Produtivo (SP) é produzir um bem ou serviço por meio da execução de processos utilizando entidades físicas (ARAKAKI, 2004; BASTIDAS, 2005; JENSEN; KRISTENSEN, 2009). Por outro lado, um sistema de informação utiliza unicamente dados ou entidades abstratas para a realização dos seus processos (SOMMERVILLE, 2007). Uma das principais características que diferenciam os SPs dos sistemas de informação é que a modificação de um dado pode implicar na alteração do estado de uma entidade física. Existem operações que não podem ser desfeitas, pois as respectivas modificações nas entidades físicas em geral são irreversíveis (VILLANI, 2004).

O desenvolvimento tecnológico e a crescente disponibilidade dos recursos computacionais em termos de hardware e software têm impulsionado a utilização dos sistemas de informação no controle dos SPs, visando a aprimorar requisitos de eficácia, eficiência e integridade desses sistemas. Nesse sentido, o SP pode ser abordado como um sistema constituído por um sistema físico que é controlado por um sistema de informação. Esse tipo particular de sistema de informação é chamado de sistema de controle e o sistema físico por ele modificado é o objeto de controle (VILLANI, 2004). A Figura 2.1 ilustra esses conceitos. 


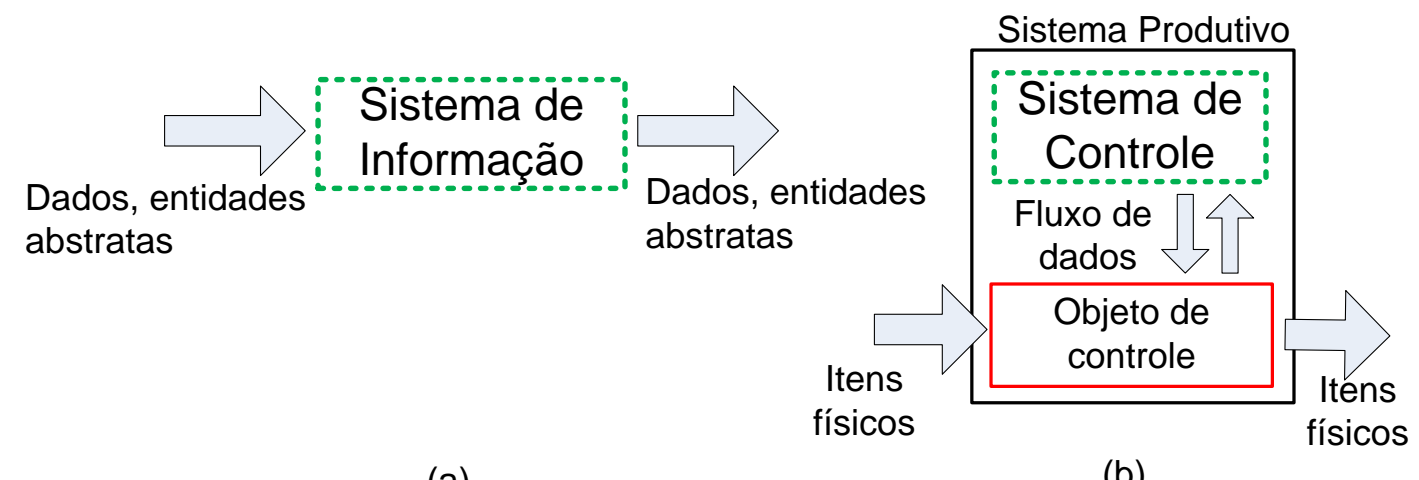

(a)

(b)

Figura 2.1 - (a) Sistema de Informação e (b) Sistema Produtivo (extraído de VILLANI, 2004)

O El é um tipo de SP orientado a serviços (ARKIN; PACIUK, 1997; VILLANI; MIYAGI; VALETTE, 2007), no qual o objeto de controle está constituído por: salas, escadas, corredores, equipamentos (ar condicionado, elevadores etc.), energia elétrica, água, tendo como objetivo final a segurança, o conforto, a mobilidade e higiene, entre outros serviços que dependem do tipo de edifício (ARAKAKI, 2004). No projeto dos Els, um fator importante a se considerar é a validação do comportamento do sistema de controle (VILLANI; MIYAGI; VALETTE, 2007), uma vez que erros de especificação podem tornar irreversível algum processo de funcionamento, gerando danos que podem atingir dimensões catastróficas por envolver diretamente vidas humanas (KANESHIRO, 2006).

\subsubsection{Diagrama conceitual do sistema de controle}

O controle pode ser entendido como a aplicação de um conjunto de operações em um dado objeto de controle visando alcançar os objetivos definidos, refletindo o comportamento dinâmico esperado para o sistema (MATSUSAKI; SANTOS FILHO, 2006; SILVA, 2008). O comportamento esperado de um El é a realização de um conjunto de atividades sobre as instalações prediais para que sejam atendidas as necessidades de seus usuários, utilizando-se os recursos disponibilizados para essas atividades. Do ponto de vista de SED, o controle corresponde à execução das 
operações segundo um procedimento preestabelecido (MIYAGI, 1996). A complexidade de representar o comportamento dinâmico dos sistemas de controle dos El se dá pela impossibilidade de se representar o comportamento global do sistema a partir de comportamentos individuais das partes ou dos componentes do sistema (NAKAMOTO, 2008).

Um modelo conceitual básico de sistema de controle é apresentado na Figura 2.2 (ARAKAKI, 2004). O sistema de controle atua sobre o objeto de controle por meio dos dispositivos de atuação, e a realimentação é realizada por meio dos dados fornecidos pelos dispositivos de detecção. O dispositivo de controle recebe os dados das variáveis controladas e os comandos do operador ou usuário e, considerando alguns dados internos, os dados fornecidos ao dispositivo de atuação são atualizados. O operador monitora o sistema de controle por meio dos dispositivos de monitoração e atua no sistema por meio dos dispositivos de comando (NAKAMOTO, 2008).

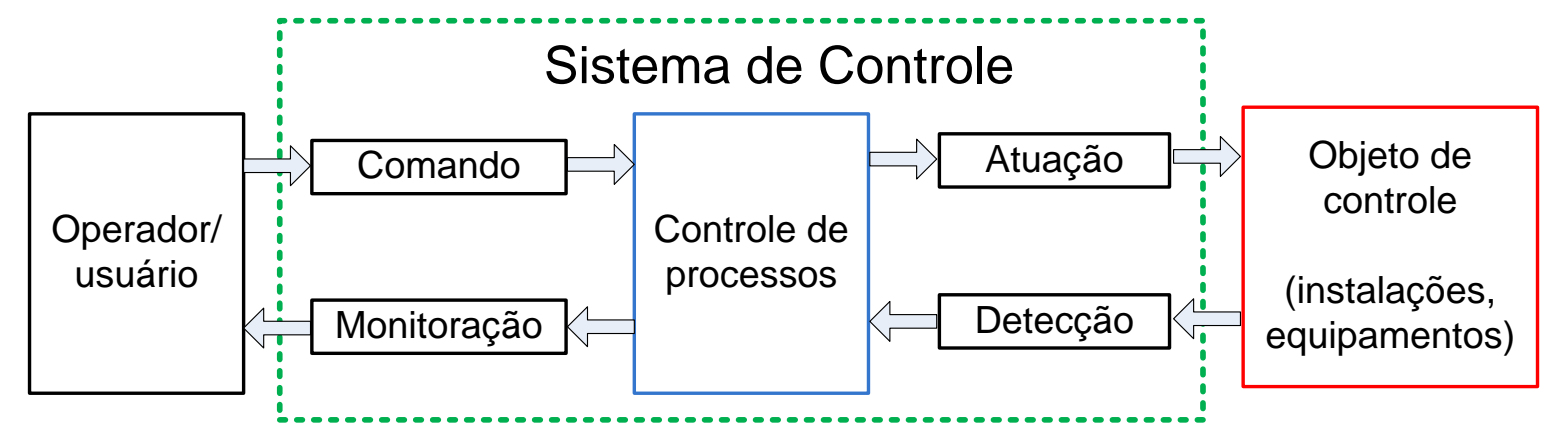

Figura 2.2 - Diagrama conceitual de um sistema de controle (MIYAGI, 1996)

\subsubsection{Arquitetura do sistema de controle}

A arquitetura do sistema de controle especifica os componentes, as interfaces, as inter-relações e as restrições. Essas especificações servem de base para as atividades de desenvolvimento desses sistemas (SILVA, 2008). Tais arquiteturas têm que possuir capacidade de adaptação a mudanças, visando a obter sistemas flexíveis, robustos e de fácil manutenção (SHARPLES; CALLAGHAN; CLARKE, 1999). Elas podem ser classificadas em: 
- centralizada: neste tipo de arquitetura, um único ou poucos controladores realizam todas as atividades envolvidas no SP. Uma das suas desvantagens é o tempo de resposta crescente com o maior porte do sistema e a dificuldade em realizar modificações, limitadas pela capacidade de processamento das unidades de controle (MATSUSAKI, 2004). Ainda, segundo Canovas (2006), a centralização do processo de controle em uma ou poucas unidades gera gargalos, que podem comprometer todo o sistema na ocorrência de falhas;

- distribuída: a execução das estratégias de controle é realizada por vários elementos distribuídos. Assim, cada controlador possui uma autonomia dentro do escopo de atuação (NAKAMOTO, 2008).

Os sistemas de controle distribuídos podem ser classificados em (DILTIS; BOYD; WHORMS, 1991; MATSUSAKI, 2004; TRENTESAUX, 2009):

\section{- Hierárquico:}

A arquitetura hierárquica é constituída por componentes do sistema de controle organizados segundo uma estrutura piramidal. Ela apresenta diversos níveis de controle, sendo que cada componente de controle pertence a um único nível de controle (MATSUSAKI, 2004; TRENTESAUX, 2009). Todas as atividades dos componentes de controle do nível inferior possuem uma relação mestre-escravo. As funções de controle dos níveis superiores são decompostas sucessivamente para os controles dos níveis inferiores, caracterizando uma abordagem de comando do tipo top-down e a realimentação de informações do tipo botton-up (NAKAMOTO, 2008).

Esse tipo de arquitetura possui robustez, capacidade de predição e eficiência classificadas como "boa" ${ }^{3}$ quando comparadas com a arquitetura centralizada, porém sua velocidade de resposta a falhas é classificada como "fraca" (SILVA, 2008). A Figura 2.3 ilustra um exemplo de como uma estrutura hierárquica pode ser implementada para um El. O sistema de controle é definido dentro de uma hierarquia em que:

\footnotetext{
${ }^{3}$ Os termos entre aspas indicam uma qualificação relativa.
} 
- o nível de gerenciamento é responsável pela integração dos sistemas supervisórios das diferentes instalações prediais;

- o nível 3 gerencia os subsistemas prediais, os quais supervisionam a evolução desses subsistemas;

- o nível 2 é constituído por controladores intermediários, os quais supervisionam o sistema de controle local;

- o nível 1 corresponde ao controle local, ao qual estão conectados os sensores e atuadores.

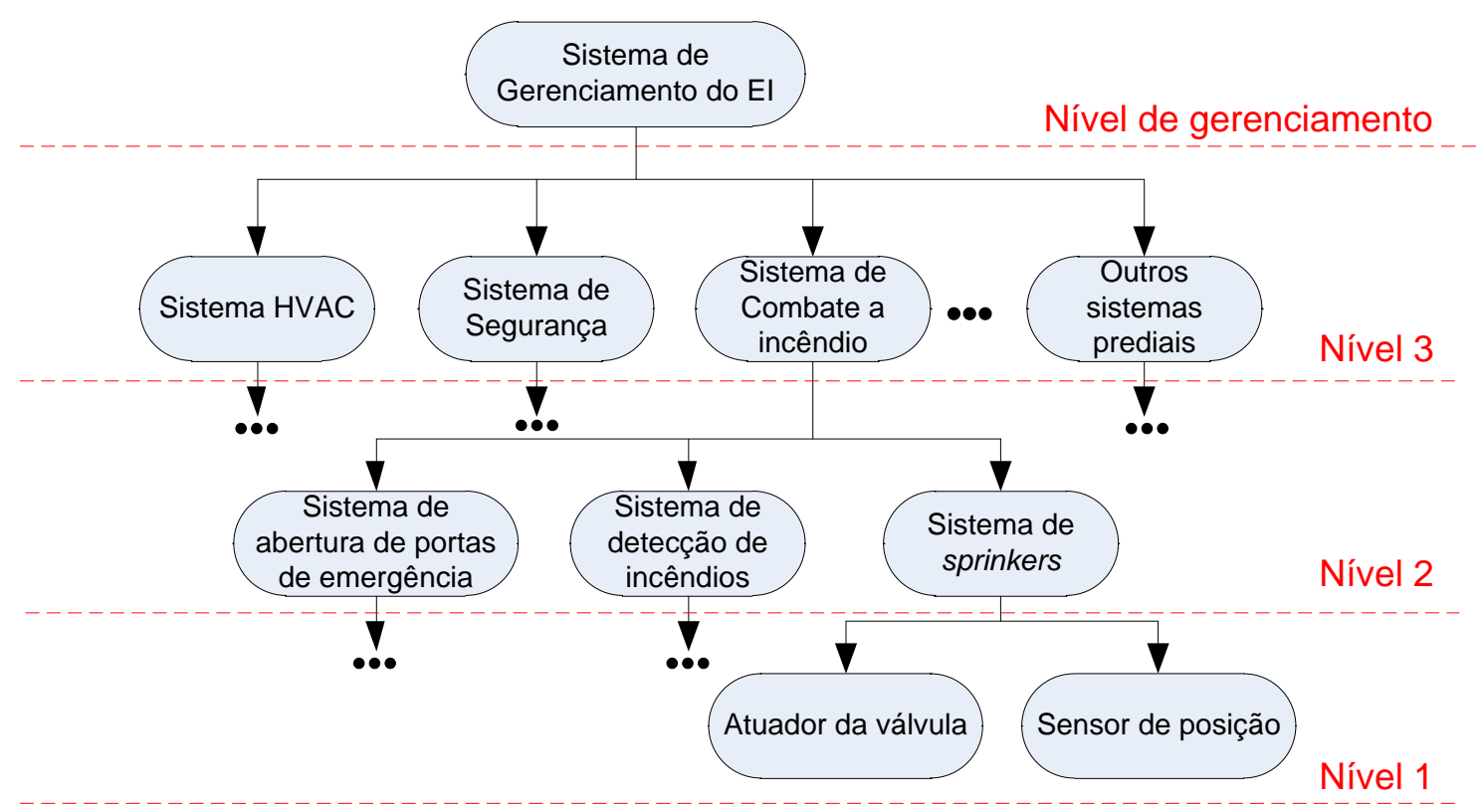

Figura 2.3 - Arquitetura hierárquica típica dos sistemas de controle para Els (baseado em Kaneshiro (2006))

\section{- Semi-heterárquico:}

Uma variação da arquitetura hierárquica é conhecida como arquitetura semiheterárquica (TRENTESAUX, 2009), hierárquica modificada (DILTIS; BOYD; WHORMS, 1991) ou híbrida (NAKAMOTO, 2008). Neste tipo de arquitetura, a formação de níveis de controle é similar à arquitetura hierárquica, mas os subordinados possuem certo grau de autonomia, que ocorre por meio da cooperação entre os componentes do mesmo nível de controle (MATSUSAKI, 2004). 


\section{- Heterárquico:}

Este tipo de arquitetura é caracterizado pelo elevado grau de autonomia dos componentes de controle, de modo que estes atuam cooperativamente na resolução dos problemas de controle. As estratégias de controle são realizadas por meio da negociação entre os componentes mediante 0 compartilhamento e a troca de informações entre os mesmos (NAKAMOTO, 2008; PUJO; BROISSIN; OUNNAR, 2009). O conceito de controle heterárquico se fundamenta na autonomia local e na abordagem cooperativa para tomadas de decisões globais. A autonomia local implica em que os componentes possuam unicamente informações locais, reduzindo ou eliminando a informação global e centralizada. Isso significa que não existem níveis de controle superiores e a cooperação com os componentes é realizada por meio da negociação (MATSUSAKI, 2004; SILVEIRA; COMBACAU, 2006). Esse tipo de arquitetura permite um alto grau de flexibilidade em relação a qualquer alteração ou mudança do sistema de controle, porém, apresenta certo grau de imprevisibilidade do comportamento dinâmico do controle (NAKAMOTO, 2008).

As arquiteturas hierárquicas e semi-heterárquicas estão sujeitas à ocorrência do "efeito cascata", isto é, uma possível modificação do sistema, como a introdução de um novo processo ou uma atividade não prevista anteriormente que requer que o componente do nível superior de controle seja modificado, e, consequentemente, os componentes dos níveis inferiores também tenham que sofrer alteração. Portanto, a integração de novos processos e funcionalidades afeta toda a arquitetura do sistema. Além disso, o componente de controle do nível superior herda as características do sistema de controle centralizado, pois é o elemento centralizador de seus subordinados (MATSUSAKI, 2004).

A Figura 2.4 sintetiza as diferentes maneiras de distribuir as decisões de controle, desde um controle centralizado até controles descentralizados baseados em relações hierárquicas e heterárquicas. 

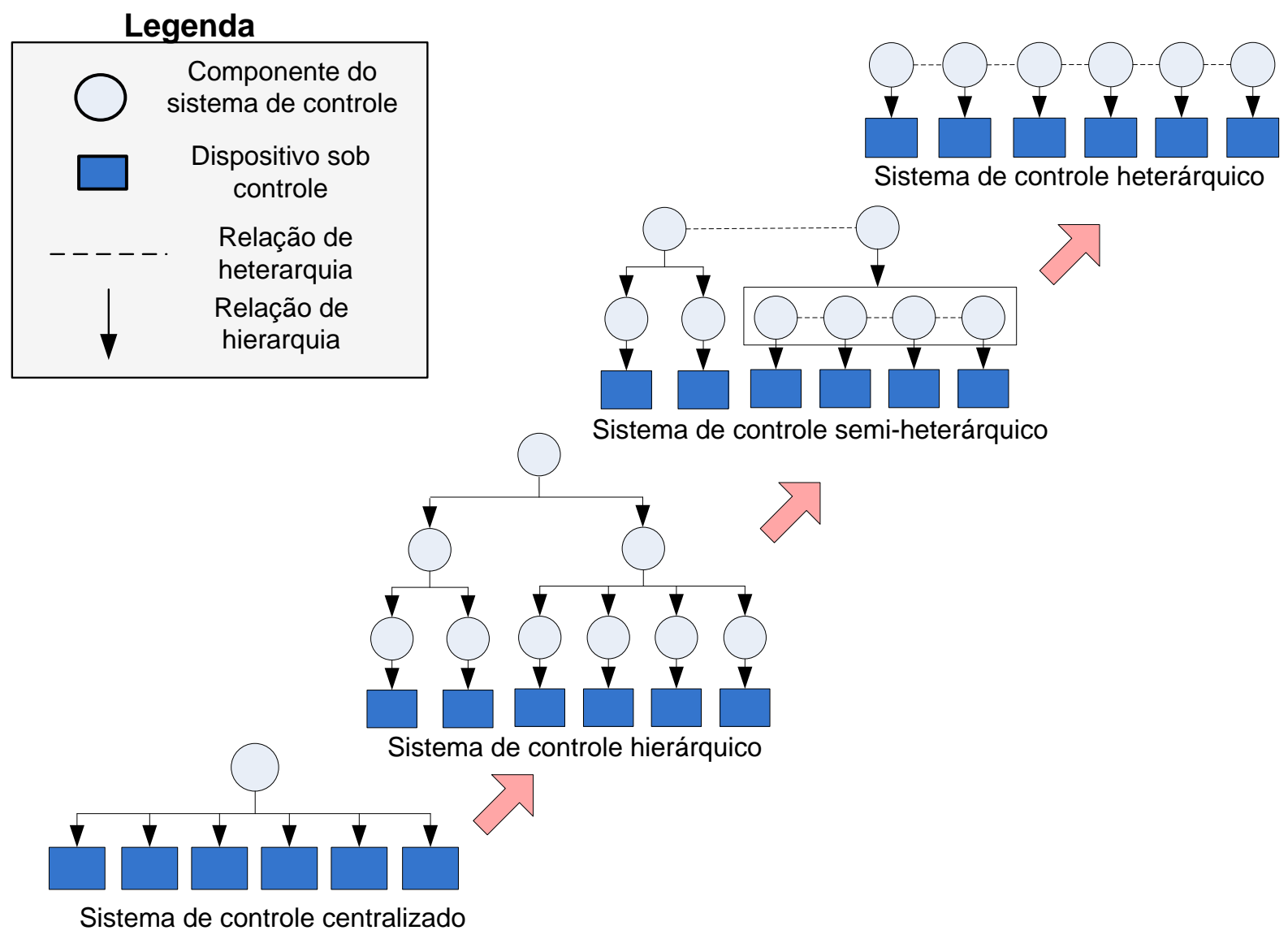

Figura 2.4 - Evolução das arquiteturas de controle (adaptado de Trentesaux (2009))

Na Figura 2.4, observa-se também que o controle hierárquico é uma distribuição de controle vertical, enquanto que a distribuição heterárquica é de controle horizontal. Segundo Trentesaux (2009), uma das vantagens dos sistemas de controle heterárquico é o suporte à agilidade. Gunasekaran (1999) define a agilidade como a capacidade de sobreviver e prosperar em um ambiente de constantes e imprevisíveis mudanças, reagindo de maneira rápida e efetiva às necessidades do mercado, que são orientadas por tendências de produtos e serviços aos clientes.

Nos Els, a agilidade pode ser dividida em duas áreas: agilidade no negócio e agilidade técnica. A agilidade nos negócios está direcionada à adaptação das funcionalidades dos serviços oferecidos pelos sistemas prediais ao modelo de negócio do prédio (hotéis, hospitais, museus etc.). Agilidade técnica, por outro lado, pode ser descrita em termos de eficiência e eficácia. 
A eficiência, segundo Gunasekaran (1999), envolve:

- melhor aproveitamento dos recursos (infraestrutura, equipamentos, água, eletricidade etc.);

- adaptação do sistema às novas tecnologias;

- modificação dos sistemas prediais para se adequar às necessidades dos usuários, redução do ciclo de desenvolvimento dos sistemas prediais no desenvolvimento de novas funcionalidades, segundo as necessidades dos usuários.

A eficácia, por outro lado, envolve a certeza de que os resultados obtidos satisfazem os objetivos esperados (GUNASEKARAN, 1999).

\subsubsection{Redes de controle predial}

As arquiteturas heterárquicas são viabilizadas por meio das redes de controle. Uma rede de controle é um sistema digital de comunicação no qual um grupo de dispositivos (sensores e atuadores em geral) trocam pequenas mensagens com elevada confiabilidade e segurança. Um protocolo de comunicação rege as regras e os detalhes da comunicação entre os componentes. Esses dispositivos possuem capacidade própria de processamento e comunicação (HUR; KIM; PARK, 2006). As funções dos programas e algoritmos de controle são distribuídas entre os dispositivos que integram a rede de controle, sendo que cada um é responsável por uma parte do processamento, a partir de informações recebidas de outros dispositivos (XIE; PU; MOORE, 1998).

Cada dispositivo possui uma função específica dentro das inúmeras necessidades do sistema predial. Esses dispositivos estão distribuídos por toda a extensão do edifício, interligados por uma rede de comunicação, trocando informações entre si e com sensores e atuadores, que podem se encontrar próximos ou integrados ao objeto de controle e/ou painel de monitoração e comando. Os dispositivos estão conectados a uma rede de comunicação por meio de um protocolo, enquanto que a 
inteligência envolvida na realização do controle, ou seja, o processamento das informações é distribuído nos componentes do sistema, cujos processadores executam as respectivas estratégias de controle.

A rede de controle aumenta a robustez do sistema, pois mesmo que alguns dispositivos deixem de operar, o restante do sistema pode continuar a operar com alguma redução de funcionalidade. A distribuição do controle conduz a uma natural modularização, sendo que a programação de cada dispositivo é mais simples quando comparada, por exemplo, à programação de um Controlador Lógico Programável (CLP) (CUNHA, 2008).

As redes de controle possuem algumas características e requisitos próprios que as tornam diferentes das redes de dados; por exemplo, o tamanho reduzido das mensagens e os tempos de resposta curtos (CANOVAS; CUGNASCA, 2010; CUNHA, 2008). O protocolo de comunicação rege as regras e detalhes de comunicação entre os componentes do sistema. Os protocolos de comunicação para as redes de dados são projetados para trafegar grandes quantidades de informação com foco no processamento em lote (batch). Por outro lado, as aplicações de controle requerem protocolos de comunicação projetados para transmitir mensagens curtas e com tempos de resposta curtos e previsíveis para processamento em tempo real (CANOVAS, 2006). Alguns protocolos de comunicação utilizados nas redes de controle em automação predial são: BACNet, LonWorks, PROFIBus (SARAMAGO, 2002).

Na Figura 2.5 é apresentada uma rede de controle para um El. O seu funcionamento é descrito a seguir:

1) sensores e outros dispositivos continuamente monitoram as mudanças de estado do ambiente físico e/ou dos seus ocupantes;

2) esses dados são processados pelos próprios dispositivos e transformados em informação relevante ao sistema;

3) os dispositivos encaminham essa informação à rede de comunicação;

4) a rede de comunicação distribui essa informação aos dispositivos necessários que a solicitam; 
5) os dispositivos processam essa informação e executam as estratégias necessárias para satisfazer os objetivos do ambiente inteligente;

6) essas estratégias são convertidas em ações, realizadas pelos atuadores sobre o ambiente físico.

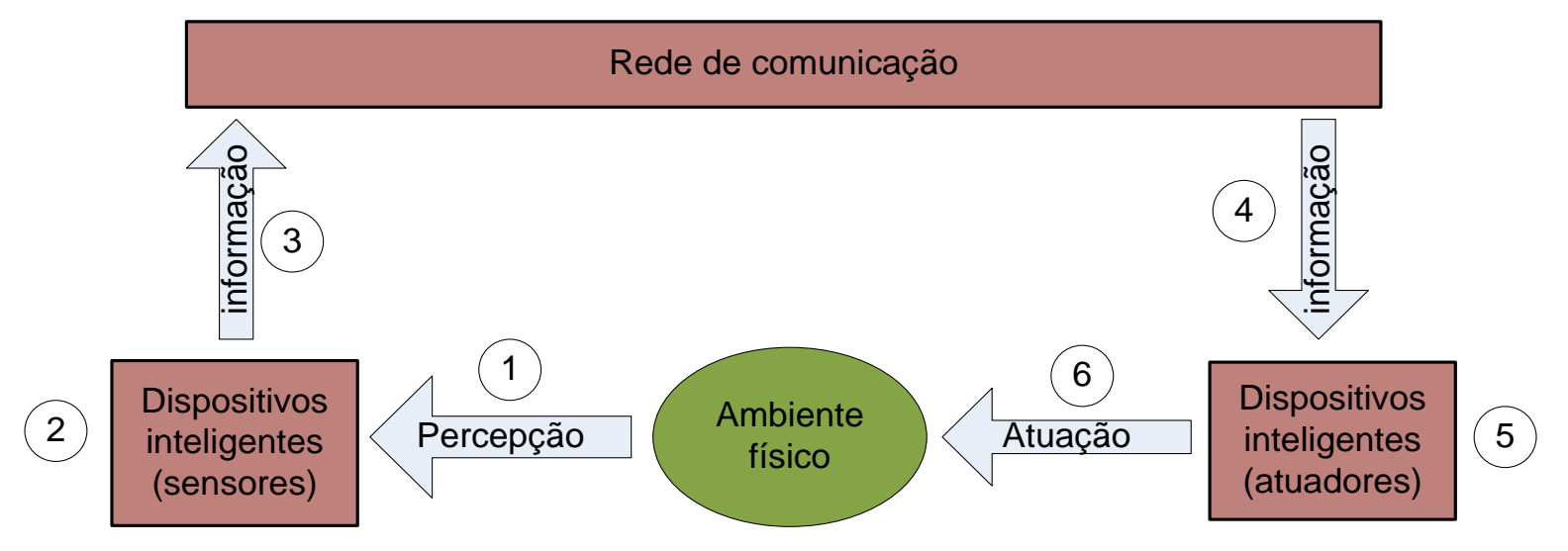

Figura 2.5 - Estrutura geral de funcionamento do EI

Algumas características das redes de controle dos Els são:

- Grande quantidade de dados que trafegam pela rede de comunicação: tais como: valores das grandezas físicas do El (temperatura, umidade, iluminação etc.), a localização e as atividades dos usuários, a disponibilidade dos recursos, entre outros. Esta informação é continuamente coletada pelos sensores e disponibilizada na rede de comunicação para que os atuadores possam realizar as estratégias de controle.

- Desacoplamento entre a coleção e utilização dos dados: A arquitetura do sistema de controle permite uma comunicação de "muitos-para-muitos" dispositivos, já que a informação fornecida por um sensor pode ser utilizada por um atuador ou por uma grande quantidade destes, da mesma forma que um atuador pode utilizar a informação de um sensor ou de uma grande quantidade destes. Neste sentido, o desacoplamento entre os dispositivos facilita este tipo de comunicação. A Figura 2.5 ilustra o desacoplamento entre os dispositivos sensores que fornecem a informação do ambiente físico e os 
atuadores que utilizam esta informação para realizar as atividades de controle.

- Utilização da informação por diversos sistemas prediais: a informação disponibilizada pelos sensores pode ser utilizada por diversos sistemas predais em diferentes aplicações. Por exemplo, o sistema de combate a incêndio pode utilizar a informação de localização dos usuários dentro do prédio assim como o sistema de comunicação pode utilizar esta informação para realizar a transferência de chamadas telefônicas.

Baseada nessas características, a arquitetura do sistema de controle do El tem que possuir um mecanismo de comunicação que possibilite a interação entre a grande quantidade de dispositivos sensores e atuadores de maneira flexível, desacoplada e que possua a capacidade de processar uma grande quantidade de informação. Neste sentido, neste trabalho propõe-se a utilização do paradigma de comunicação publish/subscribe por ser aquele que melhor se adequa a estas necessidades.

\subsection{COMUNICAÇÃO PUBLISHISUBSCRIBE (P/S)}

Segundo Becker e Schiele (2003), as redes de controle dos Els são caracterizadas por uma heterogeneidade adicional em termos de conexão à rede de comunicação quando comparadas às infraestruturas computacionais tradicionais existentes. Algumas características necessárias para estabelecer a comunicação dos dispositivos nos Els são: a capacidade de disseminar uma grande quantidade de dados para um grande número de dispositivos e a comunicação desacoplada em termos de tempo e de espaço (FENKAM et al., 2002; HUANG; GARCIA, 2004). Esta última característica possibilita que os dispositivos se comuniquem sem a restrição de estarem conectados diretamente e sem terem que conhecer as características de outras aplicações com as quais interagem, suportando assim desconexões típicas das redes de comunicação sem fio (LU; CLEMENTS CROOME; VILJANEN, 2009).

Existem diferentes tipos de arquiteturas distribuídas, que requerem diferentes níveis 
de acoplamento. Por exemplo, em uma arquitetura cliente-servidor, os componentes da aplicação estão fortemente acoplados entre si e com o middleware. Por outro lado, em processos submetidos a desconexões, como: transações off-line, computação em malha e arquiteturas para aplicações móveis, os componentes e o middleware têm que estar desacoplados em suas diferentes dimensões (ALDRED et al., 2005).

O paradigma de comunicação $P / S$ possui características que se adequam às aplicações de Els (ALDRED et al., 2005; CORSARO et al., 2006; LU; CLEMENTS CROOME; VILJANEN, 2009). Esse paradigma de comunicação é baseado na troca assíncrona de eventos entre os dispositivos ou aplicações que constituem o sistema. Nele, as aplicações que precisam receber um determinado tipo de evento (subscribers) são notificadas quando outra aplicação (publisher) publica esse evento. As principais características do paradigma $P / S$ são: eliminar o acoplamento direto entre as aplicações e permitir a disseminação seletiva de informação baseada nos interesses das aplicações (LOPES, 2008). O desacoplamento entre as aplicações pode ser dividido em três dimensões (EUGSTER et al., 2003):

(1) Desacoplamento em espaço: as aplicações que interagem não precisam conhecer a localização umas das outras. As aplicações publicam os eventos em um middleware, que se encarrega de enviá-los às aplicações que se subscrevem, as quais não têm referência de quantas e quais aplicações estão publicando o evento e nem de quantas aplicações subscritas estão participando desta interação.

(2) Desacoplamento em tempo: as aplicações que interagem não precisam participar ao mesmo tempo da interação. Assim, as aplicações que publicam os eventos podem fazê-lo enquanto as outras aplicações que se subscrevem a esses eventos podem estar desconectadas.

(3) Desacoplamento em sincronia: as aplicações que publicam eventos não estão bloqueadas durante a produção de um evento, e as que se subscrevem podem ser notificadas de modo assíncrono enquanto realizam alguma outra atividade concorrentemente. $O$ desacoplamento em sincronia é útil em aplicações de Els, já que, como foi mencionado anteriormente, esses sistemas possuem redes de 
comunicação sem fio, as quais podem sofrer desconexões durante alguns períodos de tempo (HUANG; GARCIA, 2004).

A comunicação entre os dispositivos inteligentes tem que considerar o contexto no qual a informação a ser comunicada é produzida ou consumida (CUGOLA; MARGARA; MIGLIAVACCA, 2009). Por exemplo, os usuários de um sistema de monitoração que utiliza sensores sem fio para monitorar a temperatura de um ambiente podem estar interessados em receber leituras periódicas dos sensores que possuem energia das baterias, enquanto que, para os sensores com pouca energia, os usuários podem receber unicamente sinais em situações de emergência. Assim, não somente é importante o conteúdo da informação, mas também o contexto no qual a informação é produzida e sua relação com o consumidor da informação. Um exemplo de modelo de um sistema que se comunica usando o paradigma $P / S$ baseado em tópicos (CORSARO et al., 2006) é apresentado na Figura 2.6. Os eventos são agrupados em tópicos, e as aplicações que se subscrevem a um tópico particular recebem todos os eventos que pertencem a esse tópico.

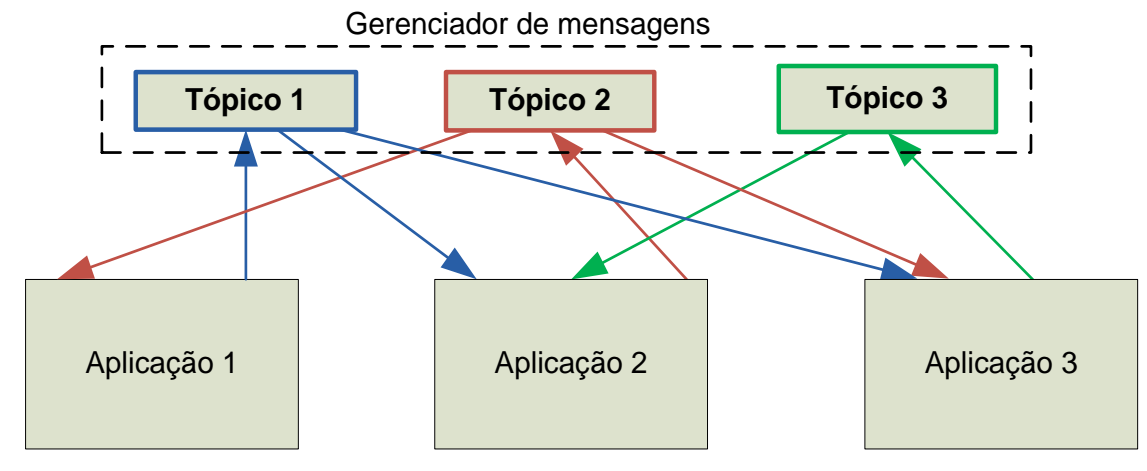

Figura 2.6 - Modelo publish/subscribe

Um tópico é um conjunto de dados constituído por um identificador e um tipo de dado. Na Figura 2.6, a "Aplicação 1" publica um dado do tópico 1. Em seguida, o gerenciador de mensagens (middleware) se encarrega de enviar esse dado às aplicações que estão subscritas a esse tópico. Nesse caso, a "Aplicação 2" e a "Aplicação 3" recebem os dados do tópico. Pode se observar nesta figura que as aplicações não estão conectadas diretamente, isto é, estão desacopladas. O desacoplamento entre as aplicações permite criar sistemas mais flexíveis (ALDRED et al., 2005; EUGSTER et al., 2003). Porém, essa vantagem é contrabalançada pelo 
aumento da complexidade no sentido do entendimento do funcionamento do sistema como um todo (BARESI; GHEZZI; MOTTOLA, 2007).

\subsection{MÉTODOS FORMAIS}

O projeto dos Els envolve a sistematização do conhecimento de como esses sistemas funcionam, isto é, quais são as tarefas realizadas por seus componentes e como elas interagem entre si. Neste contexto, verifica-se que as partes que compõem os Els podem ter seus comportamentos dinâmicos descritos por meio de mudanças de estados discretos como consequência da ocorrência de eventos instantâneos. Por exemplo, entre os eventos que podem ocorrer estão: acionamento e desligamento de sensores de presença, abertura e fechamento de portas e janelas automaticamente, ativação e desativação de dispositivos de emergência etc. A classe de sistemas definida por esse comportamento pode ser denominada SED e têm sido propostos diferentes métodos formais para sua modelagem e análise (ARAKAKI, 2004; RAMADGE; WONHAM, 1989; ZHOU; DICESARE, 1993).

Como os Els interagem diretamente com os usuários, erros de especificação durante a fase do projeto causam erros ou funcionamento inadequado durante a vida útil do sistema, podendo resultar em acidentes fatais ou consideráveis perdas econômicas. Os métodos formais são ferramentas que visam a reduzir drasticamente os erros de especificação (PRESSMAN, 2006). O "método formal" é entendido como uma linguagem formal de especificação com sólida base matemática (JENSEN; KRISTENSEN, 2009). Essa base permite criar especificações mais completas, consistentes e não ambíguas quando comparadas aos métodos convencionais. Uma informação mais detalhada dos métodos formais utilizados para desenvolver especificações de sistemas de software pode ser encontrada em Clarke et al. (1996). Dentre os principais benefícios em utilizar métodos formais durante o projeto dos Els, destacam-se (JANCZURA, 1998):

- uma especificação completa e sem ambiguidades do sistema, que pode ser verificada para satisfazer os requisitos dos projetistas;

- geração automática dos códigos do programa a partir da especificação formal 
do sistema.

Este trabalho adota a rede de Petri como linguagem para a modelagem das redes de controle dos Els pelas seguintes características: facilidades de interpretação gráfica, identificação de estados e ações de maneira clara e a possibilidade de representar a estrutura e a dinâmica de sistemas em diferentes níveis de abstração.

\subsection{REDE DE PETRI}

A rede de Petri (RP) foi inicialmente definida em 1962 por Carl Adam Petri em sua tese de doutorado Kommunikation mit Automaten pela Universidade de Darmstadt, na antiga Alemanha Ocidental (BRAUER; REISIG, 2006). É uma ferramenta matemática e gráfica para modelar, analisar e projetar sistemas com processos paralelos, concorrentes, assíncronos e não determinísticos; especialmente aqueles caracterizados por estados discretos que são alterados abruptamente por eventos assumidos como instantâneos (MURATA, 1989).

A RP permite a visualização explícita dos elementos que compõem um sistema. Assim, sua parte estrutural pode ser considerada uma ferramenta de projeto, similar ao fluxograma e aos diagramas de blocos (ZHOU; DICESARE, 1993). Adicionalmente, a RP possui o conceito de marcas e regras de evolução destas, as quais são utilizadas para representar a dinâmica do sistema. Como uma ferramenta matemática, a RP pode ser representada por matrizes, e sua dinâmica pode ser descrita por equações de estado e outras relações (MURATA, 1989; VILLANI; MIYAGI; VALETTE, 2007).

Essa representação matemática permite a verificação das propriedades relacionadas ao comportamento do sistema, tais como: relações entre eventos, operações concorrentes, sincronização, atividades repetitivas e exclusão mútua de recursos compartilhados (MIYAGl et al., 2002). Além disso, segundo Arakaki (2004), a modelagem dos sistemas físicos por meio da RP permite a verificação das chamadas "boas propriedades", tais como: limitação (existência de um número finito 
de estados), vivacidade (a inexistência de deadlock $^{4}$ ) e reversibilidade (repetição do processo infinitamente sem degradação do processo). Comparadas com outras técnicas de descrição de SEDs (cadeias de Markov, teoria das filas, álgebra de processo, álgebra max-plus, lógica temporal e/ou autômatos), a rede de Petri possui uma capacidade equivalente de modelagem. Entretanto, A RP possui maior facilidade de visualização do sistema e a possibilidade de derivação para programas de controle (SILVA, 2008).

Na modelagem de SEDs por meio da utilização do conceito de condições e eventos, os lugares representam as condições e as transições representam os eventos (MURATA, 1989). Uma transição (um evento) possui uma quantidade de lugares de entrada e de saída, que representam as pré-condições e pós-condições, respectivamente. A presença de uma marca em um lugar pode ser interpretada como uma condição verdadeira associada a esse lugar. Por exemplo, se um lugar de uma RP representa um sensor de fumaça, a existência de uma marca no lugar indicaria a existência de fumaça. Em outra representação, " $m$ " marcas em um lugar podem indicar a presença de " $m$ " recursos ou quantidade de dados disponíveis. Algumas interpretações de transições e seus respetivos lugares de entradas e saídas são mostradas no Quadro 1.

\begin{tabular}{|l|l|l|}
\hline Lugares de entrada & Transição & Lugares de saída \\
\hline Pré-condições & Evento & Pós-condições \\
\hline Dados de entrada & Processamento dos dados & Dados de saída \\
\hline Sinais de entrada & Processamento dos sinais & Sinais de saída \\
\hline Recursos necessários & Tarefa ou atividade & Recursos liberados \\
\hline Condições & Processo lógico & Conclusão(es) \\
\hline
\end{tabular}

Quadro 1 - Interpretações típicas de lugares e transições (MURATA, 1989)

\subsubsection{Estrutura de uma RP}

A estrutura de uma RP pode ser definida formalmente como uma quádrupla (P, T, F, W), sendo que (REISIG, 1992):

- $\mathrm{P}=\left\{\mathrm{p}_{1}, \mathrm{p}_{2}, \ldots, \mathrm{p}_{\mathrm{m}}\right\}$ é o conjunto de lugares da RP, no qual $m \in N$ é a

\footnotetext{
${ }^{4} \mathrm{O}$ deadlock pode ser caracterizado como uma situação que gera um impasse e dois ou mais processos são permanentemente impedidos por causa de uma falta de materiais, recursos e/ou informações (MATSUSAKI, 2004).
} 
quantidade total de lugares da RP;

- $T=\left\{t_{1}, t_{2}, \ldots, t_{n}\right\}$ é o conjunto de transições, no qual $n \in N$ é a quantidade total de transições da RP;

- $F \subseteq((P x T) \cup(T x P))$. No qual $F$ é o conjunto de arcos da rede. Os arcos podem relacionar lugares a transições ou vice-versa. (PxT) é o conjunto de arcos de entrada das transições. (TXP) é o conjunto de arcos de saída das transições.

- $\mathrm{W}:(\mathrm{PxT}) \cup(\mathrm{TxP}) \mapsto \mathrm{N}$. No qual $\mathrm{W}$ é uma função que indica o peso de cada arco possível da rede.

\subsubsection{Marcação de uma RP}

Uma RP com marcas em seus lugares é chamada de RP marcada (P, T, F, W, $\mathrm{M}_{0}$ ), na qual $\mathrm{M}_{0}$ é um vector que representa a marcação inicial. Graficamente, essas marcas são modeladas por pontos pretos no interior dos lugares. A distribuição das marcas nos lugares da rede representa o estado do sistema. A evolução da marcação (segundo as regras de disparo das transições) descrita anteriormente representa o comportamento dinâmico do sistema.

\subsubsection{Representação gráfica}

A RP é um grafo bipartido (os arcos só podem interligar elementos de natureza diferente) constituído por lugares (representados por círculos ou elipses), transições (representadas por barras), arcos orientados interligando os componentes anteriores e marcas (utilizadas para definir o estado de uma RP). $O$ peso de um arco indica 0 número de arcos orientados do mesmo sentido entre dois elementos (MURATA, 1989).

A execução de uma RP é controlada pelo número de marcas e sua distribuição na rede. As marcas se localizam nos lugares e determinam o disparo das transições da rede. 
Uma transição dispara removendo as marcas dos seus lugares de entrada e criando novas marcas em seus lugares de saída.

As regras básicas para a dinâmica da evolução dos estados da RP ordinária são descritas a seguir (BRAUER; REISIG, 2006):

- uma transição só pode ser disparada se todos os seus lugares de entrada possuírem um número de marcas igual ou maior ao peso dos respetivos arcos;

- durante o disparo, a transição remove um número de marcas de cada lugar igual ao respetivo peso do arco (de entrada da transição) e coloca um número de marcas em cada lugar de saída igual ao respectivo peso do arco (de saída da transição);

- as marcas não podem ser diferenciadas umas das outras.

Na Figura 2.7 é apresentado um exemplo de uma RP tal que:

- o conjunto $\mathrm{P}=\{\mathrm{P} 1, \mathrm{P} 2, \mathrm{P} 3, \mathrm{P} 4, \mathrm{P} 5, \mathrm{P} 6\}$, que representa o conjunto de lugares da rede;

- o conjunto $\mathrm{T}=\{\mathrm{T} 1, \mathrm{~T} 2, \mathrm{~T} 3, \mathrm{~T} 4\}$, que representa $\mathrm{o}$ conjunto de transições da rede;

- o conjunto $\mathrm{F}=\{(\mathrm{P} 1, \mathrm{~T} 1),(\mathrm{T} 1, \mathrm{P} 2),(\mathrm{P} 2, \mathrm{~T} 2),(\mathrm{T} 2, \mathrm{P} 3),(\mathrm{T} 2, \mathrm{P} 4),(\mathrm{P} 3, \mathrm{~T} 3),(\mathrm{P} 4, \mathrm{~T} 3)$, (P4,T4), (T3,P5), (T4,P6)\}, que representa o conjunto de arcos da rede;

- a função $\mathrm{W}$, que representa o peso dos arcos, está definida de maneira que $W(p)=1, \forall p \in F$

- a marcação inicial $M_{0}$ é definida de maneira que:

$$
\mathrm{M}_{0}(\mathrm{p})=\left\{\begin{array}{c}
1, \text { se } p \in\{P 1\} \\
0, \text { se } p \in\{P 2, P 3, P 4, P 5, P 6\}
\end{array}\right.
$$

Observa-se que a transição $\mathrm{T} 1$ está habilitada em $\mathrm{M}_{0}$, podendo ser disparada. 


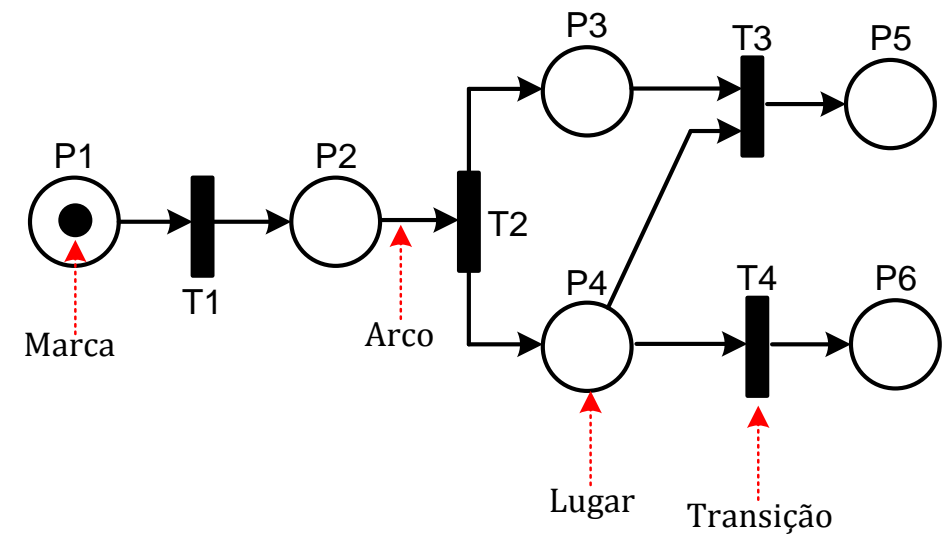

Figura 2.7 - Representação de uma RP

Na Figura 2.8 é representada a marcação resultante caso a transição T1 seja disparada na marcação inicial $\mathrm{M}_{0}$.

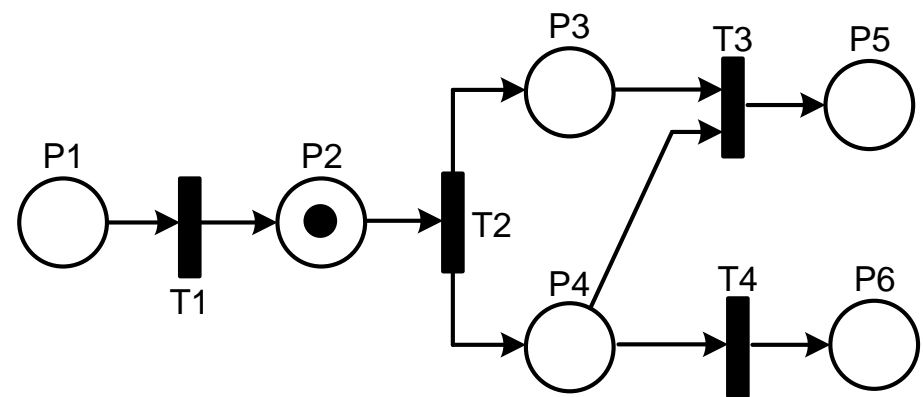

Figura 2.8 - Rede da Figura 2.6 após o disparo de T1

Nesta nova marcação, a transição T2 está habilitada e o disparo dessa transição leva a rede a uma situação de conflito entre as transições T3 e T4.

\subsubsection{Análise da RP}

As técnicas de análise da RP são utilizadas para inferir determinadas propriedades da rede, as quais são utilizadas para validar e verificar as especificações do sistema. $\mathrm{Na}$ validação da especificação, as propriedades esperadas são derivadas a partir do sistema real e comparadas com as obtidas na análise da rede. Assim, se a 
especificação não possui a propriedade esperada, conclui-se que a especificação está incorreta. Entretanto, a presença dessas propriedades não garante que a especificação esteja correta. As propriedades analisadas do modelo precisam ser interpretadas adequadamente para serem usadas na validação (SIMÃO, 2004). Por exemplo, dependendo do contexto, uma situação de deadlock pode ser tanto um estado final válido quanto uma situação a ser evitada. As principais propriedades de um modelo em RP podem ser divididas em comportamentais (dependem da marcação inicial) e estruturais (dependem da estrutura da rede).

As principais propriedades comportamentais são (SIMÃO, 2004):

Alcançabilidade: indica a possibilidade de atingir uma marcação determinada pelo disparo de um número de transições desde uma marcação inicial.

Limitação: está relacionada à existência de uma quantidade máxima de marcas que um lugar pode conter em qualquer marcação alcançável. A rede é limitada se todos os lugares são limitados.

Segurança: uma rede é segura se todos os seus lugares forem limitados a uma marca.

Deadlock: uma marcação está em estado de deadlock se nenhuma transição estiver habilitada e a marcação não for uma marcação final.

Liveness: esta propriedade está relacionada à ausência de marcações alcançáveis que estejam em deadlock.

Reversibilidade: esta propriedade tem relação com a capacidade de atingir uma marcação específica a partir de qualquer outra marcação alcançável.

Justiça: esta propriedade está relacionada com a ideia de que nenhuma transição da rede possa disparar indefinidamente, a despeito das outras.

As principais propriedades estruturais são (SIMÃO, 2004): 
Limitação estrutural: uma RP é estruturalmente limitada se ela é limitada para qualquer marcação inicial.

Conservação: se a quantidade total de marcas permanece invariável durante o disparo das transições, a RP é conservativa. Por meio dessa propriedade, é possível verificar, por exemplo, a não destruição de recursos.

\subsubsection{Classificação da RP}

Os modelos em RP podem ser classificados em função do nível de detalhe que os lugares (e suas marcas) podem representar. Em Simão (2004), três níveis são propostos.

Nível 1: nas RPs do nível 1, as marcas representam valores booleanos, isto é, um lugar pode conter no máximo uma marca não estruturada. As principais representantes desse grupo são as redes Condição/Evento e as redes elementares (BRAUER; REISIG, 2006).

Nível 2: neste nível, as marcas representam valores inteiros, isto é, um lugar pode conter marcas não estruturadas. Esse tipo de rede é genericamente denominado rede Lugar/Transição ou rede ordinária (ZHOU; DICESARE, 1993).

Nível 3: nas RPs do nível 3, as marcas representam valores em alto nível, isto é, um lugar pode conter um multiconjunto de valores estruturados (SIMÃO, 2004). As principais representantes são as redes Predicado/Transição (MURATA, 1989) e as RPCs (JENSEN; KRISTENSEN, 2009).

Além da classificação em função da complexidade das marcas, outras extensões têm sido propostas, como as que permitem representar: (i) o tempo de disparo de uma transição (RPs temporizadas); (ii) o tempo consumido por uma atividade, representado por um lugar (RP estocástica); enquanto outras incluem conceitos de orientação a objetos, tais como a RP Orientada a Objetos (SIMÃO, 2004). 


\subsubsection{Rede de Petri Colorida (RPC)}

A RPC é uma rede hierárquica que possibilita condensar a descrição do sistema (JENSEN; KRISTENSEN, 2009). Os modelos em RPC podem ser estruturados em um conjunto de módulos. Essa característica é particularmente importante quando se trata de modelar sistemas complexos (em termos do número de variáveis envolvidas e da intensiva dependência entre elas). O conceito de módulos nas RPC é baseado em estruturas hierárquicas, o que permite a construção de módulos por meio da utilização de módulos menores (JORGENSEN; TJELL; FERNANDES, 2009).

Os modelos em RPC são formais, no sentido que a RPC é uma linguagem de modelagem que tem uma base matemática na sua sintaxe e semântica. Essa característica permite que os modelos possam ser analisados por meio de ferramentas computacionais para verificação das propriedades do sistema. Por exemplo, para comprovar se certas propriedades são satisfeitas ou para que certas propriedades indesejadas sejam evitadas (JENSEN et al., 2007). Um modelo em RPC é constituído por elementos que representam a estrutura do sistema e elementos que definem o seu comportamento dinâmico.

A seguir, a RPC é apresentada por meio de um exemplo que representa um sistema de segurança simplificado. O exemplo consiste em um sistema automático que registra as digitais de usuários cadastrados no sistema. Essa informação é utilizada para liberar a porta de ingresso e enviar um sinal de alerta no caso de alguma situação de emergência.

A liberação do acesso dos usuários à sala é realizada por meio de identificação biométrica. O usuário tem suas digitais do indicador e polegar previamente cadastradas no sistema. O sistema de segurança é configurado para reagir em duas situações diferentes: quando o usuário se registra com o indicador, é estabelecida uma situação de emergência, a porta de ingresso é liberada e o sistema de segurança é alertado. Em uma situação normal, o usuário se registra com o polegar para liberar a porta de entrada. A Figura 2.9 apresenta uma estrutura do sistema, 
constituída pelos seguintes dispositivos: um sensor biométrico (em cor azul), um mecanismo que aciona a porta de entrada (em cor verde) e um módulo do sistema de alerta (cor laranja).

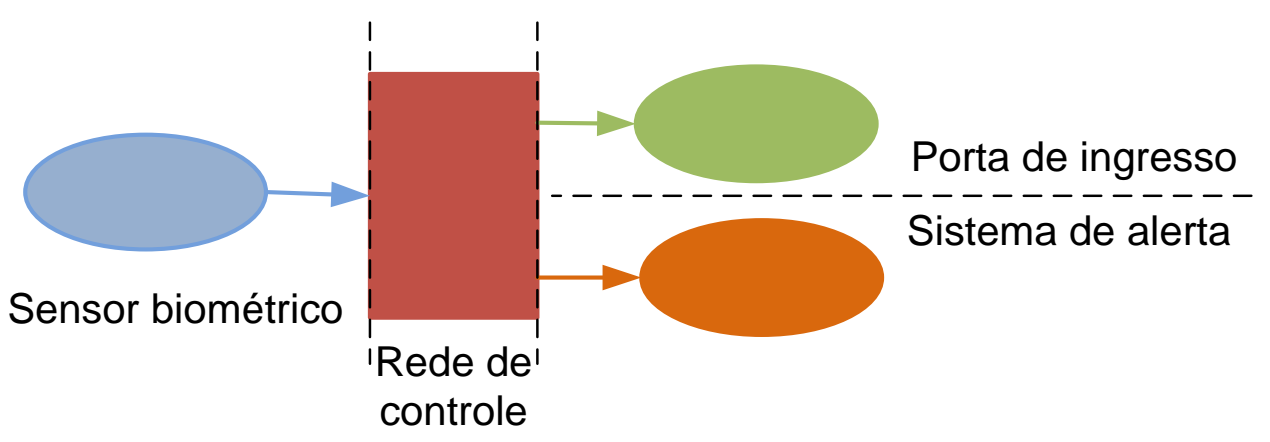

Figura 2.9 - Estrutura simplificada de um sistema de segurança predial

A rede de controle (em cor vermelho) distribui a informação do sensor biométrico para o dispositivo que libera a porta de ingresso e o sistema de alerta. Essa informação é constituída por dois dados: o nome do usuário cadastrado e sua respectiva digital, que pode ser do indicador ou do polegar. $O$ dispositivo que libera a porta de ingresso processa a identificação do usuário. Se o usuário estiver cadastrado no sistema, a porta de ingresso é liberada. Concorrentemente, o sistema de alerta processa a digital do usuário. Se essa digital corresponder à do indicador, então é estabelecida uma situação de emergência.

\subsubsection{Modelo em RPC}

Na Figura 2.10 é apresentado o modelo em RPC do exemplo anteriormente descrito. Esse modelo está dividido em quatro partes: o sensor biométrico, a rede de controle, o sistema de alerta e o dispositivo que libera a porta de ingresso. Os componentes básicos do modelo em RPC são descritos a seguir. 


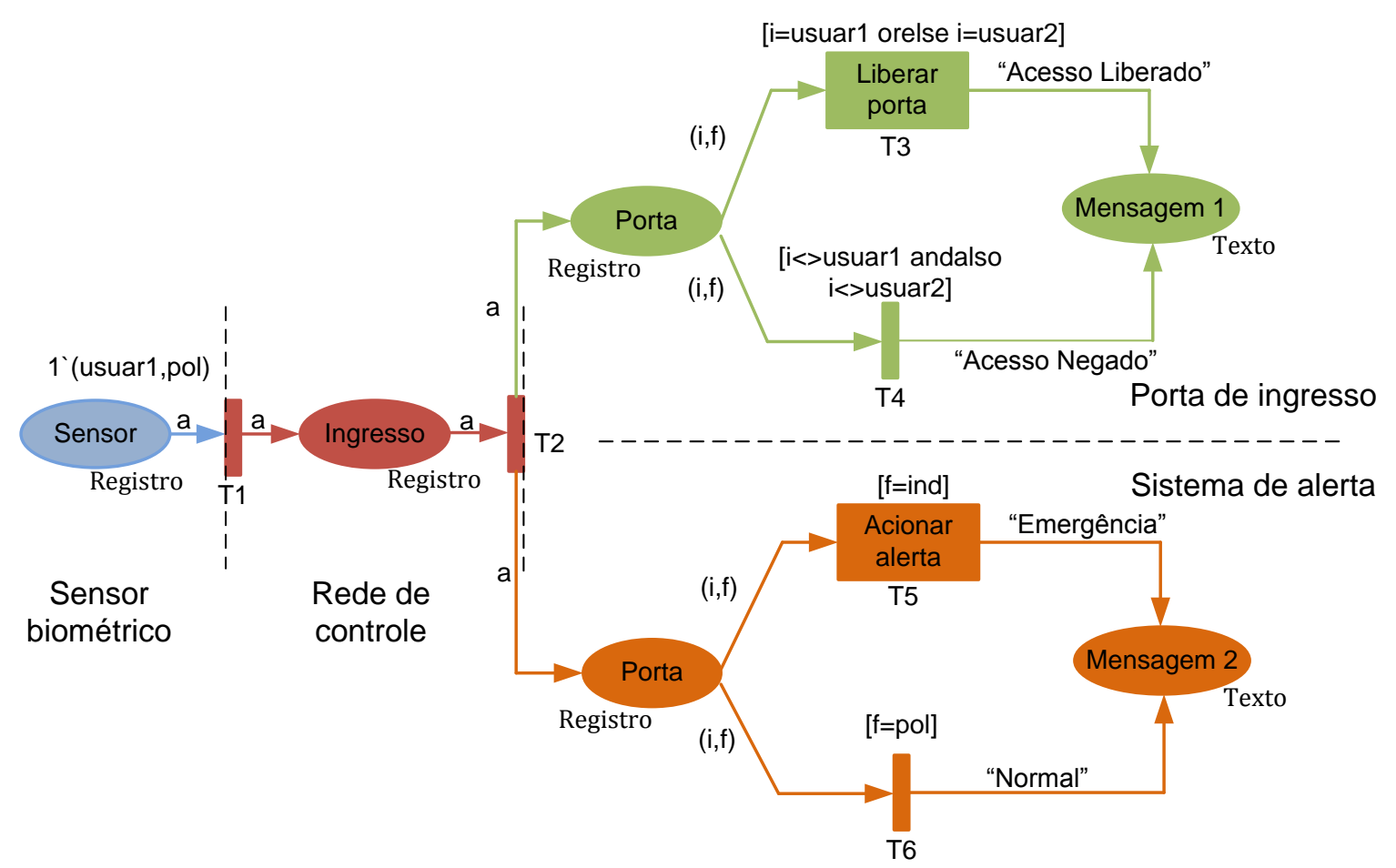

Figura 2.10 - Modelo simplificado da especificação do sistema de segurança

\section{Lugares $^{5}$}

Os lugares representam os elementos passivos do sistema, tais como: condições, recursos, buffers etc. (SIMÃO, 2004). Graficamente, lugares são representados por elipses ou círculos. A Figura 2.10 apresenta seis lugares. O lugar "Sensor" representa a informação do usuário e sua digital capturada pelo sensor biométrico. O lugar "Ingresso" representa os dados do usuário que ingressa na rede de controle e sua digital. Essa informação é encaminhada ao dispositivo que libera a porta de ingresso e ao sistema de alerta por meio dos lugares "Porta" e "Alerta", respectivamente. Os dados que chegam ao lugar "Mensagem1" indicam se o acesso foi liberado ou negado. Similarmente, os dados que chegam ao lugar "Mensagem2" indicam se o sistema está sob uma situação de emergência.

Tipo de dado

Cada lugar tem associado um tipo de dado ou conjunto de cores (colset) que o lugar pode conter. Graficamente, o tipo de dado é mostrado na parte inferior direita do seu respetivo lugar. $O$ conceito de tipo de dados nas RPC é similar ao utilizado nas

\footnotetext{
${ }^{5}$ Neste texto, termos específicos da RPC estão em fonte Arial Narrow.
} 
linguagens de programação. As definições dos tipos de dados do sistema de segurança são mostradas na Figura 2.11.

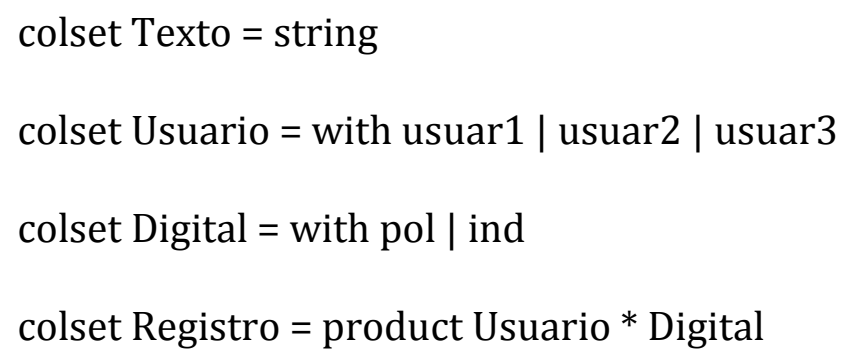

Figura 2.11 - Definições dos tipos de dados

Para o exemplo apresentado, os lugares "Sensor", "Ingresso", "Porta" e "Alerta" estão associados ao tipo de dado Registro. Esse tipo de dado é o produto do tipo de dado Usuário e Digital. $O$ tipo de dado Digital é um conjunto de dados que representa as leituras das duas digitais (polegar e indicador). O tipo de dado Usuário é um conjunto de dados que agrupa os usuários cadastrados no sistema. No sistema de segurança apresentado, são cadastrados três usuários (usuar1, usuar2 e usuar3). Os lugares "Mensagem1" e "Mensagem2" estão associados ao tipo de dado string, os quais representam as informações que podem ser mostradas na forma de texto para indicar as ações que são realizadas pelo sistema de segurança.

\section{Multiconjunto}

É um conjunto de marcas coloridas. É considerada como uma entidade matemática semelhante ao conjunto, exceto pelo fato de que diferentes elementos (marcas coloridas) podem coexistir no mesmo lugar (JENSEN et al., 2007). A notação para representar um multiconjunto é a soma de termos:

$$
M=k_{1} e_{1}++k_{2} e_{2}++\ldots k_{n}{ }^{\prime} e_{n}
$$

Em que $k_{n}$ é o número de ocorrências do elemento $e_{n}$.

Os símbolos "+r" e " " " são operadores que permitem a construção dos multiconjuntos. O operador " " " divide o argumento em duas partes. O operador "++" toma dois multiconjuntos como argumento e restaura a união (soma). Por exemplo, no multiconjunto 
$m=1^{`}$ (usuar1, pol)++1`(usuar2, ind), $m$ é um multiconjunto formado por 2 elementos, representados pela marcas 1'(usuar1, pol) e 1'(usuar2, ind). $O$ argumento da primeira e segunda marca é (usuar1, pol) e (usuar2, ind), respectivamente.

\section{Marcas}

Uma marca é um valor que pertence a um tipo de dado associado a um lugar. A marcação de um lugar é o multiconjunto de marcas presentes no lugar. Na Figura 2.10, o lugar "Sensor" contém uma marca do tipo de dado (usuar1, pol) que representa a digital do polegar do usuário 1 capturada pelo sensor biométrico.

\section{Transições}

As transições representam elementos ativos do sistema, tais como: eventos, ações e atividades. Graficamente, uma transição é representada por um retângulo. O exemplo ilustrado na Figura 2.10 apresenta seis transições. A transição T1 simboliza o envio da informação do usuário e sua respectiva digital capturada pelo sensor biométrico à rede de controle. A transição T2 simboliza o envio dessa informação ao dispositivo que libera a porta de ingresso e ao sistema de alerta. A transição T3 simboliza a ação de liberar a porta de ingresso e a transição $T 4$, a negação do acesso ao usuário. $A$ transição T5 representa o acionamento de alerta no caso de uma emergência e, finalmente, a transição T6, uma situação de normalidade.

\section{Arcos}

Os arcos conectam transições e lugares. Um arco pode relacionar:

- um lugar p a uma transição t. Nesse caso, o arco $(p, t)$ é um arco de entrada de $t$ (arco direcionado de p para t). Os arcos de entrada de um modelo podem representar pré-condições, valores de entradas, recursos necessários etc. $\mathrm{Na}$ Figura 2.10, um exemplo de arco de entrada é o arco que conecta o lugar "Sensor" à transição $\mathrm{T} 1$;

- uma transição t a um lugar p. Nesse caso, o arco (t,p) é um arco de saída de t (arco direcionado de t para p). Os arcos de saída de um modelo podem representar pós-condições, valores de saída, recursos produzidos etc. $\mathrm{Na}$ Figura 2.10, um exemplo de arco de saída é o arco que liga a transição T2 aos lugares "Porta" e "Alerta". 


\subsubsection{Comportamento dinâmico}

O comportamento dinâmico do sistema pode ser representado pela evolução das marcas na RPC, as quais mudam em função do disparo das transições e as inscrições dos arcos.

Inscrição do arco e variáveis

Uma inscrição do arco é uma expressão que, quando avaliada, atribui valores de dados às variáveis. A declaração das variáveis do exemplo descrito anteriormente é apresentada na Figura 2.12. O resultado da avaliação de uma inscrição do arco é um multiconjunto de marcas.

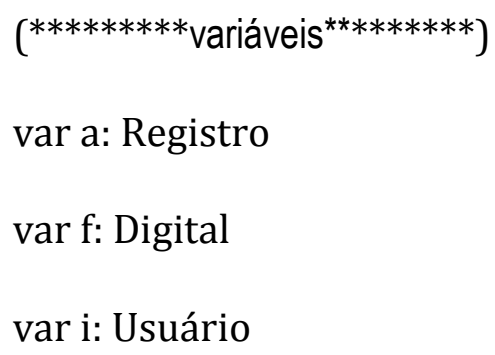

Figura 2.12 - Declaração de variáveis

As atribuições de valores de dados às variáveis são representadas da seguinte forma: $\left[v_{1}=d_{1}, v_{2}=d_{2}, \ldots, v_{n}=d_{n}\right]$, no qual $v_{i}$ para i $\epsilon[1,2, . . n]$ é uma variável e $d_{i}$ é um valor de dado atribuído a $\mathrm{v}_{\mathrm{i}}$. As inscrições dos arcos podem ser formadas por valores constantes, variáveis ou funções. Por exemplo, no arco de entrada que une o lugar "Sensor" à transição T1 (ver Figura 2.10), a inscrição associada a esse arco é a variável "a". Assim, quando a transição T1 é habilitada, à variável "a" será atribuída o valor de (usuar1, pol).

\section{Expressão de guarda}

Uma expressão de guarda é uma expressão booleana associada a uma transição. É uma condição que tem que ser verdadeira para que a transição possa disparar. Se a expressão de guarda não é declarada, assume-se o valor verdadeiro. Graficamente, é 
expressa entre colchetes e localizada próxima à respectiva transição. Na Figura 2.10, um exemplo de uma expressão de guarda é a que está associada à transição T4. Para que ela seja habilitada, a variável "i” tem que ser diferente de "usuar1" e "usuar2".

\subsubsection{RPC Hierárquicas}

Segundo Jensen e Kristensen (2009), a representação de um sistema complexo por meio de um único modelo construído com a RPC resulta em uma rede constituída por muitos elementos construtivos, o que torna difícil a visualização e o entendimento do modelo. Neste sentido, a utilização de modelos hierárquicos permite abstrair o sistema em diferentes níveis de detalhe, facilitando assim a compreensão do modelo. A modelagem de um sistema por RPCs hierárquicas permite a criação de modelos por meio de um conjunto de módulos, permitindo assim construir modelos que representem diferentes níveis de abstração do sistema.

A RPC hierárquica é um caminho para sistematizar a construção de modelos grandes e complexos. O sistema de segurança, por exemplo, descrito nas páginas anteriores, pode ser representado em um alto nível de abstração, como apresentado na Figura 2.13, constituído por quatro módulos (Rede de controle, o Sensor biométrico 1, a Porta de ingresso 1 e Sistema de alerta, representados por retângulos de bordas duplas) interconectados por meio de interfaces (A, B e C).

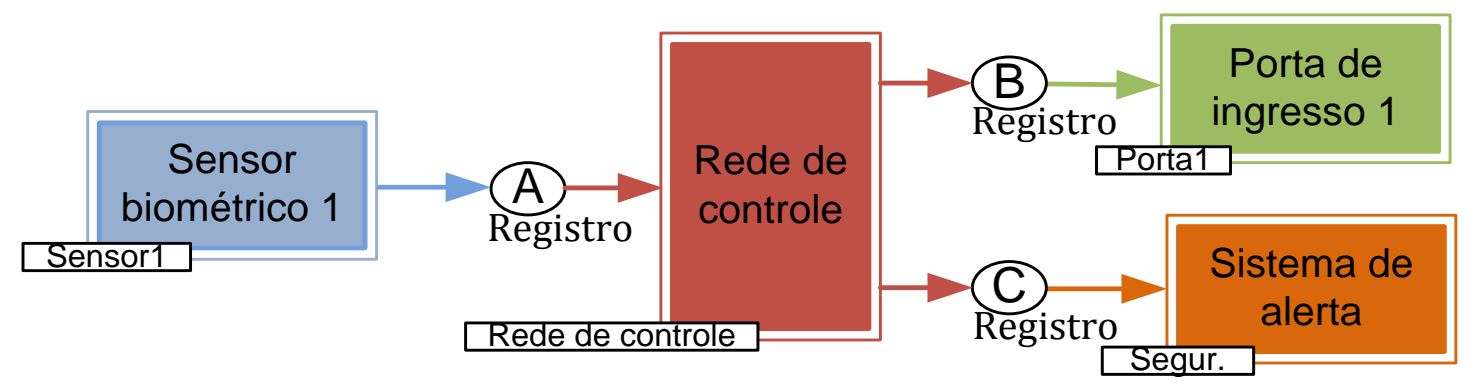

Figura 2.13 - Modelo hierárquico do sistema de segurança

Substituição de transições e interfaces

Uma substituição de transição está associada a um módulo. O módulo é uma descrição de 
um modelo mais detalhada do que a representada pela substituição de transição. Por exemplo, na Figura 2.14 e Figura 2.15 são apresentados os módulos "Rede de controle" e "Porta de ingresso", respectivamente. O módulo "Rede de controle" descreve o funcionamento da substituição de transição do mesmo nome. Esse módulo tem a função de receber uma marca contendo a informação do nome do usuário e sua digital para posteriormente encaminhar essa informação aos módulos "Porta de ingresso" e "Sistema de alerta".

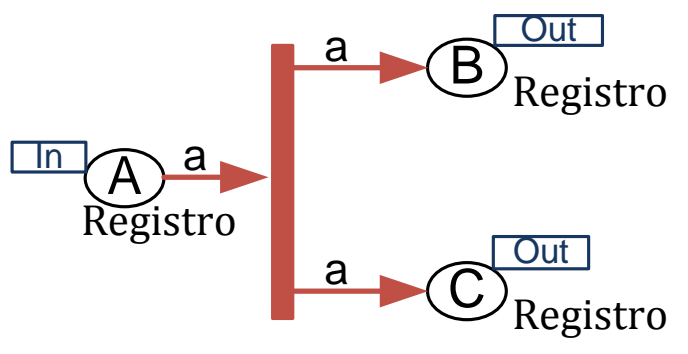

Figura 2.14 - Módulo "Rede de controle"

Na Figura 2.14, observa-se que esse módulo está constituído por três lugares e uma transição, os quais estão interconectados por meio de arcos. O lugar "A" é uma porta de entrada e os lugares "B" e "C" são portas de saída. Assim, os lugares "A", "B" e "C" são as interfaces por meio das quais o módulo "Rede de controle" intercambia marcas com seu entorno (outros módulos). Esse módulo importa e exporta marcas por meio da porta de entrada "A" e das portas de saída "B" e "C", respectivamente. Os lugares que constituem as portas de entrada e/ou saída são representadas por meio de etiquetas retangulares com a inscrição in (porta de entrada) ou out (porta de saída), inscritas dentro de um retângulo e posicionadas perto do seu respetivo lugar. O módulo "Porta de ingresso 1" apresentado na Figura 2.15 é constituído por duas transições e dois lugares. O lugar "Mensagem1" é um lugar interno, relevante unicamente ao próprio módulo. 


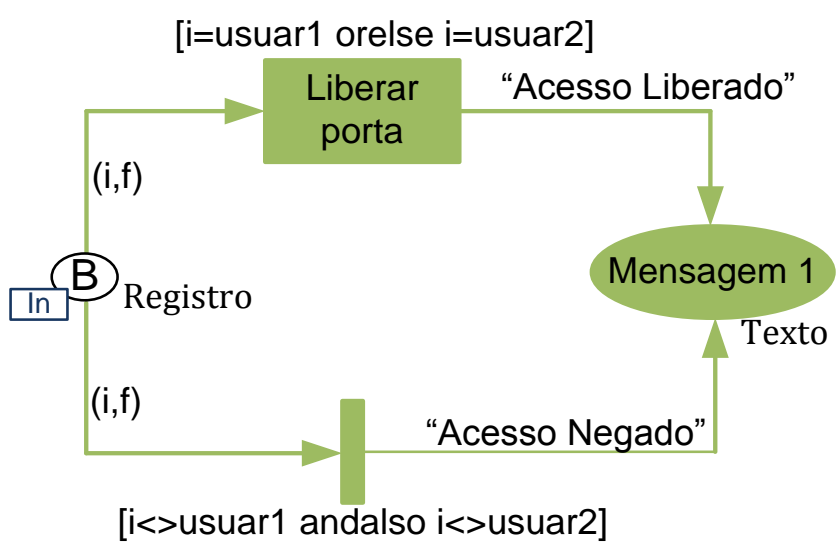

Figura 2.15 - Módulo "Porta de ingresso"

Os lugares de entrada das substituições de transições são chamados sockets de entrada e os lugares de saída são chamados sockets de saída. Na Figura 2.13, o lugar "A" representa o socket de entrada da substituição de transição "Rede de controle" e o socket de saída para a substituição de transição "Sensor biométrico". Os lugares que representam os sockets de entrada e saída são as interfaces das substituições de transições. O modelo hierárquico completo é obtido conectando-se as interfaces de cada módulo com sua respectiva substituição de transição. As portas de entrada e saída são vinculadas aos sockets de entrada e saída, respectivamente.

Quando uma porta e um socket estão relacionados, os dois lugares constituem duas vistas diferentes do mesmo lugar. Assim, a porta e o socket compartilham a mesma marcação (JENSEN; KRISTENSEN, 2009). Por exemplo, o socket "A" na Figura 2.13 tem sido atribuído à porta de entrada "A" na Figura 2.14, sendo que a marcação do socket "A" é a mesma que a marcação da porta de entrada "A".

Uma variação do modelo apresentado anteriormente utilizando uma abordagem de modelagem hierárquica é apresentada a seguir. Esse novo sistema considera outra sala ao modelo existente. Assim, é necessária a utilização de outro sensor biométrico e um dispositivo para liberar a porta de ingresso para esta nova sala. Estes novos dispositivos possuem as mesmas características que as especificadas no modelo original. $O$ objetivo deste modelo é ilustrar o reaproveitamento dos módulos existentes na ampliação do sistema. Na Figura 2.16 é apresentado o modelo hierárquico do sistema de segurança modificado. Foram reaproveitados os 
módulos "Sensor biométrico" e a "Porta de ingresso".

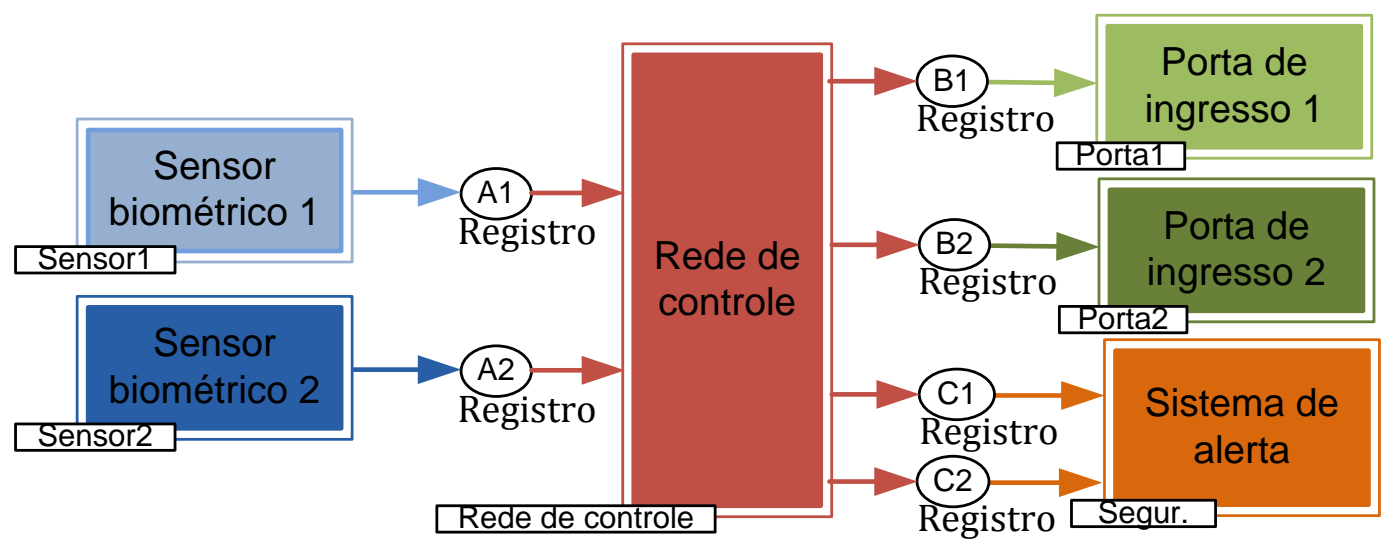

Figura 2.16 - Sistema de segurança para duas salas

Na Figura 2.17 é apresentado o módulo do sistema que monitora as duas salas. A chegada de uma marca contendo o dado do usuário e sua respectiva digital da sala 1 e da sala 2 é realizada por meio das portas de entrada $\mathrm{C} 1$ e C2, respectivamente. Se a leitura do sensor biométrico da sala 1 coincidir com a digital do indicador do usuário, o sistema acusará uma situação de emergência na sala 1. Por outro lado, se a leitura da digital coincidir com a do polegar, o sistema de alerta registrará uma situação de normalidade na sala 1 . O funcionamento do sistema de alerta para a sala 2 é similar ao da sala 1.

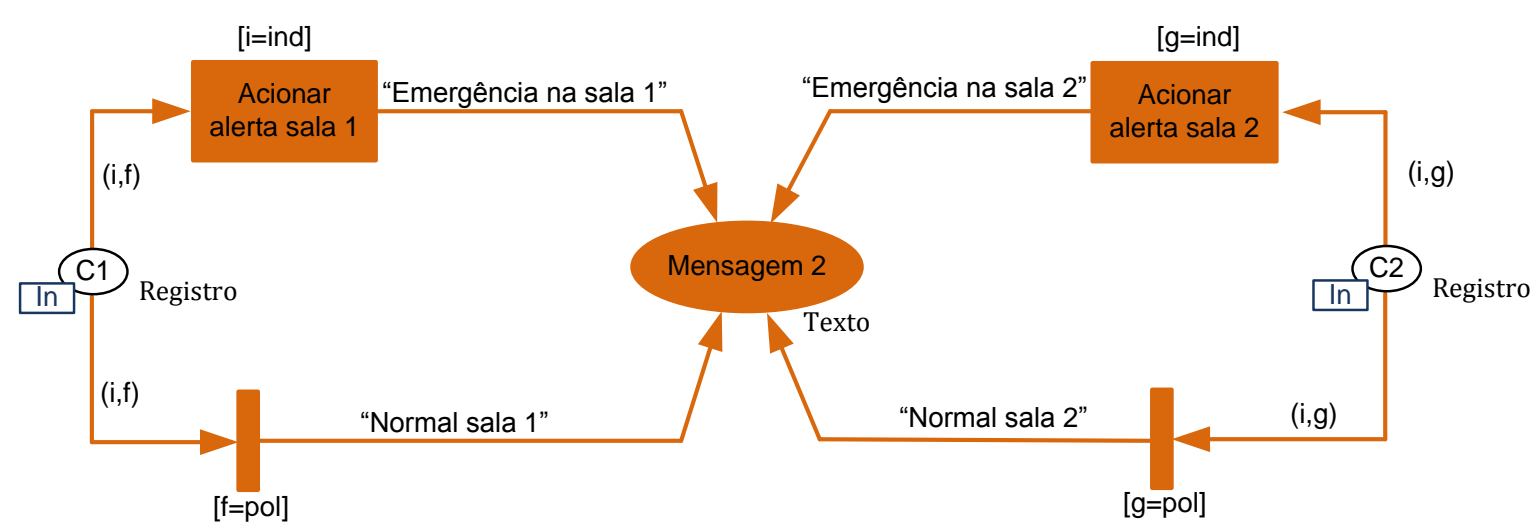

Figura 2.17 - Módulo do Sistema de alerta

Entretanto, durante o desenvolvimento dos modelos, percebe-se certa dificuldade de agregar outros componentes ao sistema. Por exemplo, no caso de ampliar o sistema de segurança para monitorar dez salas, o novo modelo estaria constituído por dez sensores biométricos, dez acionadores de portas de ingresso e um sistema de 
alerta, o que tornaria o modelo difícil de ser representado, em razão do grande número de elementos construtivos. Essa dificuldade se torna mais evidente nos sistemas de grande porte como os Els, constituídos por mais de uma centena de dispositivos (sensores, atuadores, controladores etc.) com caraterísticas idênticas, distribuídos pelo prédio.

Parametrização dos modelos

No modelo apresentado na Figura 2.16, foram reutilizados os módulos do sensor biométrico e da porta de ingresso para criar o novo sistema que monitora duas salas. No entanto, como foi descrito anteriormente, uma desvantagem desse modelo está na dificuldade de ampliação para sistemas de grande porte. Visando a contornar essa dificuldade, este trabalho propõe a utilização de módulos paramétricos.

O conceito de módulos paramétricos é similar ao conceito de classes e objetos, utilizado na orientação a objetos. Por exemplo, a criação do módulo "SALA(n)" representa uma estrutura ou um "molde" que abstrai o conjunto de salas com características similares. Já a "SALA(1)" representa uma entidade física ou conceitual da SALA(n).

A seguir, é apresentado um modelo com múltiplas salas. A abordagem utilizada para desenvolver os modelos facilita a ampliação do sistema para um número elevado de salas. Para isso, foi necessário modificar as definições dos tipos de dados apresentados na Figura 2.12. Assim, os novos tipos de dados são mostrados na Figura 2.18 .

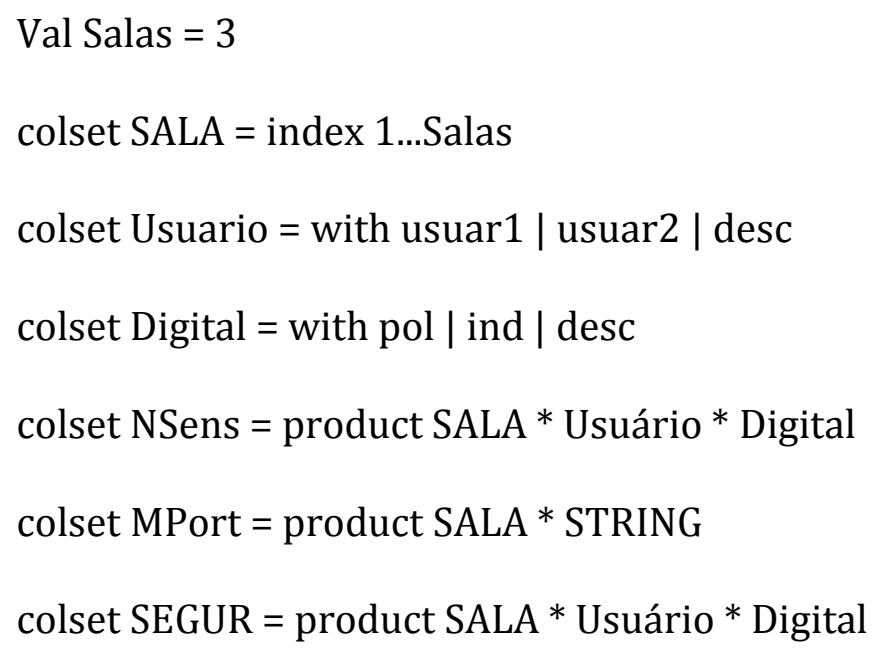

Figura 2.18 - Definições dos novos tipos de dados 
Na Figura 2.18, foi introduzida uma constante simbólica (JENSEN; KRISTENSEN, 2009) que determina o número de salas do novo sistema de segurança. Essa constante é utilizada para definir o conjunto SALA, que representa o número da sala do sistema. SALA(1), SALA(2) e SALA(3) representam a primeira, segunda e terceira sala do sistema. A Figura 2.19 apresenta o modelo do sistema de segurança para múltiplas salas. Observa-se que esse modelo é similar ao da Figura 2.13, descrito anteriormente para o caso de uma sala. Entretanto, uma única substituição de transição "Sensor Biométrico" representa os sensores de suas respectivas salas e uma única substituição de transição "Porta de Ingresso" representa os módulos que acionam as portas de ingresso das respectivas salas. Adicionalmente, as marcas nos sockets $\mathrm{A}, \mathrm{B}$ e $\mathrm{C}$ possuem as seguintes informações: o número da sala, o usuário e a digital.

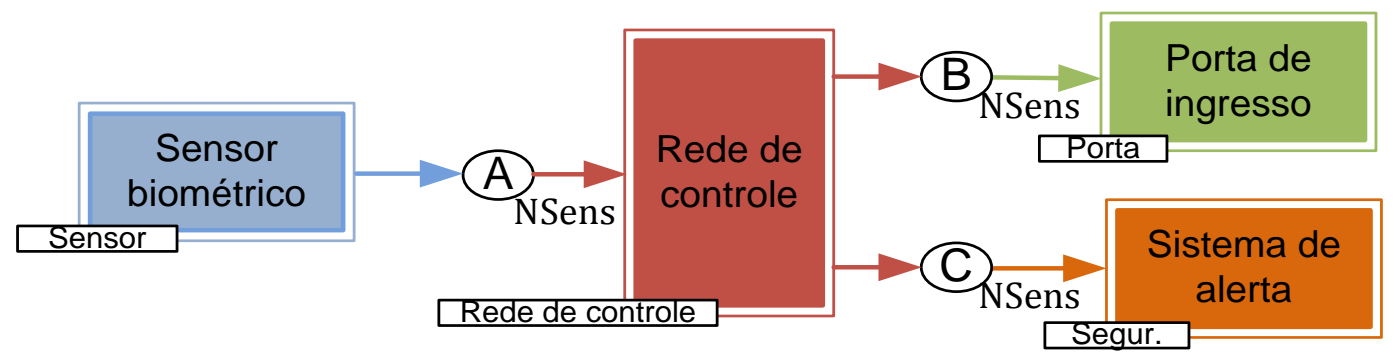

Figura 2.19 - Modelo do sistema de segurança com múltiplas salas

Na Figura 2.20, apresenta-se o módulo do sistema de segurança. Esse módulo possui a variável adicional " $x$ ", que representa o número da sala.

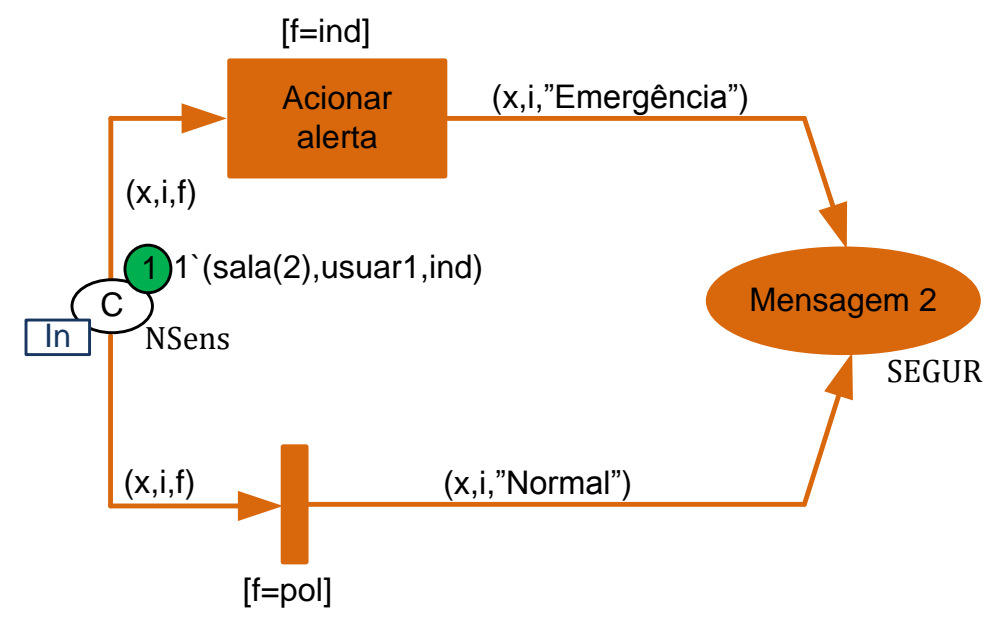

Figura 2.20 - Chegada de uma marca ao módulo do Sistema de alerta 
A chegada de uma marca ao módulo do sistema de alerta é realizada por meio da porta de entrada "C". Na Figura 2.20, a marca no lugar "C": 1'(sala(2),usuar1,ind) indica que na sala 2 (sala(2)) o usuário 1 (usuar1) registrou a digital do indicador (ind). Com essas condições iniciais, a transição "Acionar alerta" é habilitada e envia a seguinte marca ao lugar "Mensagem2": 1'(sala(2),usuar1,"Emergência"), como apresentada na Figura 2.21.

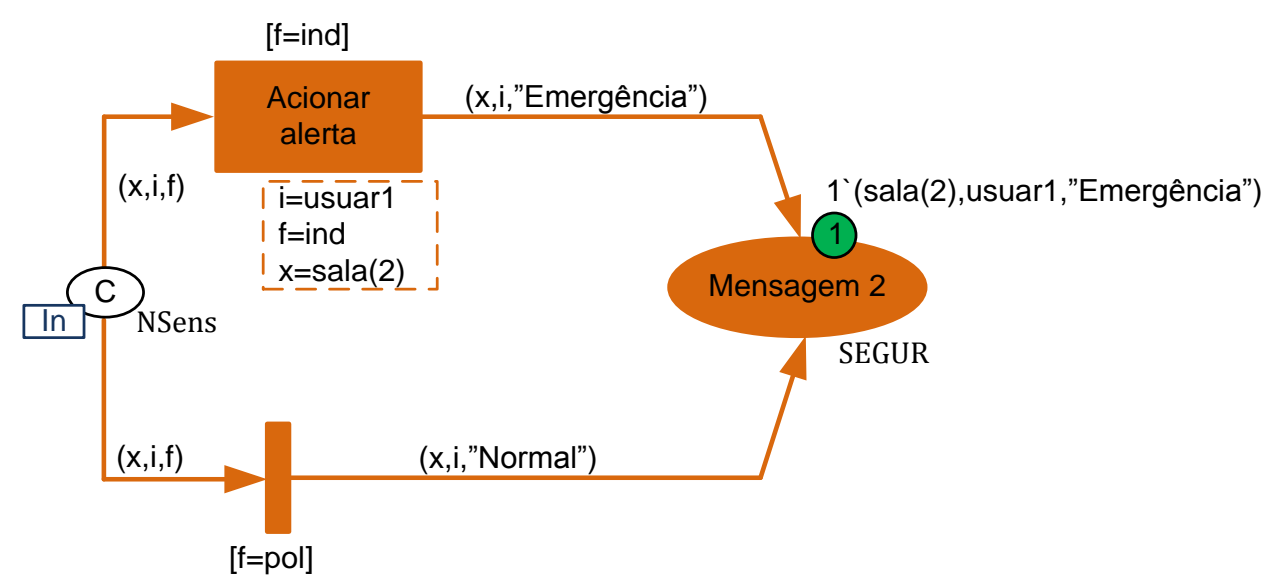

Figura 2.21 - Módulo de alerta depois que a transição "Acionar alerta" é disparada

Essa marca indica que o usuário 1 (usuar1), que está localizado na sala 2 (sala(2)) acionou um sinal de alerta ("Emergência"). Desta forma, por meio dos módulos paramétricos é possível criar modelos compactos de sistemas de grande porte que facilitam a sua representação.

\subsection{DESENVOLVIMENTO DE SOFTWARE BASEADO EM COMPONENTES}

O desenvolvimento de software baseado em componentes (DSBC) surgiu no final da década de 1990 como uma abordagem baseada no reuso para o desenvolvimento de sistemas de software (SOMMERVILLE, 2007). O DSBC consiste na criação de sistemas de software a partir da integração de componentes de software previamente existentes. Esses componentes podem ser desenvolvidos internamente pela organização ou ser obtidos por meio de terceiros (HIRATA, 2008). As principais 
características dos componentes são:

- intercambiabilidade;

- reusabilidade;

- alguns são de uso mais geral, outros são de uso mais específico;

- interabilidade entre componentes.

A arquitetura de sistemas baseada em componentes se caracteriza pelo reuso. Isto é, um componente poderá ser utilizado em outras aplicações. Segundo Sommerville (2007), a comunicação entre os componentes é realizada por meio de interfaces bem definidas. Detalhes da implementação são ocultados, o que facilita a substituição de um componente por outro com funcionalidade adicional ou mais aprimorada.

O desenvolvimento de sistemas de controle de grande porte como nos Els é uma tarefa complexa, tornando-se necessária a utilização de ferramentas e abordagens que busquem melhorar a qualidade dos artefatos ${ }^{6}$ de software, bem como diminuir o tempo e esforço necessários para produzi-los (SILVA, 2000). Entre as principais propostas, destaca-se o DSBC (ARAKAKI, 2004; FEIJÓ, 2007; PRESSMAN, 2006; SILVA, 2000). A principal vantagem dessa abordagem é a promoção da reutilização de componentes, que pode diminuir o tempo e o esforço exigidos na produção do software. O desenvolvimento de software baseado em componentes visa a organizar a estrutura de um software como uma interligação de artefatos de software independentes, os componentes (SILVA, 2000). Frameworks são entendidos como projetos reutilizáveis de um sistema que descreve como um sistema é decomposto em um conjunto de componentes interagindo entre si (ARAKAKI, 2004). componente está integrado ao framework por meio de suas interfaces.

Um componente pode ser definido como uma unidade de software independente que encapsula, dentro de si, o seu projeto e implementação, e oferece serviços por meio de interfaces bem definidas para o meio externo (GIMENES; HUZITA, 2005). Os componentes podem ser objetos, conjunto de objetos, sistemas ou qualquer implementação que seja independente. O componente possui funcionalidade

\footnotetext{
${ }^{6}$ A expressão artefato é utilizada aqui para se referir de forma genérica a um código, aplicação, framework ou componente.
} 
específica e mantém as características e funcionalidades independentemente do framework utilizado (FEIJó, 2007).

Na Figura 2.22 é apresentado um possível framework para um sistema constituído por três sistemas prediais. Nesse caso, os elementos são representados por componentes (hardware e software) interconectados por interfaces de comunicação. Em um primeiro nível, têm-se os controladores que gerenciam três sistemas prediais: "controle de elevadores", "controle de incêndio" e "controle de ar condicionado". No detalhamento do componente "controle de ar condicionado", incluem-se outros componentes: "rede de comunicação", "sensores" e "atuadores".

A reutilização de componentes nesse exemplo pode ser ilustrada por meio do detalhamento do "controle de incêndio". Neste caso, os componentes "sensores" e "atuadores", utilizados no "controle de ar condicionado", são utilizados no "controle de incêndio". O framework desenvolvido também pode ser reaproveitado no desenvolvimento de outros projetos semelhantes para automação de edifícios.

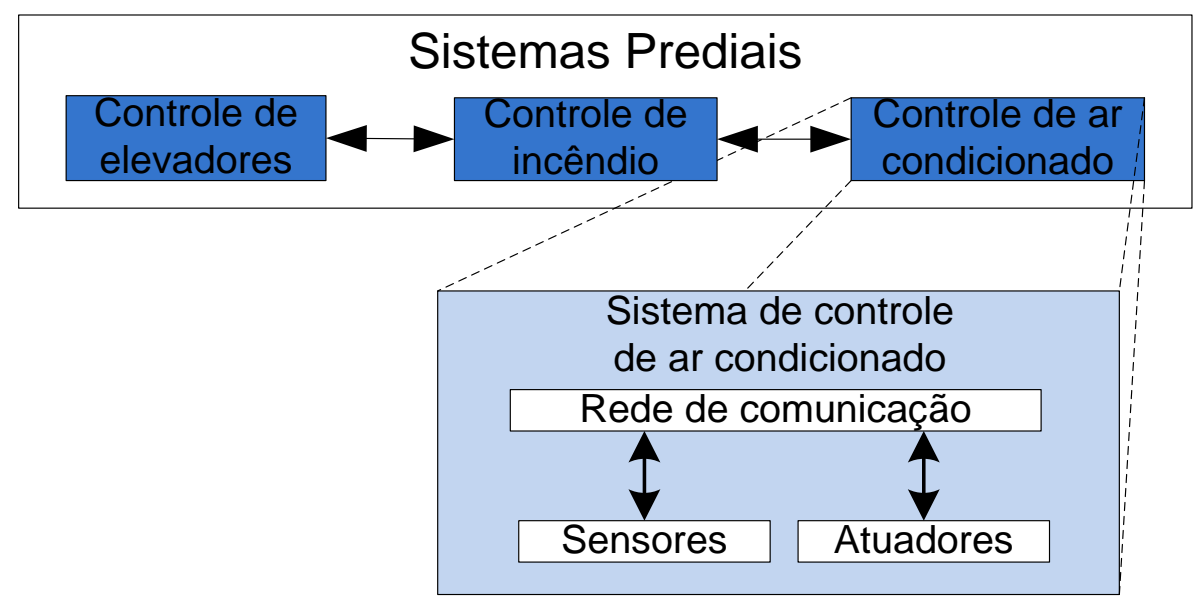

Figura 2.22 - Framework de um sistema predial (Adaptado de Arakaki (2004))

Nos processos de desenvolvimento de software tradicionais, a aplicação é desenvolvida praticamente desde o início, embora existam procedimentos que visem a maximizar o reuso dos modelos existentes. Geralmente, os projetos de sistemas de controle estão constituídos pelas seguintes etapas: 

a) análise das necessidades;
b) definição das necessidades;
c) projeto do sistema;
d) projeto do software de controle, no qual alguns desenhos de projeto podem ser reutilizados;
e) implementação do software, no qual se procura reaproveitar funções desenvolvidas em outros projetos;
f) testes;
g) implantação do software.

Por outro lado, no processo de desenvolvimento baseado em componentes, o sistema é desenvolvido pela integração de diversos componentes existentes, envolvendo as seguintes etapas (SOFTEX, 2007):
a) análise das necessidades;
b) definição das necessidades;
c) projeto do sistema;
d) busca e seleção dos componentes que serão utilizados;
e) desenvolvimento das partes que não foram atendidas por componentes já existentes;
f) integração;
g) testes de integração;
h) implantação do software.

Existem diferenças significativas entre os dois processos de desenvolvimento, mesmo nas etapas comuns (SOFTEX, 2007). Por exemplo, nas três primeiras etapas do processo de desenvolvimento baseado em componentes, é preciso ser levada em consideração a disponibilidade dos componentes, quais componentes terão que ser desenvolvidos e como maximizar o reuso dos mesmos. Em Deboni (2003), é apresentado um esquema de um processo cíclico de desenvolvimento de software, mostrado na Figura 2.23. 


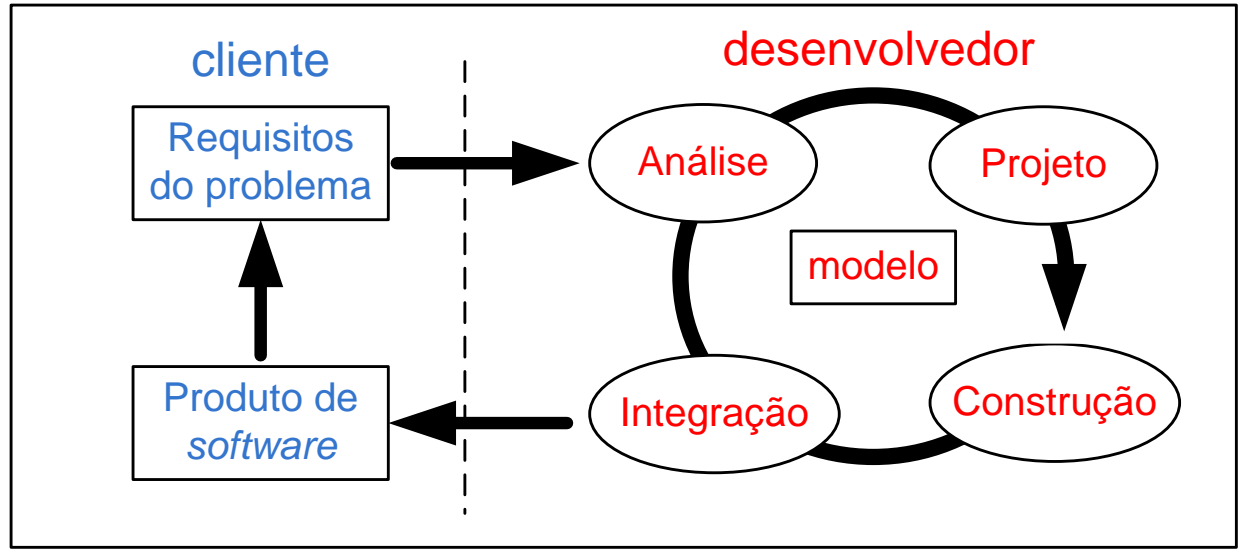

Figura 2.23 - Esquema de um projeto de software (DEBONI, 2003)

Nessa figura, observam-se a evolução do modelo durante o projeto de um sistema, as atividades realizadas para a obtenção do produto de software e os principais personagens envolvidos nessas atividades. O ciclo de desenvolvimento é representado pelas atividades do lado direito e o ciclo de testes do produto é representado pela seta vertical à esquerda.

O ciclo de testes do produto visa a garantir que o produto fornecido pelo ciclo de desenvolvimento esteja de acordo com os requisitos do projeto. Nessa etapa são realizados testes com o produto em situações normais de funcionamento, visando à detecção de falhas e novos requisitos que ainda não foram identificados. A partir das correções e das novas necessidades agregadas aos requisitos de uma nova versão do produto, dá-se início a um novo ciclo de desenvolvimento. O ciclo de desenvolvimento do software é um processo cíclico constituído por quatro atividades principais (DEBONI, 2003):

- Análise: nesta etapa é delimitado o escopo do problema e são identificadas as necessidades do sistema. $\mathrm{O}$ produto da fase de análise e um modelo inicial do sistema que fará parte do documento de especificação;

- Projeto: esta etapa visa a encontrar alternativas para a solução do problema definido na etapa de análise. Finalizada a fase de projeto, todas as definições do projeto são registradas no documento de especificação. Modelos, listas e esquemas servem como referências para as etapas posteriores do desenvolvimento; 
- Construção: a fase de construção dos componentes envolve a programação dos componentes de software. Nessa etapa são utilizados conceitos de reutilização de componentes de software para a redução de prazos e custos no desenvolvimento, mantendo-se a qualidade do produto;

- Integração: finaliza o processo de desenvolvimento gerando como produto final uma nova versão do software. Nessa fase, a atividade mais importante é a de configuração da versão do software. Os componentes são compilados e instalados nos equipamentos de computação. É preciso assegurar-se de que todos os componentes foram adequadamente integrados. Finalizada a integração, é importante realizar testes de funcionamento.

\subsection{ABORDAGENS PARA ESPECIFICAÇÃO DOS EIs}

A seguir são apresentados alguns trabalhos relacionados ao desenvolvimento dos sistemas de controle dos Els com o intuito de especificar as funcionalidades desses sistemas.

Em Jorgensen (2002) foi apresentada uma abordagem para modelar um sistema de controle por meio da utilização da linguagem Unified Modelling Language (UML) e a RPC, de forma a complementarem-se na modelagem e análise das especificações do sistema. $\mathrm{Na}$ abordagem, foi utilizada a linguagem UML para modelar a estrutura do sistema e a RPC, na representação da sua dinâmica. Para demonstrar a viabilidade desta proposta, Jorgensen (2002) desenvolveu a especificação de um sistema de controle para um prédio hospitalar que se adapta a situações de contexto. A principal função do sistema é facilitar o acesso de médicos e enfermeiras aos registros médicos dos pacientes (RAATIKAINEN; CHRISTENSEN; NAKAJIMA, 2002). Nos Els, o sistema de controle predial pode utilizar a informação contextual de: localização dos usuários, a temperatura das salas e a localização dos dispositivos inteligentes mais próximos aos usuários, dentre outras, para otimizar as funcionalidades do ambiente predial. A complexidade desses sistemas advém do fato de que a informação contextual muda constantemente e provém de diversas fontes distribuídas. 
Outra abordagem, utilizada para desenvolver um sistema de controle para sistemas prediais com capacidade de adaptação ao contexto dos usuários foi proposta em Chen, Finin e Joshi (2003). No sistema de controle, os sensores, atuadores e outros dispositivos compartilham conhecimento contextual e fornecem serviços relevantes aos usuários baseados nas preferências e características individuais dos usuários. Uma base de dados disponibiliza a informação necessária aos dispositivos que a solicitam. Essa abordagem é baseada em ontologias para a modelagem das relações entre os componentes de controle. O termo ontologia, neste caso, faz referência a uma forma de organizar um conjunto de conceitos dentro de um domínio e os relacionamentos entre eles.

Em Kwon, (2004), foi apresentada uma abordagem que utilizou uma variação da RPC (Amended CPN) para modelar a dinâmica dos sistemas prediais sensíveis ao contexto. A informação contextual de uma entidade (pessoa, dispositivo ou lugar) foi representada por meio da combinação de um conjunto de marcas coloridas. Com esta informação, foi executado um conjunto de estratégias de controle que se adaptam em função da evolução destas marcas coloridas.

Seguindo a linha de pesquisa de modelagem por meio da RPC, em Bastidas (2005), foi apresentado um procedimento para desenvolver um sistema de controle para Els. A base do sistema de controle considerada é uma arquitetura de controle hierárquica e orientada a objetos. Essa abordagem utiliza o padrão Open Distributed Processing $(O D P)$ para descrever a arquitetura do sistema de controle e o UML e a RPC para modelar e analisar as especificações do sistema. O procedimento de modelagem está constituído por 4 etapas interativas: (1) modelagem de domínio do sistema; (2) modelagem dos relacionamentos e serviços do sistema; (3) modelagem dinâmica e análise formal dos modelos e (4) implementação dos algoritmos de controle.

Em Arakaki (2004) foi abordada a detecção e tratamento de falhas que podem ocorrer durante o funcionamento do sistema de controle do El. A arquitetura proposta do sistema considera requisitos de degeneração, a qual é entendida como a redução gradual das funcionalidades do sistema. $O$ autor propõe a utilização de uma arquitetura hierárquica, na qual se inclui um componente para gerenciar as funções de degeneração. Esse componente realiza as seguintes atividades: (i) 
identifica as partes do sistema em que há grande probabilidade de ocorrer uma situação crítica de funcionamento, (ii) avalia se o comportamento do sistema está de acordo com as suas e, (iii) no caso de uma situação crítica, reconfigura automaticamente ou manualmente o sistema de controle para tratar a falha no sistema.

Uma vez estabelecida a arquitetura do sistema de controle, foi apresentado um procedimento para desenvolver as suas especificações, considerando-se a redução gradual das funcionalidades do sistema. O procedimento é dividido em duas etapas. Inicialmente, são especificados os requisitos do sistema de controle sem considerar a sua degeneração. A partir dessas especificações, é realizado um procedimento para definir novas especificações considerando requisitos de degeneração. Essa última etapa consiste em: (i) identificar os elementos do sistema com maior probabilidade de ocorrência de falhas e (ii) definir as atividades que o sistema de controle realizará durante a ocorrência de falhas. A modelagem e análise do funcionamento do sistema de controle foi realizada por meio do Mark Flow Graph (MFG) (Miyagi, 2002).

Em Silva (2008), foi apresentada outra abordagem para construir sistemas de controle de Els tolerantes a falhas. Para o desenvolvimento do sistema de controle, foram consideradas as especificações funcionais em situações normais de funcionamento e durante a ocorrência de falhas. Foi proposta uma arquitetura de controle híbrida (hierárquica e heterárquica). Durante o funcionamento normal do sistema, a arquitetura predominante é a hierárquica (constituída pelos seguintes níveis de controle: planejamento, supervisão e controle local). Em situação de falha, o sistema de controle atua como um sistema heterárquico (cooperativo). Em relação à modelagem do sistema de controle, o seu comportamento dinâmico foi modelado com um tipo de RP que não diferencia uma marca das outras, gerando assim modelos com uma grande quantidade de elementos construtivos que dificultam a sua interpretação. Além disso, a ferramenta de simulação utilizada não permite criar modelos hierárquicos, o que dificulta a modelagem de sistemas de grande porte.

Como foi apresentado nos trabalhos anteriores, o sistema de controle do El tem que possuir a capacidade de adaptação às necessidades dos seus ocupantes e do seu 
entorno. O comportamento incerto e muitas vezes aleatório das pessoas tem motivado a aplicação de modelos matemáticos que permitam capturar e analisar fatores comportamentais no projeto dos sistemas de controle (LU; CLEMENTS CROOME; VILJANEN, 2009). Segundo esses autores, abordagens matemáticas de modelagem com características de incerteza e flexibilidade, tais como: as redes neurais, sistemas expertos, lógica fuzzy e modelos estatísticos, podem aprimorar o desenvolvimento dos sistemas de controle em relação a esses fatores comportamentais.

Um procedimento para especificar as principais características de um El foi apresentado em Wong, Li e Lai (2008). Esses autores utilizaram o método Analytic Network Process (ANP) para especificar os requisitos funcionais dos sistemas prediais. O ANP é uma técnica de análise para classificar um conjunto de indicadores segundo o grau de importância em relação a múltiplos critérios (WONG; LI, 2010). Nesta técnica, inicialmente um conjunto de características funcionais dos principais sistemas que constituem o El é obtido. Em seguida, é feita uma análise para determinar quais dessas características são as mais importantes a se considerar durante o projeto dos sistemas de controle dos Els. O objetivo do trabalho foi obter uma classificação dos indicadores em função de um conjunto de critérios, considerados requisitos necessários para tornar "inteligente" um edifício. 0 resultado desse estudo foi sintetizado em um procedimento sistemático para especificar os requisitos funcionais do sistema de controle de um El.

Visando à automação do processo de especificação dos requisitos do sistema de controle do El em Runde, Fay e Wutzke (2009), foi apresentado um software para otimizar o processo de especificação dos requisitos. Esta ferramenta foi desenvolvida a partir de conceitos de sistemas especialistas, cuja função principal é gerenciar uma base de dados. A informação de diversos dispositivos inteligentes, tais como: sensores, atuadores, as suas funcionalidades etc. está armazenada nessa base de dados. Durante a etapa de especificação dos requisitos, o software disponibilizou uma lista de dispositivos com funcionalidades específicas para cada ambiente predial. Dessa maneira, o projetista utilizou essa informação para criar especificações do sistema de controle que se adaptam aos requisitos do sistema projetado. No entanto, uma das limitações encontradas nessa ferramenta foi a 
dificuldade em analisar o comportamento interno dos componentes do sistema de controle e a sua integração com outros componentes.

O trabalho apresentado nesta tese se diferencia dos trabalhos relacionados aos Els resumidos anteriormente em ao menos três aspectos:

- a proposta de uma arquitetura heterárquica do sistema de controle: neste trabalho, é adotado um sistema de controle no qual toda a lógica de controle está distribuída entre os seus componentes;

- $\quad$ a utilização do paradigma publish/subscribe para estabelecer a comunicação desacoplada entre os componentes do sistema de controle. Dessa forma, podem ser desenvolvidos sistemas mais robustos e facilmente expansíveis;

- a utilização de uma abordagem de modelagem orientada por componentes: os componentes desenvolvidos podem ser reaproveitados em outras aplicações.

\subsection{CONSIDERAÇÕES FINAIS DO PRESENTE CAPÍTULO}

Foram apresentados, neste capítulo, uma breve revisão dos Els e os avanços tecnológicos que visam a manter os Els produtivos ao longo do seu ciclo de vida. Nesse sentido, ressaltou-se a importância da computação pervasiva como um meio de aumentar as funcionalidades e a capacidade dos Els de se adaptar às necessidades dos usuários. Para que os dispositivos que constituem o El possam estar integrados e em cooperação para atender os objetivos da aplicação, torna-se necessária a comunicação entre eles. Nesse sentido, foi apresentado o paradigma da comunicação $P / S$, utilizado para estabelecer a comunicação entre os dispositivos e sistemas do El.

A elevada interação entre os componentes e a grande quantidade de dispositivos do El tornam necessária a utilização de uma linguagem formal para especificar o sistema de controle dos Els. Dentre as linguagens formais existentes, foi introduzida 
a RPC, por possuir diversas características que a tornam ideal para a modelagem dos Els. Para ilustrar essas características, um exemplo de aplicação foi apresentado. A última parte deste capítulo apresentou uma revisão de algumas das principais abordagens utilizadas para o desenvolvimento dos sistemas de controle dos Els. 


\section{PROCEDIMENTO DE MODELAGEM PROPOSTO}

O objetivo deste capítulo é apresentar um procedimento sistemático para especificar os sistemas de controle dos Els. Inicialmente, propõe-se uma arquitetura do sistema de controle heterárquico, visando ilustrar a organização e a interação dos elementos que integram o sistema de controle. Em seguida, é apresentada uma sequencia de etapas que sistematiza o desenvolvimento do sistema de controle seguindo a arquitetura proposta. Este procedimento pode ser utilizado como suporte para aprimorar os algoritmos de controle existentes ou para desenvolver novas aplicações para Els.

\subsection{DESCRIÇÃO DA ARQUITETURA DE CONTROLE HETERARQUICA}

A arquitetura proposta adota uma abordagem heterárquica, baseada em uma distribuição totalmente horizontal do controle. O controle global do El emerge da interação entre os componentes, de maneira que a colaboração é realizada de forma paralela (todos os componentes podem interagir ao mesmo tempo) e distribuída (não existe um coordenador). Esse tipo de arquitetura desconsidera qualquer nível de hierarquia entre os dispositivos de controle.

$\mathrm{Na}$ Figura 3.1, tem-se um diagrama que representa a arquitetura do sistema proposto. O sistema de controle predial está constituído pelos dispositivos inteligentes, os quais podem ser agrupados para formar subsistemas prediais (p. ex., HVAC, elevadores e iluminação, entre outros). A complexidade do controle global do El é dividida entre os dispositivos inteligentes que realizam um controle local. Esses dispositivos são autônomos, possuem uma visão parcial do sistema sob controle e podem se comunicar entre si por meio de uma rede de controle. A arquitetura proposta utiliza o paradigma de comunicação $P / S$ para estabelecer a cooperação entre os dispositivos inteligentes que realizam o controle. 


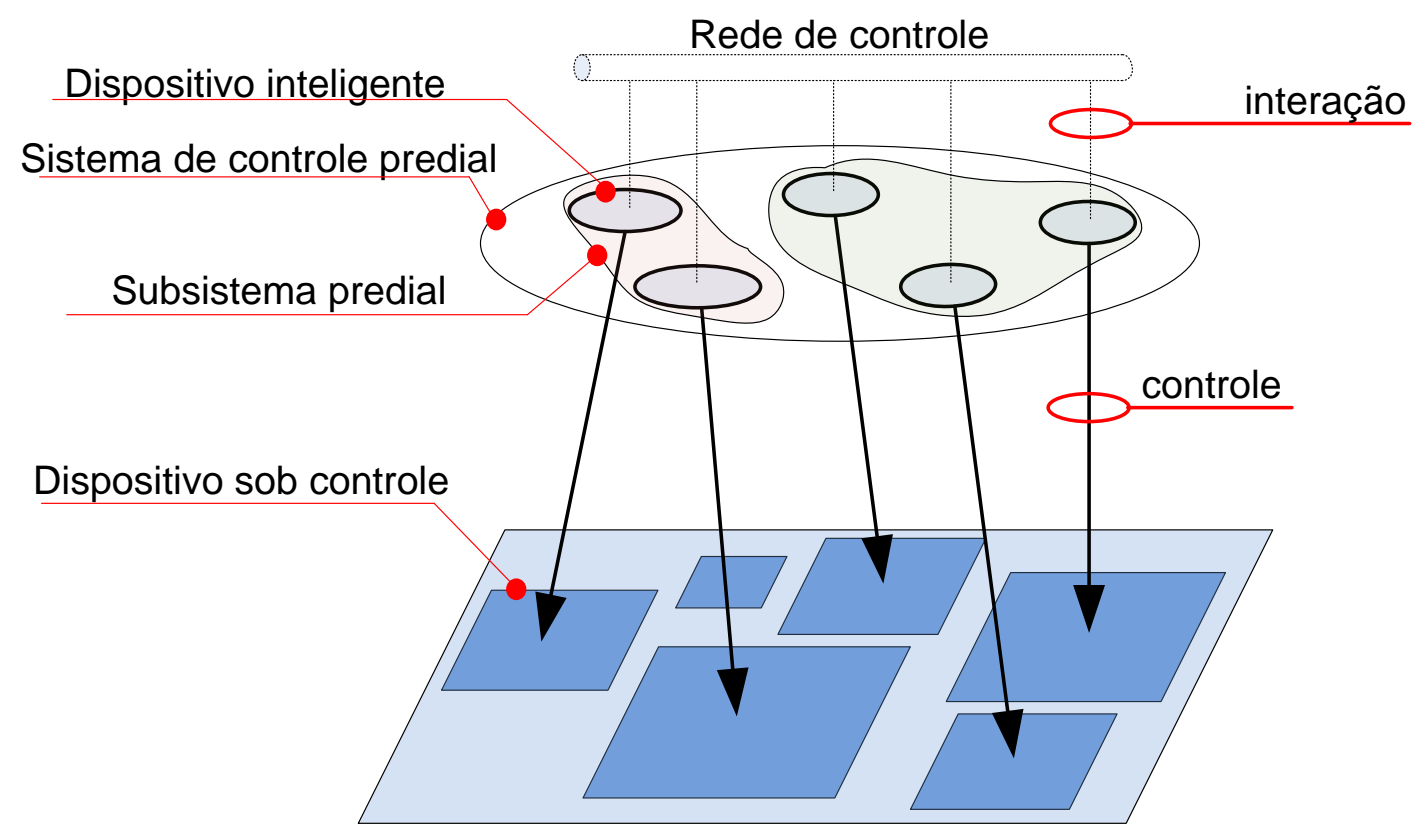

Figura 3.1 - Arquitetura do El

Na Figura 3.2 é apresentado um diagrama de comunicação que exemplifica a colaboração entre três dispositivos que controlam os níveis de temperatura de uma sala. O dispositivo 1 representa um sensor de temperatura, os dispositivos 2 e 3 representam atuadores que controlam os dampers do sistema de ventilação. $O$ dispositivo 2 é o atuador principal e o dispositivo 3 é o atuador secundário, configurado para executar a função do atuador principal caso este apresente uma falha de funcionamento. Os valores da temperatura da sala são agrupados no tópico 1, de acordo com o paradigma de comunicação P/S. A ampliação do sistema de controle pode ser realizada conectando-se novos dispositivos à rede de controle por meio de interfaces de comunicação, os quais podem se subscrever ao tópico 1. 


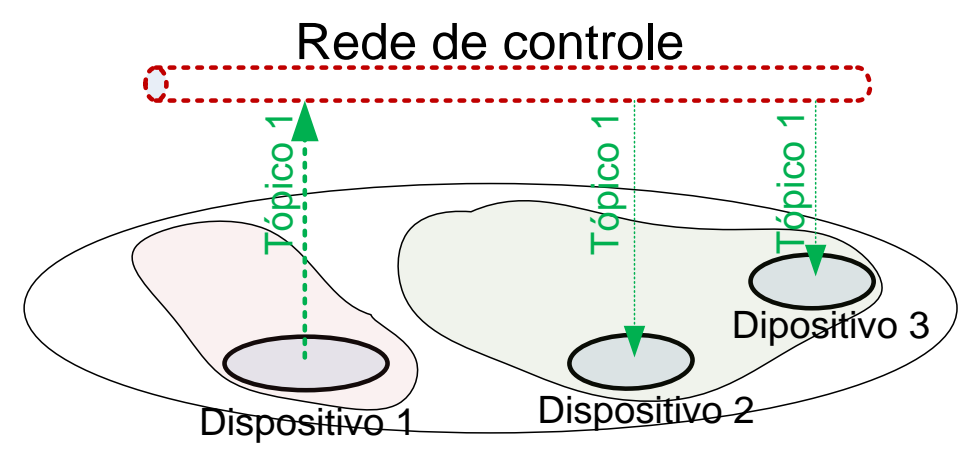

Figura 3.2 - Comunicação entre os dispositivos

Cada um dos dispositivos inteligentes está constituído pela integração de componentes (Figura 3.3), os quais foram construídos visando à reutilização em outras aplicações. Os componentes representam funcionalidades específicas, que podem ser aprimoradas ou modificadas e reaproveitadas em outros dispositivos. Por exemplo, o componente 1, mostrado na Figura 3.3, foi utilizado na construção dos três dispositivos. As interfaces de comunicação são representadas pelo lugar com a inscrição "in", que representa a interface de entrada e o lugar com a inscrição "out", que representa a interface de saída. O tópico 1 é representado por uma transição. $A$ comunicação entre os dispositivos é realizada pelo fluxo das marcas coloridas, as quais representam os valores dos tópicos de dados.

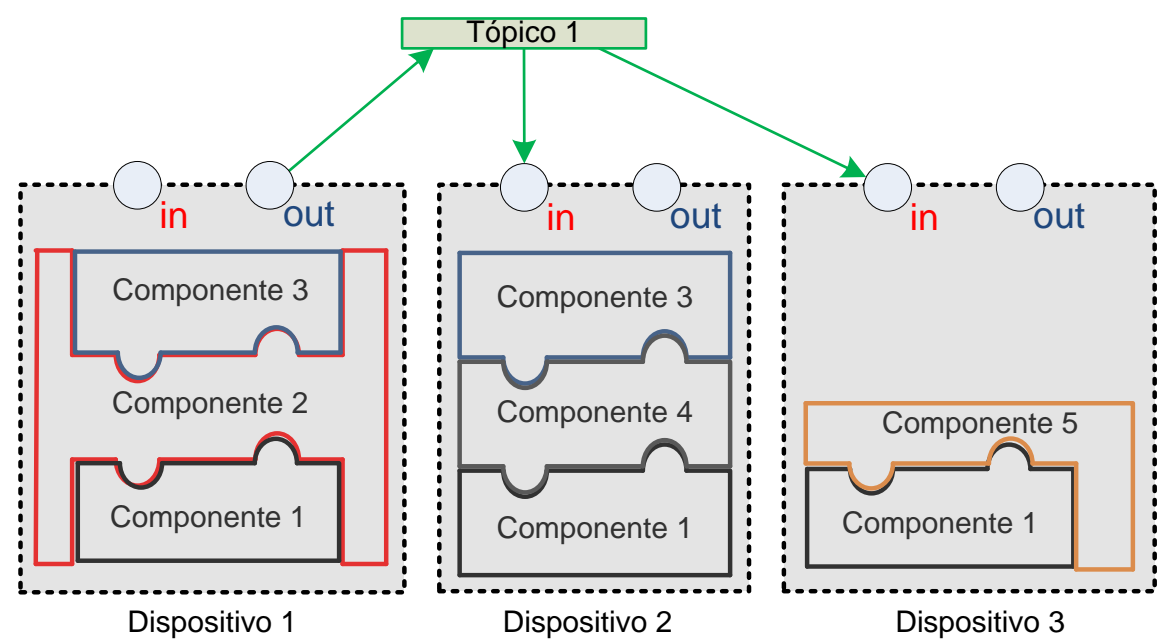

Figura 3.3 - Representação interna dos dispositivos de controle 


\subsection{CARACTERÍSTICAS DA ARQUITETURA DE CONTROLE HETERARQUICA}

A arquitetura de controle heterárquica permite 0 desenvolvimento de sistemas de controle flexíveis, robustos e escaláveis. A flexibilidade do sistema está relacionada à inclusão ou modificação de funcionalidades de forma simples e eficiente. Essa característica é viabilizada pela utilização de uma abordagem baseada em componentes na construção dos dispositivos. Atualizações do sistema de controle podem ser realizadas pela modificação ou troca dos componentes internos dos dispositivos.

A robustez do sistema está relacionada à tolerância a falhas, isto é, manter certo nível de estabilidade sem comprometer o funcionamento normal do sistema. Esta característica pode ser viabilizada mediante a incorporação de dispositivos secundários ou redundantes na rede de controle. Assim, esses podem assumir 0 controle das atividades em caso de falha de um dos dispositivos primários. A escalabilidade do sistema é facilitada pela utilização do paradigma $P / S$. No caso de incorporar outro dispositivo à rede de controle, como apresentado na Figura 3.4, este será conectado por meio da interface de entrada. Observa-se que não existe um acoplamento direto entre os dispositivos. Dessa forma, uma falha ou modificação de um dos dispositivos não afetaria o comportamento dos outros.

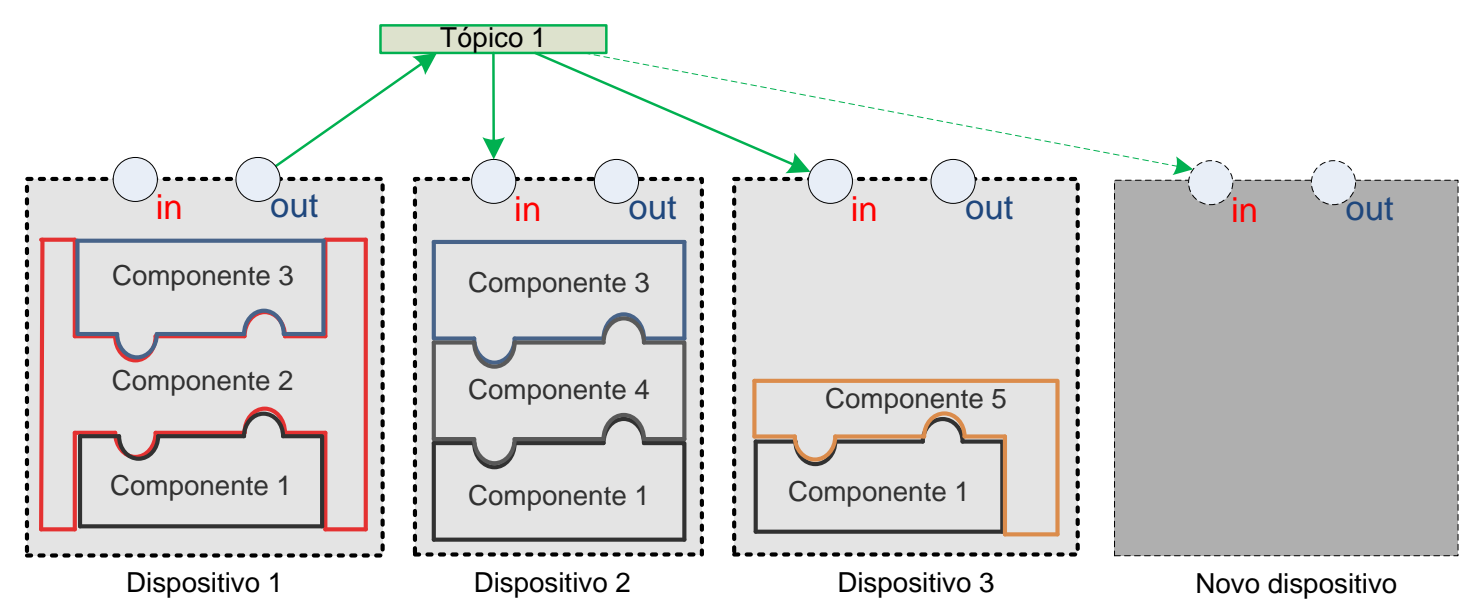

Figura 3.4 - Incorporação de um dispositivo 
O principal diferencial desta arquitetura em relação às apresentadas na literatura (capítulo 2.6) é a estrutura hetarárquica, na qual todos os dispositivos de controle possuem o mesmo nível hierárquico de controle. Esta arquitetura se caracteriza pelo elevado grau de autonomia dos dispositivos que realizam o controle.

A arquitetura proposta divide o sistema em dois grupos: os dispositivos que realizam o controle e os dispositivos sob controle. Desta maneira, pode ser modelada a colaboração entre os dispositivos que constituem o sistema de controle e a evolução dinâmica do objeto de controle. A limitação desta arquitetura é a complexidade inerente a este tipo de sistema distribuído. Neste sentido, na seguinte seção e proposta uma sistemática para a construção dos modelos que representam as especificações do sistema de controle na qual se propõe a separação das funcionalidades dos dispositivos e os dados, os quais são disponibilizados na rede de controle. Estes dados são necessários para estabelecer o controle colaborativo do El.

\subsection{ETAPAS DO PROCEDIMENTO DE MODELAGEM}

O procedimento é constituído por uma sequência interativa de seis etapas (Figura 3.5) na qual a finalização de uma etapa pode levar à revisão das etapas anteriores. Essas seis etapas são descritas a seguir. 


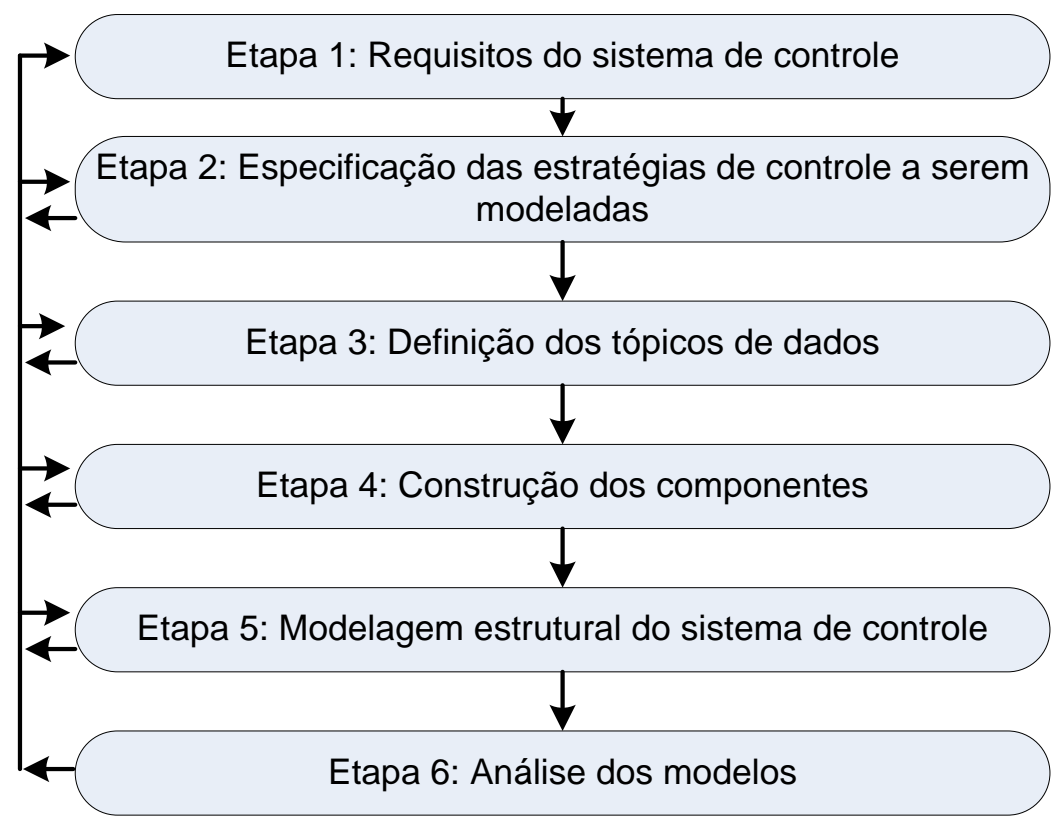

Figura 3.5 - Procedimento de modelagem proposto para o sistema de controle

\subsubsection{ETAPA 1: Requisitos do sistema}

Nesta etapa inicial de modelagem, procura-se identificar o objeto de controle (instalações prediais) e o sistema de controle predial (Figura 3.6). Para isso, definese o escopo e as principais funcionalidades do sistema de controle do El.

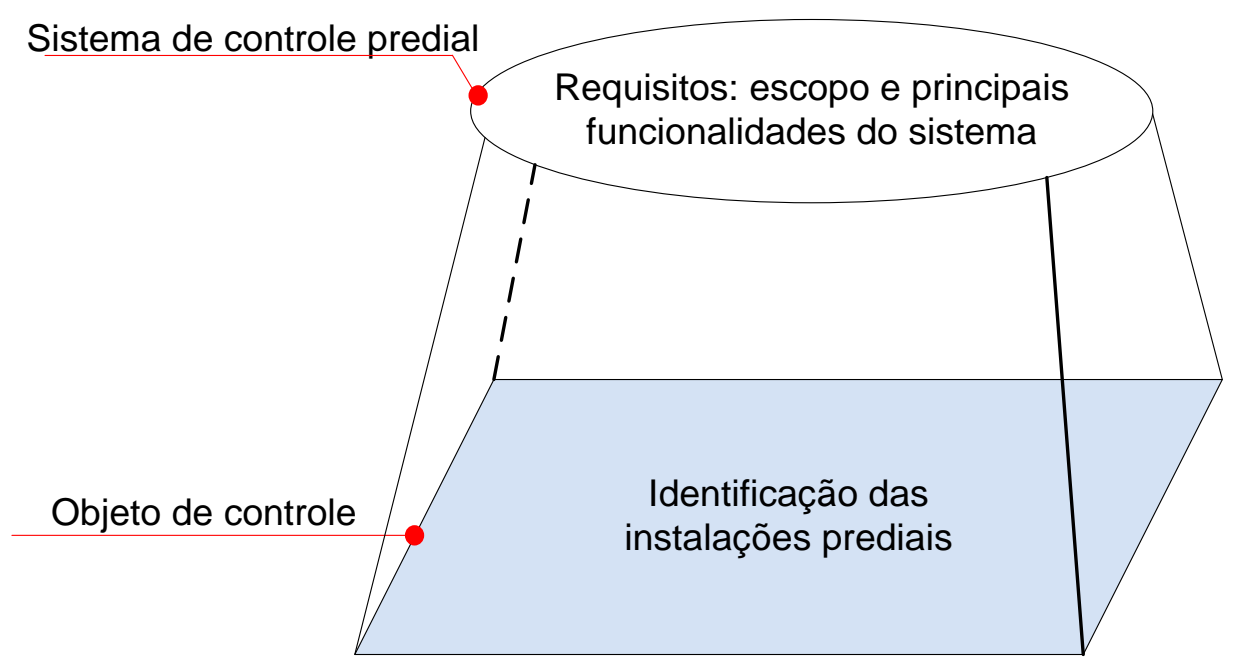

Figura 3.6 - Definição dos requisitos do sistema de controle predial 
Esta etapa prevê a participação dos usuários e das pessoas envolvidas no projeto, com o objetivo de descobrir, priorizar, negociar e documentar os requisitos do sistema de controle. A documentação dos requisitos é realizada por meio de uma descrição informal das características do sistema.

Em um sistema de controle residencial, por exemplo, alguns requisitos podem ser definidos:

- liberação das portas de acesso: o sistema deve permitir o ingresso a certos ambientes apenas para moradores e equipe de serviços previamente cadastrados;

- direcionamento das mensagens: o sistema deve ser capaz de identificar o morador e sua localização dentro da residência para encaminhar as mensagens da secretária eletrônica ao ramal telefônico mais próximo ao usuário.

\subsubsection{ETAPA 2: Especificação das estratégias a serem modeladas}

Uma vez identificados os requisitos do sistema de controle, as principais estratégias de cada dispositivo de controle são definidas. O objetivo desta etapa consiste em definir funcionalidades para cada componente do sistema de controle predial, os quais atuam cooperativamente visando a atingir o objetivo definido na Etapa 1. $\mathrm{Na}$ Figura 3.7, tem-se uma visão sistemática da área de atuação dos dispositivos inteligentes sob o objeto de controle. A cooperação entre os componentes é realizada por meio do compartilhamento de informações relevantes para a execução das estratégias de controle.

Essa etapa está dividida nas seguintes atividades:

1. Classificação dos dispositivos segundo o subsistema predial ao qual pertence.

2. Identificação das instalações e dispositivos que estão sob o comando dos 
dispositivos de controle.

3. Atribuição das funcionalidades de cada dispositivo de controle. Essa atividade está subdividida nas seguintes etapas:

- sequência da execução das atividades de controle;

- condições para o início das atividades de controle;

- condições para a finalização das atividades de controle.

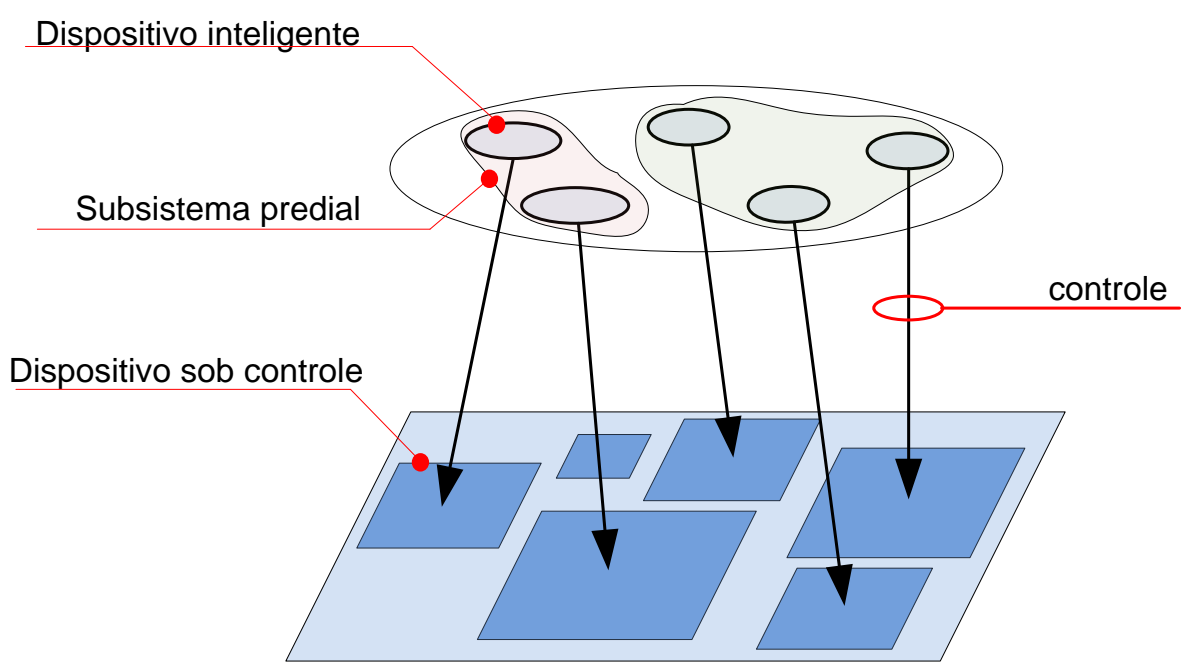

Figura 3.7 - Visão sistemática das estratégias de controle

\subsubsection{ETAPA 3: Definição dos tópicos de dados}

Como os dispositivos inteligentes possuem uma informação parcial do comportamento global do sistema, estes precisam interagir para realizar as atividades de maneira colaborativa. Nesse sentido, a comunicação entre os dispositivos é realizada por meio da troca assíncrona de mensagens segundo o paradigma $P / S$. As mensagens estão agrupadas em tópicos. Os dispositivos que enviam informação de um determinado tópico na rede de controle são chamados de produtores e os que declaram seu interesse em receber essa informação são chamados de consumidores. A Figura 3.8 ilustra o os componentes do sistema de controle. Os dispositivos não estão diretamente acoplados uns aos outros, sendo que o processo de colaboração entre eles é realizado por meio da publicação e 
subscrição de tópicos de dados. A rede de controle se encarrega de gerenciar o processo de recebimento e entrega das mensagens.

A modelagem do processo de comunicação é realizada por meio da RPC. Diferentemente das RPs tradicionais, os lugares podem conter diversos tipos de dados e as marcas possuem atributos. Dessa forma, é possível diferenciar uma marca das outras. Esta é a principal característica que motivou a utilização da RPC em relação às RPs tradicionais. Como visto anteriormente, no paradigma $P / S$, as mensagens são diferenciadas em função do tópico de dados. A utilização da RPC permite representar os dados por meio de marcas coloridas. A marca colorida é constituída por um tipo de dado (tópico) e um valor do dado (conteúdo).

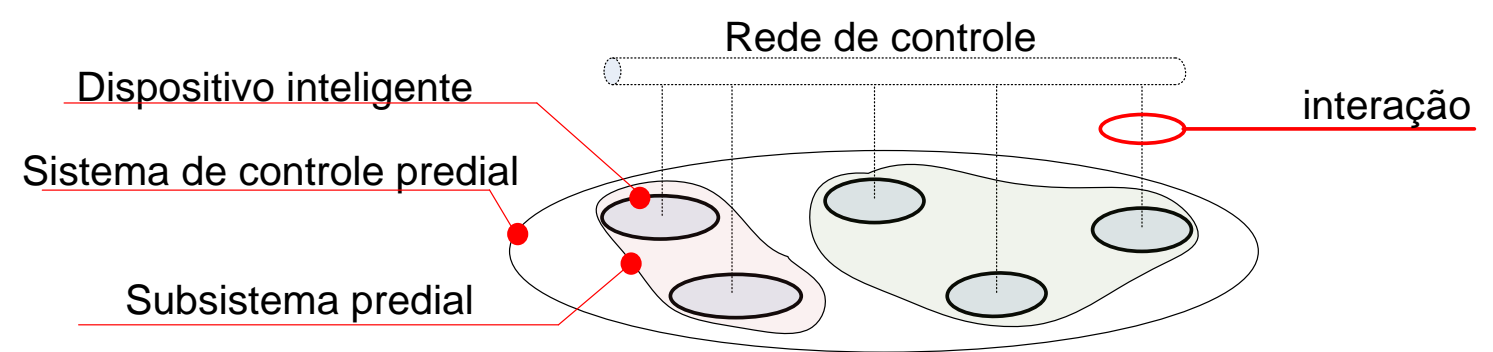

Figura 3.8 - Visão sistemática da interação entre os dispositivos

A Figura 3.9 e a Figura 3.10 apresentam um exemplo da dinâmica de funcionamento de um sistema constituído por três dispositivos (um produtor de dados do tópico $1 \mathrm{e}$ dois consumidores do mesmo tópico). A produção de um dado do tópico 1 é representada por uma marca na interface de saída do 'Produtor 1'. Na Figura 3.10, é apresentada a chegada do mesmo dado depois que a transição tópico 1 dispara e envia uma marca colorida ao 'Dispositivo 2' e ao 'Dispositivo 3'. 


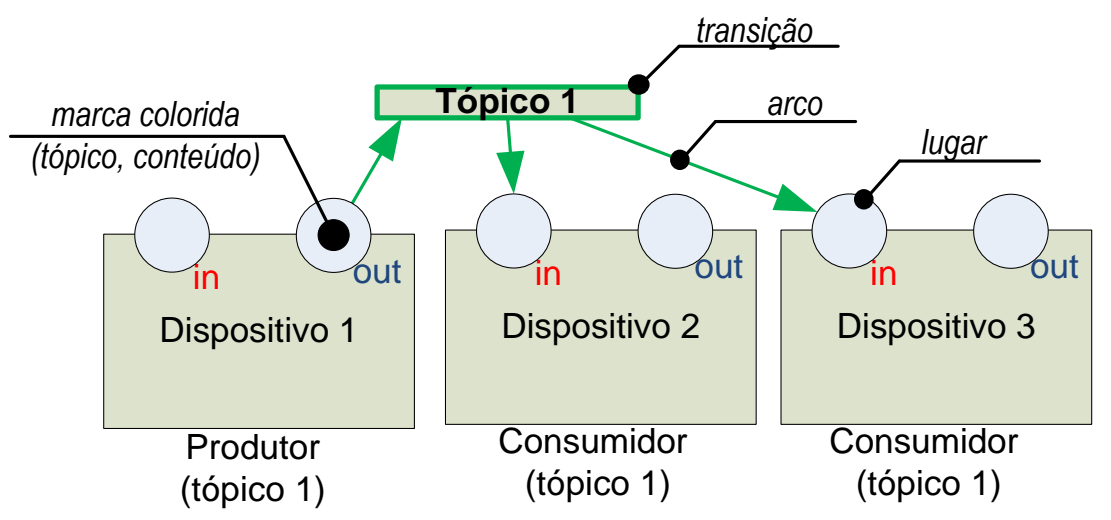

Figura 3.9 - Saída de um dado do produtor

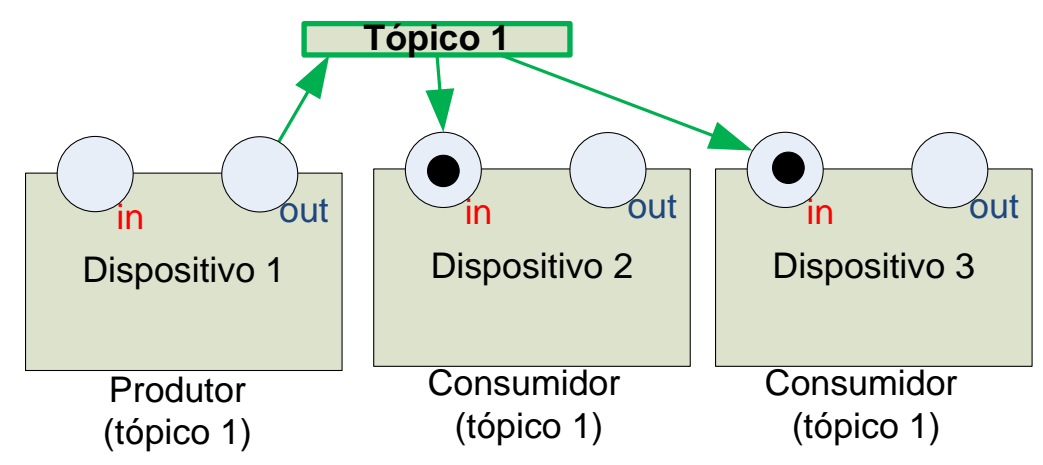

Figura 3.10 - Chegada de um dado aos consumidores

Este paradigma de comunicação facilita a escalabilidade do sistema de controle predial. Por exemplo, no caso de aumentar o número de dispositivos que necessitem de um tópico de dados (p. ex., do tópico 1), é suficiente ligar a interface de entrada do novo dispositivo à transição do tópico 1.

\subsubsection{ETAPA 4: Construção dos componentes}

Nesta etapa são identificados e construídos os componentes básicos das aplicações (algoritmos de controle dos dispositivos inteligentes), os quais são modelados utilizando-se a RPC, considerando-se o seu reaproveitamento para desenvolver outras aplicações. Assim, é possível reduzir o tempo de desenvolvimento dos 
modelos do sistema. A Figura 3.11 ilustra um exemplo de construção de 5 componentes com suas respectivas interfaces.

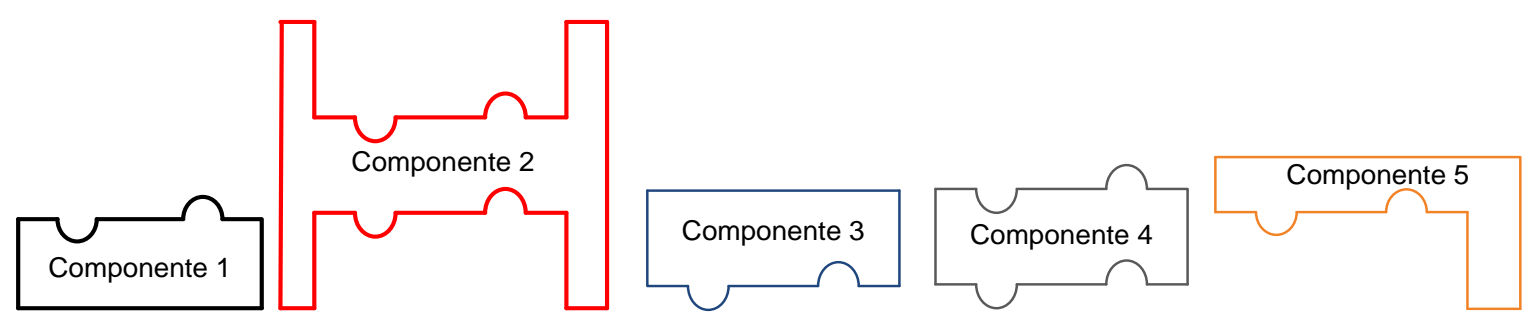

Figura 3.11 - Construção de componentes

Uma vez que os componentes são desenvolvidos, estes podem ser integrados para construir novas aplicações. Cada componente é um módulo representado por uma substituição de transição. As interfaces de comunicação entre esses módulos são representadas por sockets. A Figura 3.12 apresenta o dispositivo 1, apresentado anteriormente na Figura 3.3. Esse dispositivo é constituído por três componentes, os quais são representados internamente por meio de substituições de transições.

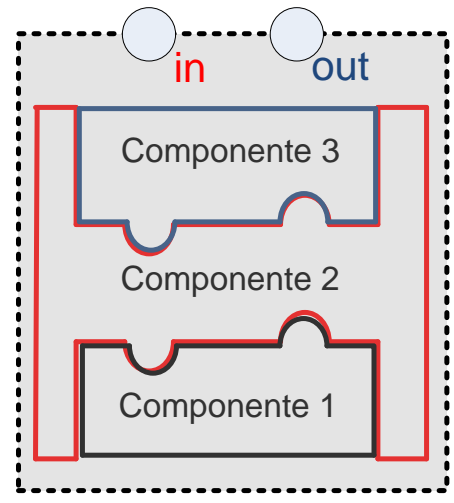

Dispositivo 1

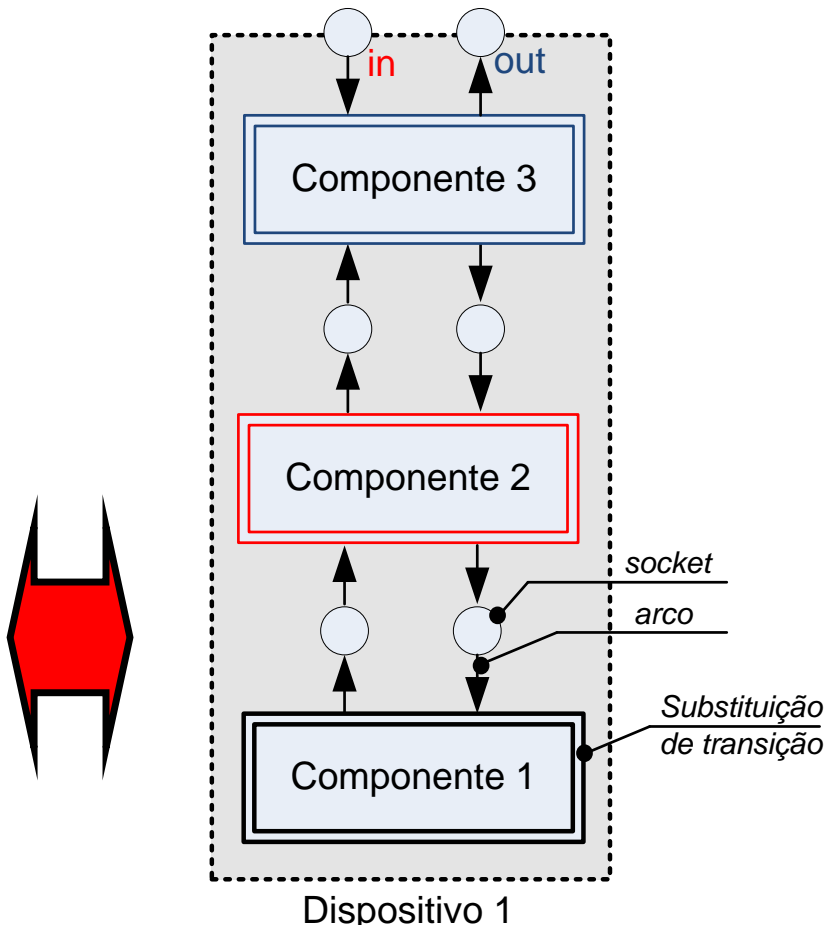

Dispositivo 1

Figura 3.12 - Modelo do dispositivo 1 em RPC 


\subsubsection{ETAPA 5: Modelagem estrutural do sistema de controle}

Nesta etapa, inicialmente constrói-se um modelo em rede de Petri considerando todos os parâmetros de entrada e saída do sistema, no qual são representados os estímulos de entrada no sistema e a resposta a esses estímulos na forma de dados de saída. Esse modelo é importante porque possibilita um entendimento comum entre os participantes do projeto no sentido de conhecer o que é requisitado e o que se pretende obter.

$\mathrm{Na}$ Figura 3.13 é representada, por meio de uma RPC, a sequência de funcionamento do sistema de controle. Esse modelo é constituído por três substituições de transições. A primeira delas agrupa os dados de entrada do sistema. A substituição de transição 'Processos' agrupa as aplicações que constituem o sistema de controle do El. Finalmente, a substituição de transição 'Dados de saída' agrupa as respostas aos estímulos dos dados de entrada. A dinâmica de funcionamento do sistema segue a sequência de disparo das RPC. As interfaces de entrada E1, $E 2$...E(n) representam os tipos de dados que ingressam ao sistema e as interfaces de saída $S 1, S 2 . . S(m)$ representam os tipos de dados que saem do sistema, sendo que "n" e "m" são números inteiros.

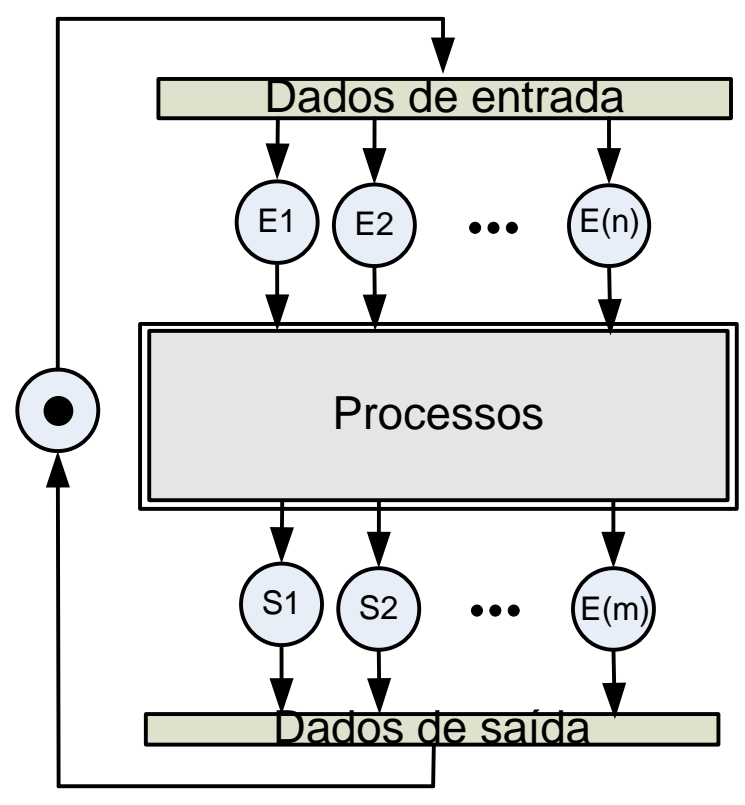

Figura 3.13 - Dinâmica do funcionamento do sistema de controle 
A Figura 3.14 apresenta um exemplo do módulo "Processos", constituído por 5 aplicações que se comunicam por meio do paradigma publish/subscribe, na qual as aplicações 1 e 2 fornecem dados do tópico 1 e tópico 2. As aplicações 3 e 5 estão subscritas aos tópicos 1 e 2 , respectivamente. A aplicação 4 está subscrita aos dois tópicos. A construção das aplicações é realizada por meio da integração de componentes reutilizáveis, apresentados na etapa seguinte.

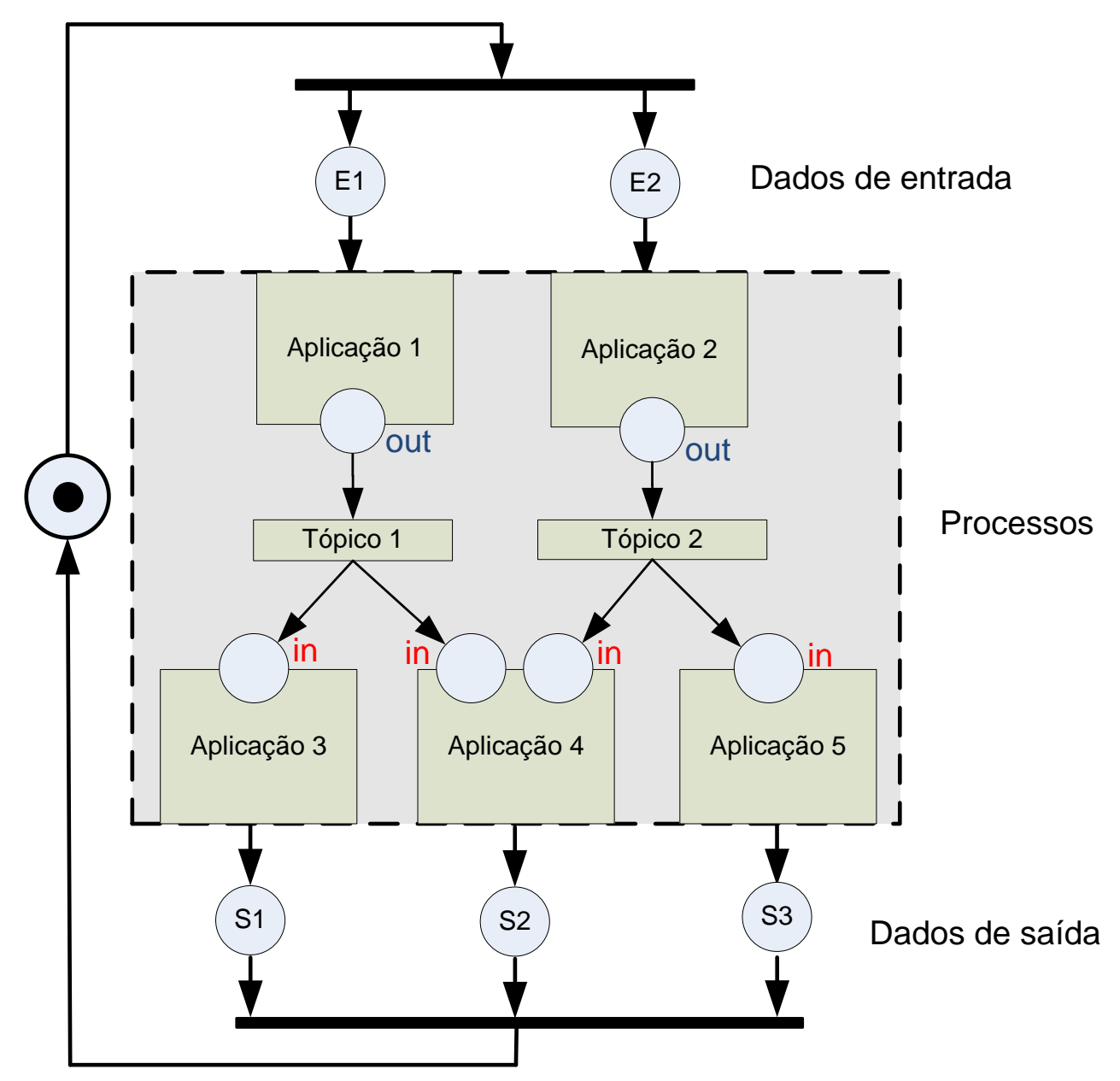

Figura 3.14 - Substituição de transição "Processos"

Nos casos em que há diversas aplicações com funcionalidades idênticas, a parametrização dos módulos permite simplificar a construção dessas aplicações. Por exemplo, um sistema contra incêndio pode conter mais de uma centena de sensores de temperatura idênticos distribuídos no prédio. Nesse sentido, a modelagem do 
sistema de controle de um El, o qual é constituído por um conjunto de sensores, atuadores, dispositivos de controle, entre outros, pode se tornar inviável por conta da quantidade de elementos construtivos que o modelo pode alcançar. Utilizando o conceito de parametrização modular, reduz-se significativamente a quantidade de modelos necessários para representar o sistema, simplificando assim sua modelagem.

A Figura 3.15 e a Figura 3.16 representam exemplos de sensores de um sistema de controle para um sistema contra incêndio. Os dados de temperatura que cada sensor registra são representados pelo tópico de dados (tópico 1). Esse tópico contém duas variáveis: o número do sensor $(\mathrm{Sn})$ e a temperatura registrada pelo sensor (Tn).

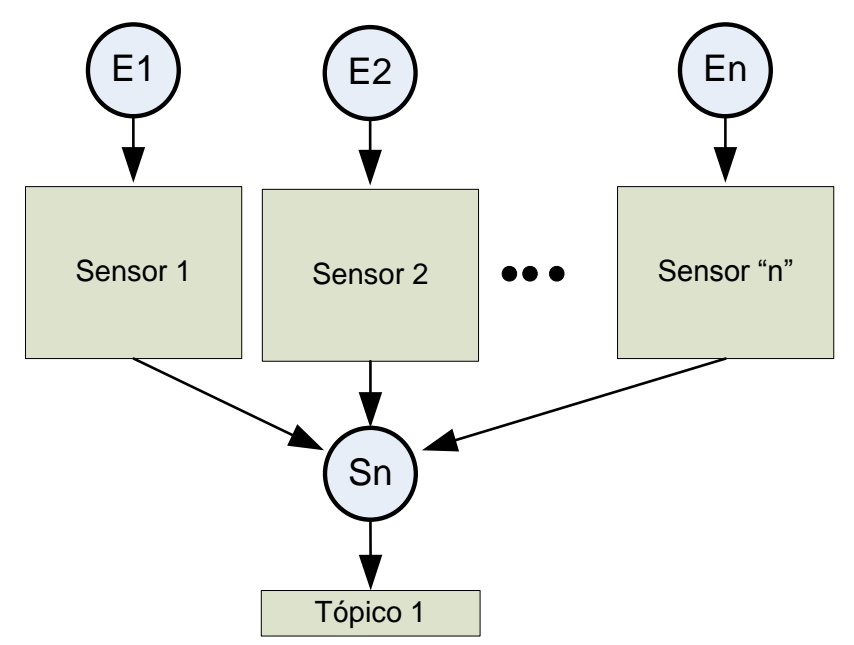

Figura 3.15 - Modelo com "n" sensores 


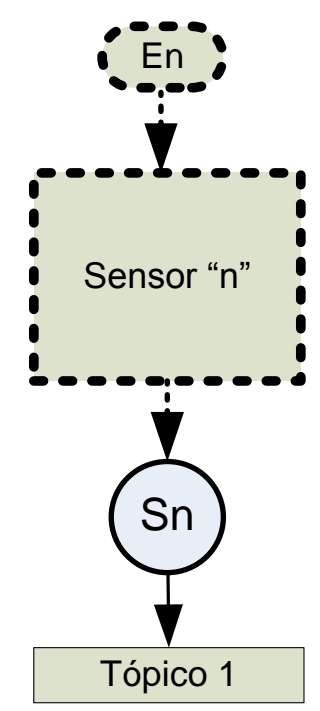

Figura 3.16 - Modelo parametrizado de "n" sensores

A informação dos sensores chega ao lugar de entrada Sn. Essa informação contém a identificação do sensor e o valor da temperatura registrada. Na Figura 3.16 é apresentado o modelo parametrizado dos sensores. Para diferenciar a parametrização dos modelos, estes são representados com linhas de traços. A variável " $n$ " representa o número de sensores do sistema contra incêndio. Dessa forma, a representação de múltiplas aplicações pode ser simplificada, facilitando assim a modelagem de sistemas constituídos por uma grande quantidade de aplicações com características similares.

\subsubsection{ETAPA 6: Análise dos modelos}

Esta etapa consiste em verificar e validar se os modelos criados atendem adequadamente os requisitos levantados nas etapas anteriores. Inicialmente, uma análise estrutural do sistema é realizada com base no estudo das propriedades da rede de Petri "lugar/transição" (MURATA, 1989). Entretanto, para um melhor entendimento da dinâmica do sistema de controle por parte dos projetistas, considera-se fundamental a análise por meio da simulação dos modelos do sistema. A simulação permite analisar a evolução das consequências das especificações do sistema, comportamentos inesperados do modelo sob certas condições e, inclusive, 
descobrir novas funcionalidades que não foram tratadas nas etapas anteriores. Dessa forma, é possível voltar às etapas anteriores para rever e/ou definir novas especificações. A modelagem e análise dos componentes e aplicações desenvolvidas em RPC são suportadas pelo software CPNTools (JENSEN; KRISTENSEN, 2009). O software permite que as propriedades estruturais e comportamentais do modelo possam ser estudadas. Adicionalmente, durante a edição dos modelos, o software indica se existe algum erro estrutural e, por meio da definição de condições iniciais específicas, diferentes situações podem ser estudadas.

\subsection{CARACTERÍSTICAS DO PROCEDIMENTO PROPOSTO}

As principais características advindas do procedimento proposto são expostas a seguir.

Maior simplicidade do sistema de comunicação: como os sistemas de controle dos Els possuem uma grande quantidade de dispositivos que intercambiam informações, o estabelecimento de uma comunicação síncrona sobrecarrega o fluxo de dados na rede de comunicação, além de aumentar a sua complexidade desde o ponto de vista de projeto. A abordagem do procedimento proposto utiliza o paradigma $P / S$, sendo que a comunicação entre as aplicações é realizada assincronamente (inexistência de bloqueio de dados). As aplicações que se subscrevem não precisam enviar um reconhecimento de que a mensagem foi entregue. Naturalmente, as informações de maior importância em um sistema de controle podem receber outro tratamento (mais complexo) no sentido de torná-lo mais confiável. Por exemplo, um publicador também poderia se tornar um subscritor de modo a receber a confirmação do recebimento (subscrição) de um tópico de dados gerado. Para as variáveis que não são críticas, consegue-se a maior simplicidade mencionada previamente.

Redução da complexidade dos modelos: a RPC permite que as marcas possuam tipos de dados e atributos. Essa é uma das principais razões para se optar por este tipo de rede em relação à rede de Petri tradicional (que não diferencia uma marca das outras). Essa característica é aproveitada na modelagem da comunicação entre as 
aplicações. No paradigma $P / S$, as mensagens são diferenciadas por meio do agrupamento em tópicos. Para realizar o processo de comunicação, os tipos de dados são testados e classificados em função do tópico de dados. A RPC permite realizar esse processo com facilidade, simplificando os modelos e suas representações. Outro ponto a destacar é o fato de as RPC utilizarem conceitos de hierarquias, possibilitando a construção de sistemas a diferentes níveis de abstração. Essa característica permite criar sistemas a partir de refinamentos sucessivos, o que facilita o desenvolvimento do projeto. Caso a RP tradicional fosse utilizada, haveria a necessidade de se utilizar mais de um tipo de RP nas representações.

Menor custo de desenvolvimento: uma das características da componentização é a redução dos custos e do tempo de desenvolvimento dos sistemas de controle, além do aumento da confiabilidade dos mesmos, já que as aplicações são desenvolvidas a partir de componentes com especificações já verificadas.

\subsection{CONSIDERAÇÕES FINAIS DO PRESENTE CAPÍTULO}

Foi apresentado um procedimento sistemático para especificar os sistemas de controle dos Els, baseados em uma arquitetura de controle hetarárquica.

O principal diferencial do procedimento sistemático proposto em relação às abordagens apresentadas no capítulo 2.6 consiste na interação entre os dispositivos por meio da publicação e subscrição de tópicos de dados, os quais são disponibilizados na rede de controle. Esta abordagem possibilita a modelagem do sistema de controle do El em diferentes níveis de abstração, possibilitando um melhor entendimento do sistema em estudo. A modelagem do sistema de controle é particularmente importante porque permite compreender o comportamento do sistema, analisar novas formas de interação entre os dispositivos e novas aplicações do sistema de controle.

A simulação dos modelos resultantes permite reproduzir as condições reais do El. Isto reduz os custos de desenvolvimento do projeto, já que os modelos minimizam a 
construção de protótipos e o deslocamento dos projetistas às instalações reais para testar as características comportamentais do sistema. Outra vantagem referente ao desenvolvimento dos modelos é a facilidade de simular o sistema em lugares de difícil acesso e perigosos, tais como plantas de energia nuclear ou plataformas petrolíferas em alto mar, nas quais o sistema de controle tem que ser testado em diversas situações e condições extremas de funcionamento.

$\mathrm{O}$ procedimento de modelagem proposto utiliza uma abordagem baseada em componentes para construir o sistema de controle, visado facilitar a construção de sistemas de grande porte. Inicialmente, realiza-se a construção de componentes menores para posteriormente serem integrados até criar os dispositivos que constituem o sistema de controle. A lógica de controle do El está distribuída entre os dispositivos que realizam o controle, sendo que a comunicação é um requisito importante para estabelecer a cooperação entre os dispositivos. O procedimento propõe a utilização de uma arquitetura desacoplada, na qual cada um dos dispositivos não está conectado diretamente a outros dispositivos. Desta forma, é facilitada a inserção de novos dispositivos, já que estes precisam unicamente se conectar à rede de controle por meio da subscrição do tópico de dados. Cada vez que estes dados são disponibilizados, a rede de controle disponibiliza esta informação aos dispositivos subscritos.

O desenvolvimento dos sistemas de controle dos Els podem utilizar diversas linguagens de modelagem, em função dos requisitos que precisem ser modelados. A RPC foi proposta pela facilidade de representar comportamentos concorrentes, por possuir uma notação gráfica intuitiva e uma semântica formal que possibilita a análise das propriedades comportamentais. 


\section{EXEMPLO DE APLICAÇÃO E DISCUSSÃO}

Para validar o procedimento descrito no capítulo anterior, foi idealizada a construção de um sistema de controle de um El que considera unicamente a integração de um sistema de comunicação distribuído (SCD) e um sistema de vigilância predial (SVP). Com isso, o procedimento de modelagem proposto pode ser aplicado e discutido. Neste exemplo de aplicação, apenas as principais funcionalidades de ambos os sistemas prediais são estudadas. A sua escolha se deu em função das características destes sistemas, que aproveitando as funcionalidades do sistema de vigilância predial, outros sistemas prediais, como O SCD pode aproveitar a informação de localização dos usuários dentro do prédio para aprimorar as funcionalidades do SCD como exemplo, transferir automaticamente uma chamada telefônica ao ramal mais próximo do usuário. Esse sistema pode ser útil para usuários que se deslocam frequentemente dentro do edifício. Em se tratando de um hospital, por exemplo, localizar um médico e estabelecer a comunicação para atender prontamente a um chamado de emergência é fundamental.

O sistema de controle tem a função de detectar a localização do usuário e realizar as conexões lógicas para estabelecer a comunicação. No caso de uma chamada interna, um usuário que procura falar com outro liga a um número que identifica o usuário. O sistema de controle rastreia a localização do usuário e transfere a chamada para o ramal telefônico próximo a ele. Assim, o El possui a característica de reconhecer a localização dos usuários por meio dos dispositivos sensores do sistema de vigilância predial. Essa informação é utilizada por outros sistemas prediais visando a aprimorar as funcionalidades do edifício. Se, por exemplo, o sistema de controle detecta que o usuário está indisponível para atender a ligação telefônica, por estar em uma reunião, o sistema encaminha a mensagem para uma secretária eletrônica, ou pode ser implementado algum outro procedimento para essa situação. 
O SCD considerado é restrito a um sistema telefônico distribuído cuja principal função consiste em encaminhar as chamadas automaticamente ao ramal telefônico mais próximo do usuário. Diferentemente dos sistemas telefônicos tradicionais, o SCD procura estabelecer o enlace telefônico entre a linha telefônica que ingressa ao prédio e o ramal interno mais próximo à atual localização usuário.

Por outro lado, o SVP possui, entre outros dispositivos, sensores inteligentes que identificam a localização dos usuários dentro do prédio. Essa identificação, juntamente com a chegada de uma chamada telefônica para esse usuário gera automaticamente o direcionamento da chamada ao ramal telefônico mais próximo do usuário. Dessa forma, a informação contendo a localização e os dados dos usuários que fornece o SVP pode ser aproveitada pelos outros sistemas prediais. Por exemplo, os sistemas de ar condicionado e de iluminação podem se adequar às preferências de conforto térmico e luminoso na sala segundo as próprias preferências dos usuários ou desligar esses sistemas automaticamente, caso a sala esteja desocupada, para reduzir o consumo energético. Outro sistema predial que pode ser beneficiado com o compartilhamento dessa informação é o de combate a incêndio. Em uma situação de emergência, por exemplo, o sistema envia a informação da localização dos usuários aos bombeiros para agilizar as operações de busca e resgate.

A seguir, são apresentadas as etapas do procedimento de modelagem proposto.

\subsection{ETAPA 1: REQUISITOS DO SISTEMA DE CONTROLE PREDIAL}

O sistema de controle do El considerado integra os dispositivos inteligentes de duas salas. Cada uma dessas salas possui dispositivos que formam parte do SVP e do SCD. A Figura 4.1 ilustra o sistema de controle. Os dispositivos estão integrados por meio da rede de controle. A 'linha tronco 1' e 'linha tronco 2' são responsáveis por interconectar os ramais telefônicos com a concessionária de telefonia fixa. É por meio delas que os usuários realizam e recebem ligações telefônicas externas ao prédio (CUNHA, 2008). O 'sensor 1' e 'sensor 2', que constituem parte do SVP, 
detectam e identificam a presença de usuários nas salas. O 'módulo de vigilância predial' se encarrega de executar as estratégias que garantem a segurança dos ocupantes. A 'secretaria eletrônica', identifica uma chamada telefônica para um usuário. Se o usuário não estiver disponível, a chamada é automaticamente encaminhada para uma caixa de mensagens. Quando o usuário está disponível, a secretária eletrônica estabelece a conexão com o 'ramal telefônico 1' ou 'ramal telefônico 2' mais próximo ao usuário para transmitir a mensagem. Os ramais telefônicos e a secretária eletrônica possuem a capacidade de realizar enlaces telefônicos mutuamente. Dessa forma, cada dispositivo de comunicação é capaz de se comunicar com o outro diretamente, ou seja, a comunicação entre os dispositivos é de ponto a ponto (CUNHA, 2008).

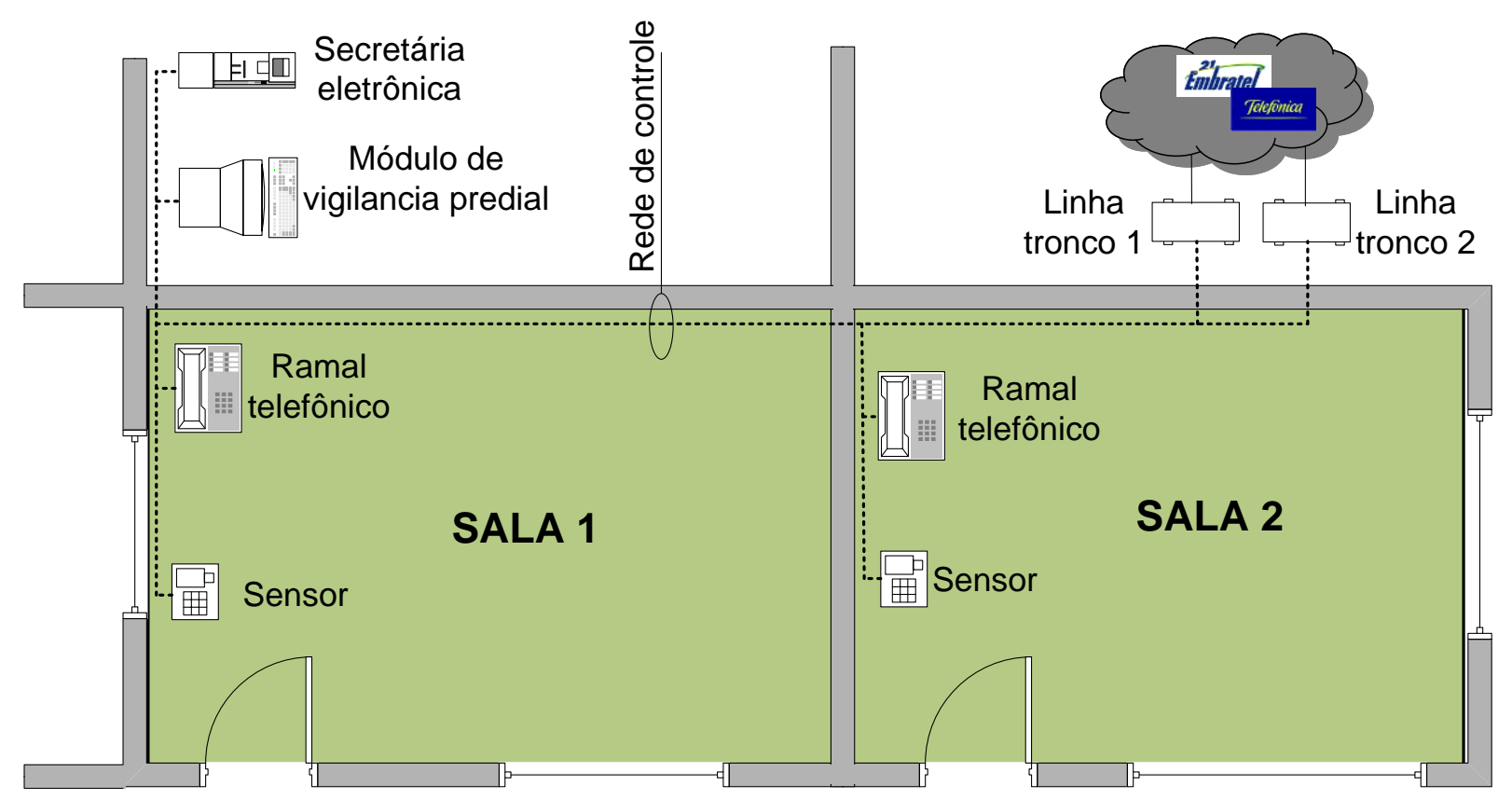

Figura 4.1- Diagrama do sistema de controle do EI

Nesse caso específico, foram definidos os principais requisitos da integração do SCD com o SVP:

- reconhecer a localização de um usuário dentro do prédio e transferir uma chamada telefônica para o ramal telefônico (aparelho que pode funcionar como um telefone) mais próximo ao usuário. Se o usuário estiver fora do prédio, automaticamente essa chamada telefônica é encaminhada a uma secretária 
eletrônica. Esse dispositivo inteligente se encarrega de receber a mensagem telefônica e, posteriormente, retransmiti-la por meio de um dos ramais telefônicos quando o usuário ingressar novamente ao prédio;

- quando um indivíduo não cadastrado ingressar em uma das salas do prédio, o sistema de vigilância emite um sinal de alerta. Dessa forma, deverá ser executada alguma estratégia como, por exemplo, mostrar as imagens no monitor da sala na qual foi registrada a ocorrência.

\subsection{ETAPA 2: ESPECIFICAÇÃO DAS ESTRATÉGIAS A SEREM MODELADAS}

A seguir, são especificadas algumas das estratégias que o sistema de controle considerado deverá realizar:

- o SVP identifica os usuários que estão nas duas salas do prédio;

- os dispositivos sensores do SVP publicam a informação dos dispositivos sensores na rede de controle predial;

- o SCD direciona a chamada telefônica, que pode vir da 'linha tronco 1' ou 'linha tronco 2', para o ramal telefônico mais próximo ao usuário de destino;

- o SCD encaminha a chamada telefônica da 'linha tronco '1 ou da 'linha tronco 2' para a 'secretária eletrônica' se o usuário a quem se destina a chamada não estiver no prédio;

- o SCD encaminha a mensagem que está na 'secretária eletrônica' para o ramal telefônico mais próximo ao usuário quando este ingressa em uma das salas do prédio;

- o SVP envia um sinal de alarme quando um usuário não cadastrado ingressa em uma das salas do prédio. O SVP executa uma estratégia predefinida para essa situação.

Uma vez definidas, de maneira geral, as atividades de cada um dos sistemas prediais, são especificadas as principais atividades de cada um dos dispositivos 
inteligentes que constituem a rede de controle predial, as quais são sintetizadas no Quadro 2.

\begin{tabular}{|c|c|}
\hline Dispositivos & Atividades \\
\hline Sensor sala 1 & $\begin{array}{l}\text { - } \quad \text { Identificar os usuários que ingressam na sala 1; } \\
\text { - } \quad \text { Publicar na rede de comunicação a identificação dos } \\
\text { usuários que permanecem na sala } 1 .\end{array}$ \\
\hline Sensor sala 2 & $\begin{array}{l}\text { - } \quad \text { Identificar os usuários que ingressam na sala 2; } \\
\text { - } \quad \text { Publicar na rede de comunicação a identificação dos } \\
\text { usuários que permanecem na sala } 2 \text {. }\end{array}$ \\
\hline Linha tronco 1 & $\begin{array}{l}\text { - } \quad \text { Receber ligação telefônica da concessionária; } \\
\text { - } \quad \text { Publicar na rede de comunicação o usuário de destino da } \\
\text { ligação telefônica. }\end{array}$ \\
\hline Linha tronco 2 & $\begin{array}{l}\text { - Receber ligação telefônica da concessionária; } \\
\text { - Publicar na rede de comunicação o usuário de destino da } \\
\text { ligação telefônica. }\end{array}$ \\
\hline $\begin{array}{l}\text { Ramal } \\
\text { telefônico sala } \\
1\end{array}$ & $\begin{array}{l}\text { - Receber a chamada telefônica se a ligação telefônica tem } \\
\text { como destinatário o usuário que está dentro da sala } 1 \text {; } \\
\text { - Receber a mensagem telefônica gravada da secretaria } \\
\text { eletrônica quando o destinatário ingressa na sala } 1 .\end{array}$ \\
\hline $\begin{array}{l}\text { Ramal } \\
\text { telefônico sala } \\
2\end{array}$ & $\begin{array}{l}\text { - Receber a chamada telefônica se a ligação tem como } \\
\text { destinatário o usuário que está dentro da sala } 2 \text {; } \\
\text { - Receber a mensagem telefônica gravada da secretaria } \\
\text { eletrônica quando o destinatário ingressa na sala } 2 \text {. }\end{array}$ \\
\hline $\begin{array}{l}\text { Secretária } \\
\text { eletrônica }\end{array}$ & $\begin{array}{l}\text { - Receber a chamada telefônica e gravar a mensagem e o } \\
\text { destinatário; } \\
\text { Quando o destinatário ingressa em uma das salas, a } \\
\text { mensagem deve ser enviada para o ramal telefônico mais } \\
\text { próximo ao usuário. }\end{array}$ \\
\hline $\begin{array}{l}\text { Módulo de } \\
\text { segurança } \\
\text { predial }\end{array}$ & $\begin{array}{l}\text { - Alertar o sistema de segurança predial quando um usuário } \\
\text { não cadastrado ingressa em uma das salas do prédio. }\end{array}$ \\
\hline
\end{tabular}

Quadro 2 - Descrição das atividades dos dispositivos 


\subsection{ETAPA 3: DEFINIÇÃO DOS TÓPICOS}

A seguir são definidos os tópicos de dados que o SCD e o SVP utilizam para estabelecer a comunicação entre os dispositivos inteligentes do sistema de controle.

- Sensor1 e Sensor2: Estes tópicos agrupam os usuários localizados nas salas 1 e 2, respectivamente. Essa informação está relacionada ao SVP.

- Linha1 e Linha2: Estes tópicos agrupam as chamadas telefônicas provenientes das linhas telefônicas 1 e 2, respectivamente. Essa informação está relacionada ao SCD.

A Figura 4.2 apresenta um esquema constituído por tópicos e dispositivos que fornecem e recebem esses dados. Por exemplo, os dados do tópico Sensor1 são fornecidos pelo 'Sensor 1' e requeridos pelas seguintes aplicações: 'Ramal telefônico (sala 1)', 'Módulo de segurança predial' e 'Secretária eletrônica'. Esses dados são necessários para executar as atividades definidas na etapa 2.

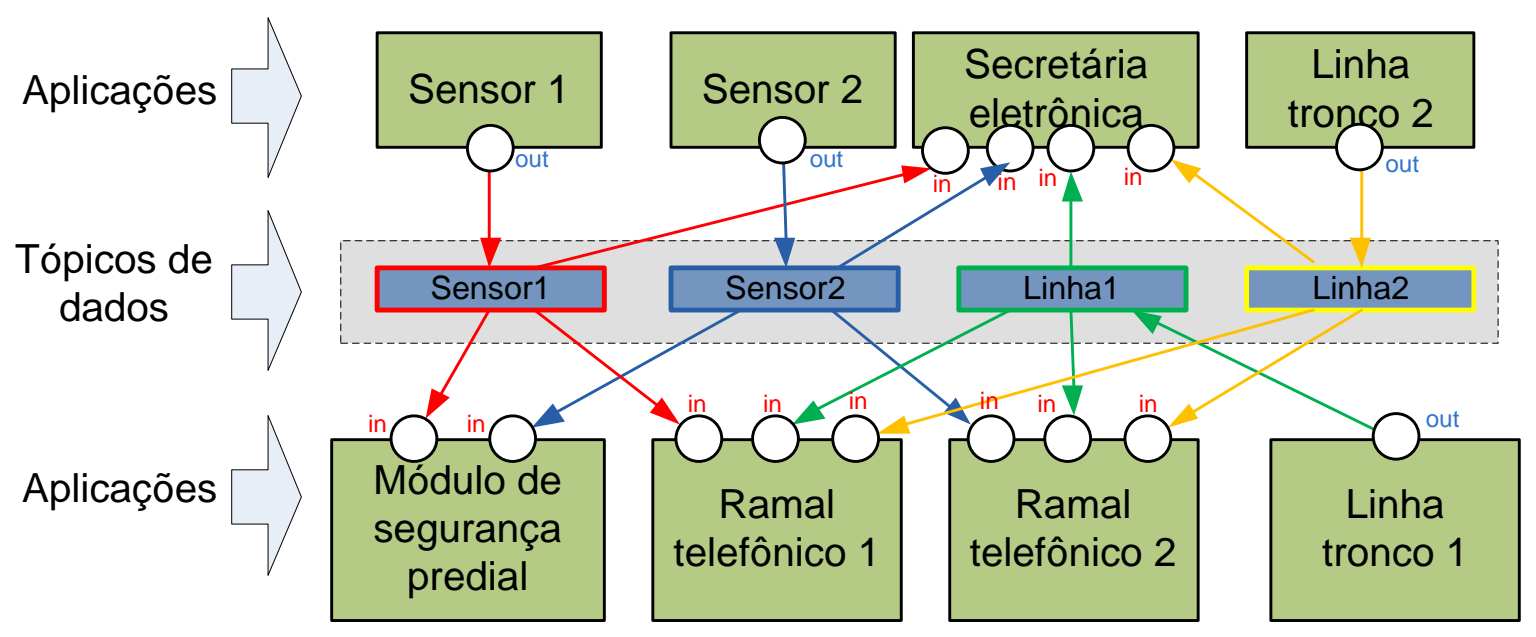

Figura 4.2 - Tópicos de dados e aplicações 


\subsection{ETAPA 4: CONSTRUÇÃO DOS COMPONENTES}

Nesta etapa são identificados os componentes básicos das aplicações, os quais são modelados utilizando a RPC. Inicialmente, foi desenvolvido um componente que permite simular os usuários que ingressam nas salas do prédio. Esse componente é representado pela substituição de transição "Usuários nas salas" (Figura 4.3). O funcionamento desse componente começa com a chegada de uma marca ao lugar "Usuar". O disparo da substituição de transição "Usuários nas salas" gera automaticamente duas marcas, sendo uma marca no lugar "sala 1" e outra no lugar "sala 2", as quais simulam os nomes dos usuários que chegam às salas 1 e 2 , respectivamente.

O comportamento interno da substituição de transição "Usuários nas salas" é apresentado na Figura 4.4. A interface de entrada é o lugar "Usuar". O registro dos usuários cadastrados está representado como um conjunto de marcas coloridas no lugar "Buffer usuários". O número 6 circunscrito ao "Buffer usuários" indica a quantidade de usuários cadastrados, representados pelas letras "A", "B", "C", " $X$ ", "Y" e "Z". As interfaces de saída são os lugares "sala 1" e "sala 2", que simulam os usuários que ingressam nas duas salas, respectivamente.

No módulo "Usuários nas salas" (Figura 4.4), a chegada de uma marca no lugar "Usuar" habilita a transição "T15". A inscrição associada ao arco de entrada que une o lugar "Usuar" à transição "T15" é a variável "m", sendo que o valor atribuído a "m" é uma constante de valor "1". O disparo da transição "T15" retira a marca do lugar "Usuar" e coloca uma marca nos lugares "Cont1" e "Cont2", deixando habilitadas as transições "T12" e "T13." Com estas duas transições habilitadas, às variáveis "i1" e "i2" são atribuídos valores aleatórios de marcas que se originam no lugar "Buffer usuários". Por exemplo, à variável "i1" pode ser atribuído o valor de "A" e à variável "i2", o valor de "B". Assim, a marca no lugar "usu1" é "A" e no lugar "usu2" é "B". Finalmente, o disparo das transições "T14a" e "T14b" devolvem as marcas retiradas no "Buffer usuários" e colocam uma marca no lugar de saída "sala 1" e outra no lugar de saída "sala 2" com os valores "A" e "B", respectivamente. Dessa maneira, são gerados aleatoriamente os usuários que ingressam nas duas salas. 


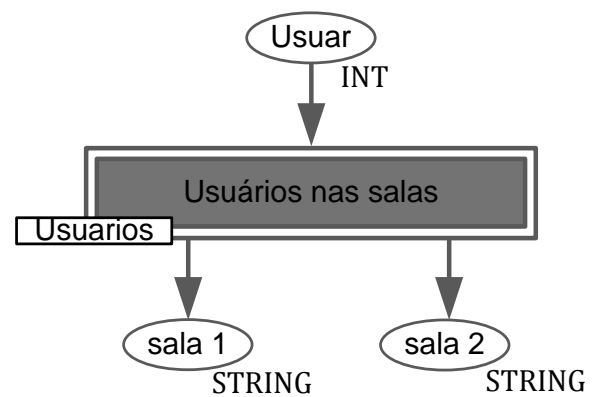

Figura 4.3 - Substituição de transição "Usuários nas salas"

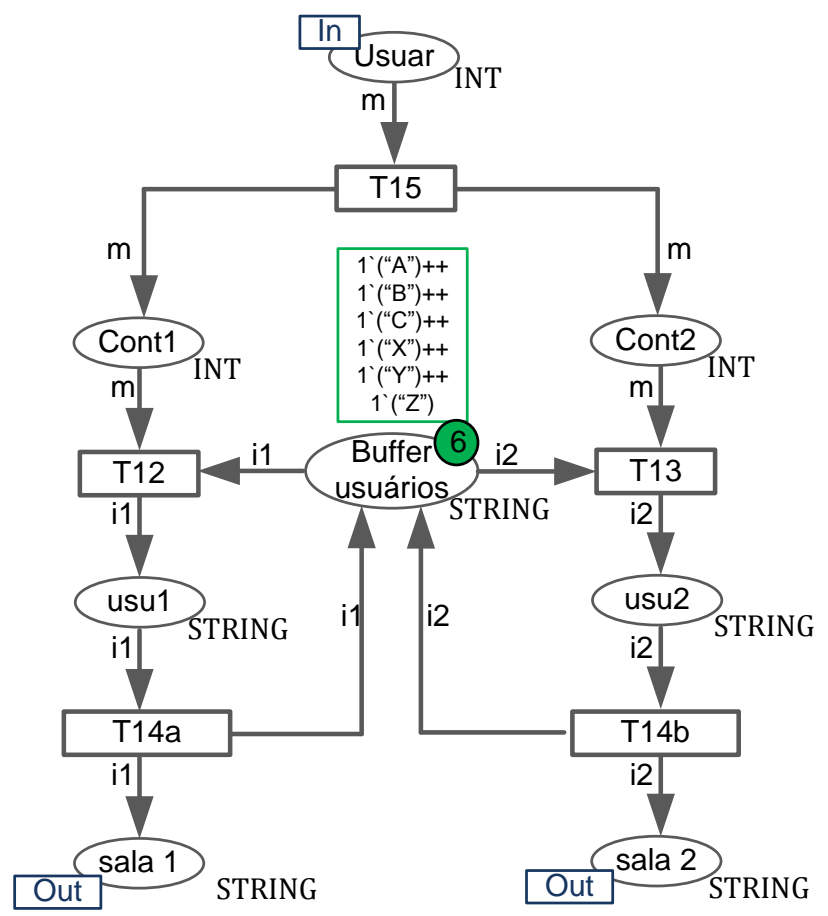

Figura 4.4 - Componente "Usuários nas salas"

A chegada de uma chamada telefônica pelas linhas telefônicas 1 e 2 foi representada pela substituição de transição "Chamadas telefônicas" (Figura 4.5). Para criar o modelo que representa o comportamento da substituição de transição, foi reaproveitado o componente descrito na Figura 4.4. Assim, a Figura 4.6 representa o modelo resultante do gerador de chamadas telefônicas. Esse modelo permite representar simultaneamente a chegada de duas chamadas telefônicas para usuários cadastrados no sistema. Os usuários cadastrados no sistema que recebem chamadas telefônicas são: "A", "B" e "C". Esses usuários estão representados por marcas no lugar "Chamadas". 


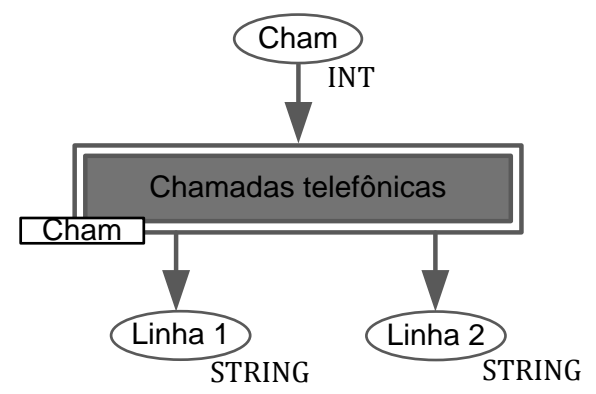

Figura 4.5 - Substituição de transição "Chamadas telefônicas"

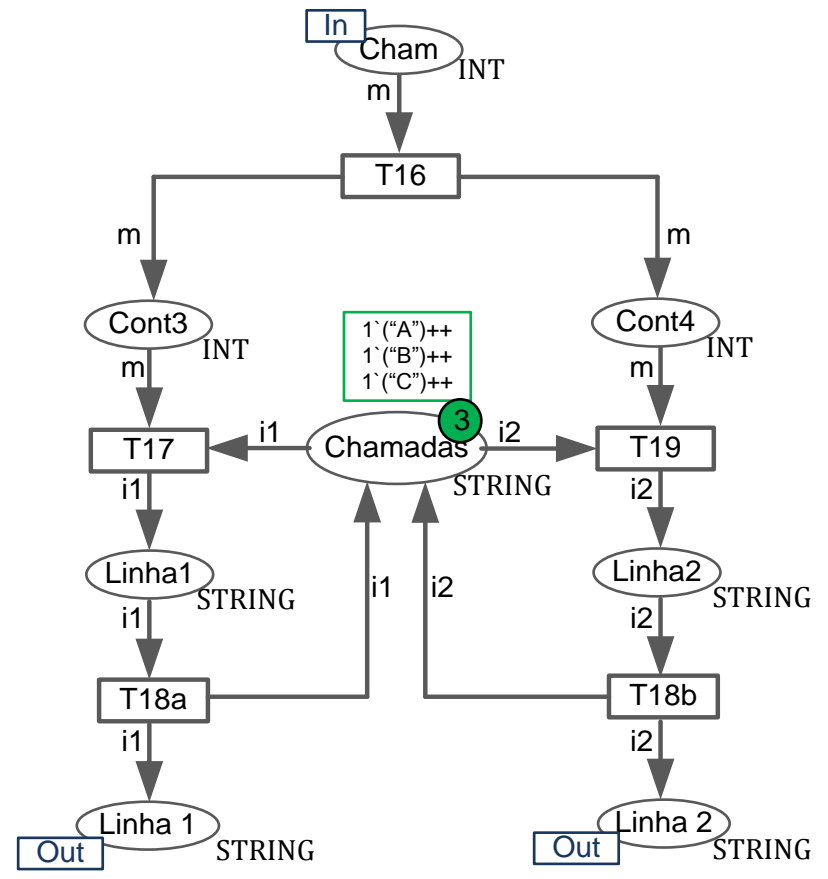

Figura 4.6 - Componente "Chamadas telefônicas"

Utilizando-se esses dois componentes desenvolvidos, foi construído o componente "Dados de entrada", representado pela substituição de transição ilustrada na Figura 4.7. Esse componente representa os dados que ingressam ao sistema de controle, os quais são os usuários que ingressam nas duas salas e as chamadas telefônicas para os usuários cadastrados. Com esta informação, a chegada de uma chamada telefônica e a localização dos usuários dentro das salas pode ser simulada. A Figura 4.8 ilustra o comportamento interno desse componente. 


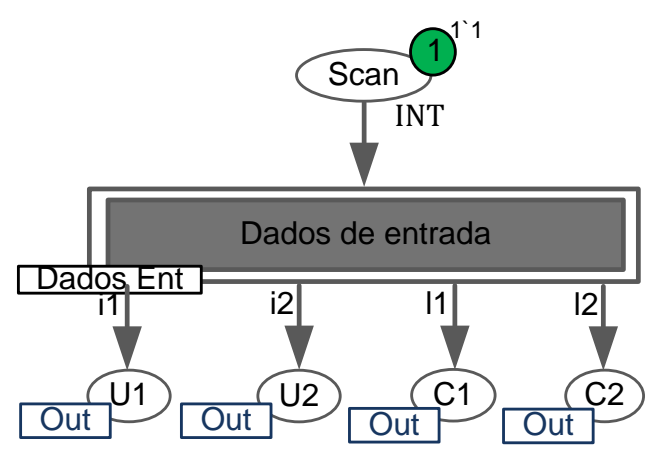

Figura 4.7 - Substituição de transição "Dados de entrada"

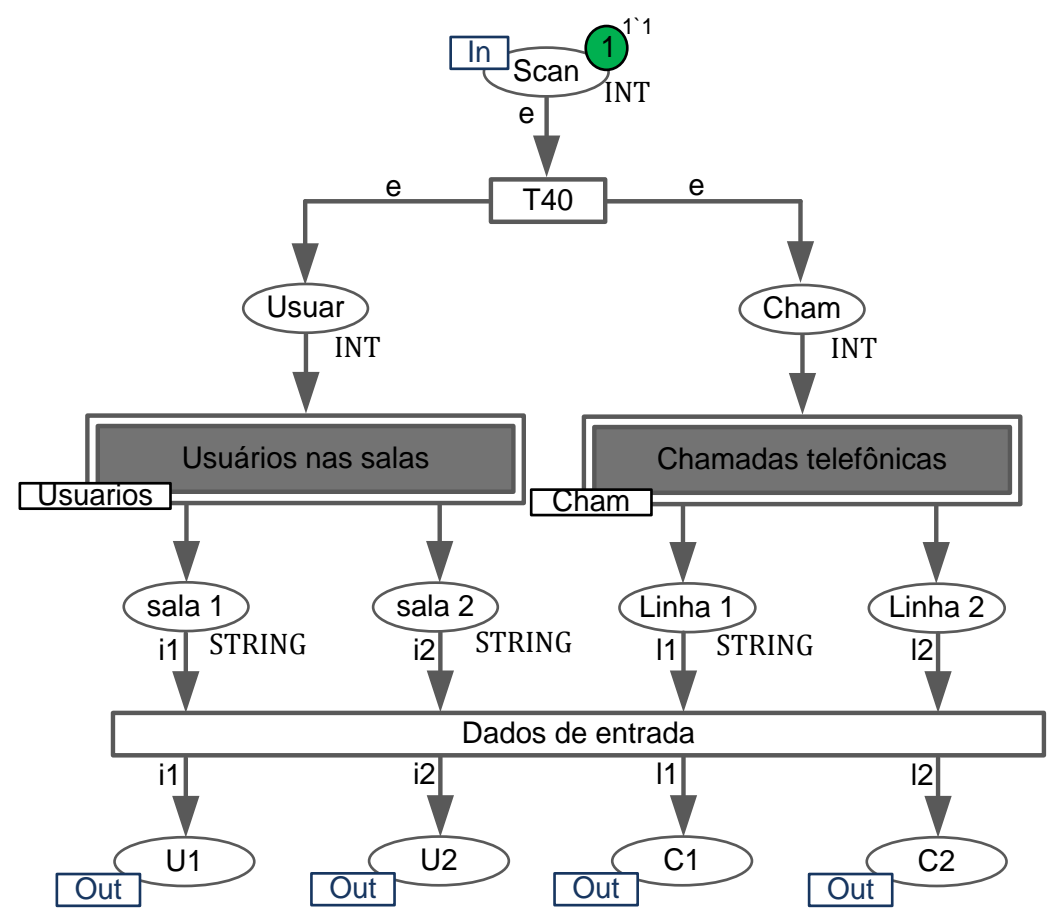

Figura 4.8 - Módulo "Dados de entrada"

A Figura 4.9 representa a substituição de transição do componente Tópicos, constituído pelos tipos de dados utilizados na comunicação entre as aplicações, definido na etapa 3. A Figura 4.10 ilustra os componentes internos da substituição de transição. Nesse modelo, os tópicos de dados são representados por transições. Quando uma das aplicações gera um dado de um tópico específico (p. ex., a chegada de um usuário na sala 1), esse dado ingressa ao componente Tópicos por meio do socket S1. Após o ingresso do dado, é habilitada a transição Sensor1. O disparo dessa transição gera uma marca com o dado do usuário para as aplicações subscritas a este tópico de dados. Nessa figura observa-se, por exemplo, que, para o tópico Sensor1, as interfaces de saída são os sockets S1_1, S1_2 e S1_3, que representam as interfaces 
de entrada das aplicações: "Módulo de segurança predial", "Ramal telefônico sala 1" e "Secretária eletrônica", as quais estão subscritas a este tópico de dados.

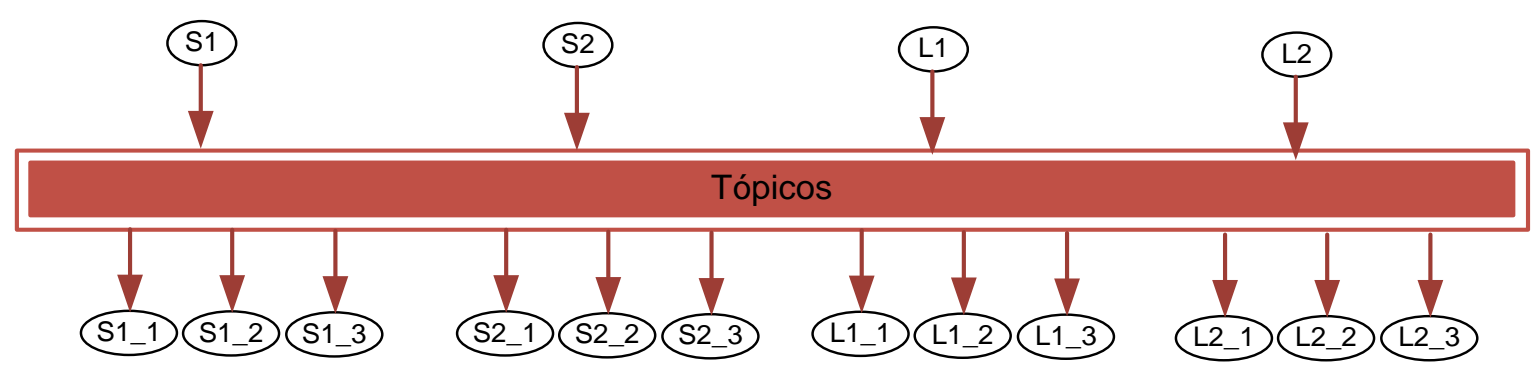

Figura 4.9 - Substituição de transição Tópicos
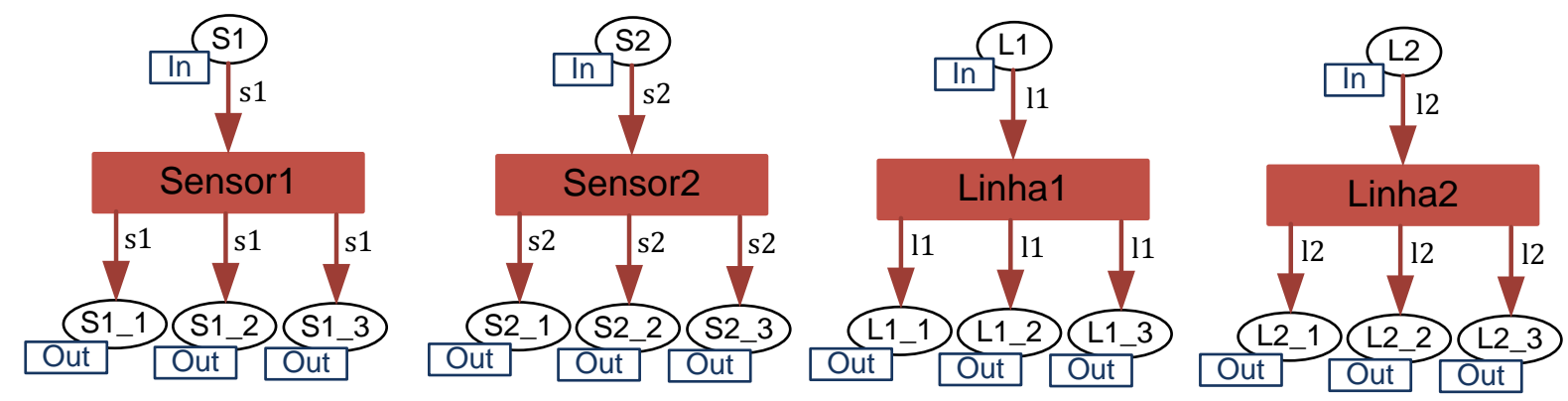

Figura 4.10 - Módulo Tópicos.

A seguir, são descritos alguns dos componentes utilizados para desenvolver o dispositivo "Ramal telefônico sala 1", que é subscrito aos tópicos: Sensor1, Linha1 e Linha2. A informação desses tópicos chega ao dispositivo por meio do componente representado pela substituição de transição "Filtro Ramal 1", ilustrado na Figura 4.11. A função deste componente é verificar se a chamada telefônica proveniente das linhas telefônicas 1 e 2 estão destinadas ao usuário que está localizado na sala 1. O funcionamento desse componente começa com a chegada das marcas que representam os valores dos tópicos: Sensor1, Linha1 e Linha2 aos sockets de entrada: "S1_2", "L1_1" e "L2_1", respectivamente. O resultado dessa verificação é enviado ao socket de saída "FR1". 


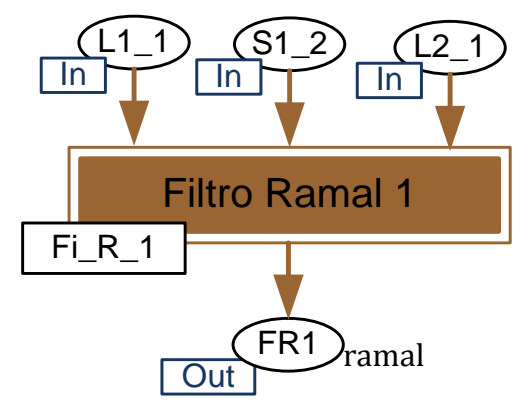

Figura 4.11 - Substituição de transição "Filtro Ramal 1"

O comportamento interno do componente "Filtro Ramal 1" é apresentado na Figura 4.12. As inscrições dos arcos de entrada da transição "T25" ("11", "usuário" e "12") representam os valores dos tópicos: Linha2, Sensor1 e Linha2, respectivamente. Quando a transição "T25" é habilitada, as marcas dos sockets de entrada "L1_1", "S1_2" e "L2_1" são retiradas e as inscrições dos arcos de saída da transição "T25" realizam a comparação entre os valores das variáveis. Se os valores das variáveis "12" e "usuário" são iguais, então é enviada uma marca ao socket de saída no valor de 1" "Linha2", usuário). Essa marca indica que existe uma chamada telefônica proveniente da linha telefônica 2 para o usuário que está na sala. Se a chamada telefônica for destinada a um usuário que não está na sala, o socket de saída recebe uma marca no valor de 1 (“"O,O”). Por último, se os valores das variáveis "11" e "usuário" forem iguais, então é enviada uma marca ao socket de saída no valor de 1`("Linha1", usuário), indicando que existe uma chamada telefônica proveniente da linha telefônica 1 para o usuário que está na sala 1.

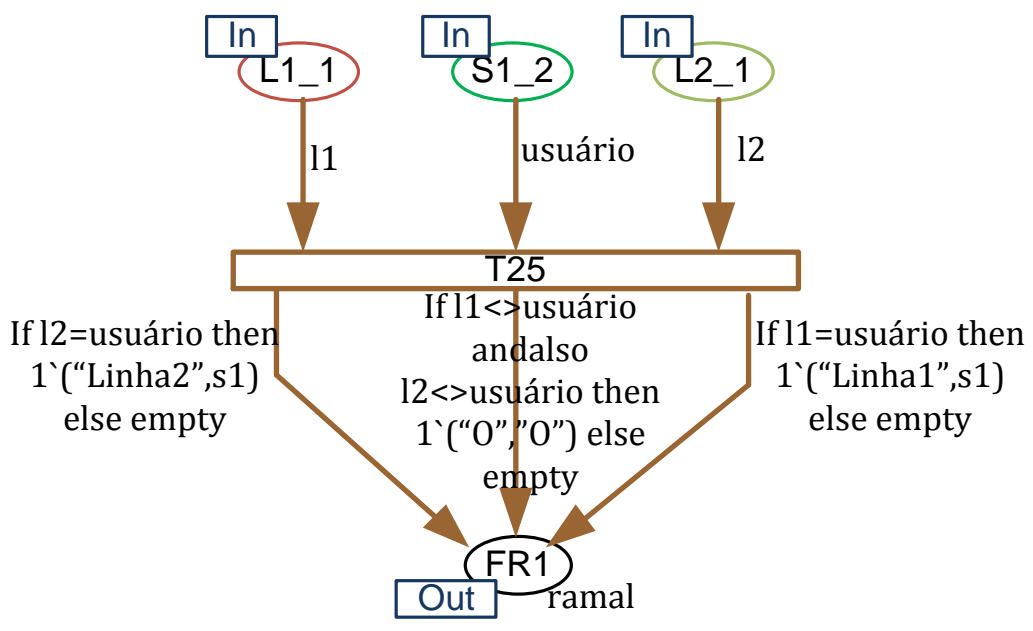

Figura 4.12 - Módulo "Filtro Ramal 1" 
A Figura 4.13 apresenta o componente desenvolvido para estabelecer as ligações telefônicas, representado pela substituição de transição "Ramal 1".

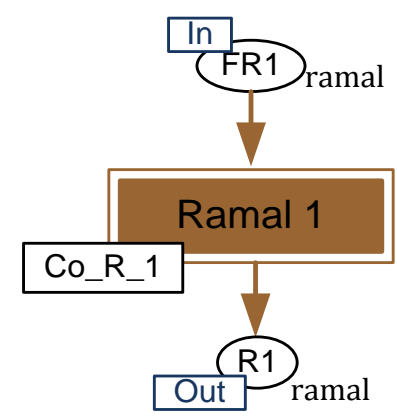

Figura 4.13 - Substituição de transição "Ramal 1"

Na Figura 4.14 é apresentado o comportamento interno do "Ramal 1". A chegada de uma marca no socket de entrada "FR1" proveniente do "Filtro Ramal 1" habilita as transições que realizam a conexão dinâmica entre as linhas telefônicas 1 e $2 \mathrm{com}$ o ramal telefônico 1. As expressões de guarda: "[R="Linha1"]", "[R="Linha2"]" e "[R="O"]" são condições que têm que ser verdadeiras para que as respectivas transições possam disparar. Por exemplo, a transição "Realizar binding dinâmico do Ramal $1 \mathrm{com}$ Linha 1" é disparada quando a variável "R" é igual à "Linha1". O disparo dessa transição representa o processo de configuração do sistema para estabelecer uma conexão entre a linha telefônica 1 e o ramal telefônico localizado na sala 1. A transição "T26" é disparada quando a chamada telefônica é destinada a um usuário que não está presente na sala 1, não sendo estabelecida nenhuma conexão com 0 ramal telefônico.

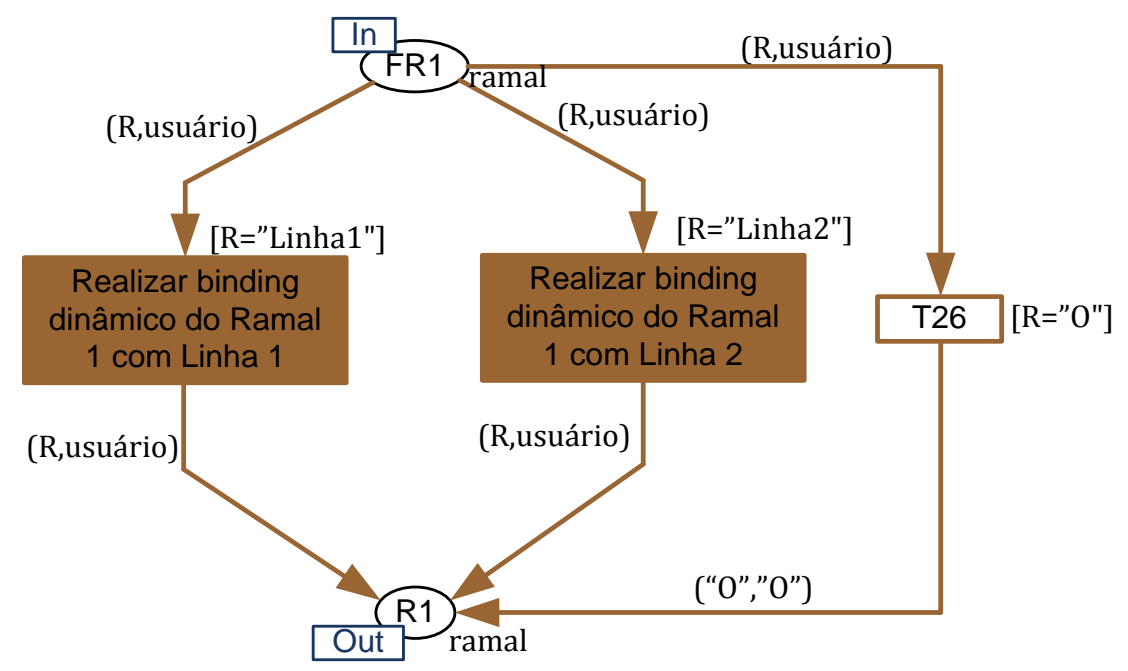


Figura 4.14 - Módulo "Ramal 1"

Com os componentes desenvolvidos, foi criada a aplicação que realiza o enlace telefônico entre o ramal telefônico 1 e as linhas telefônicas. A Figura 4.15 e a Figura 4.16 apresentam os modelos resultantes.

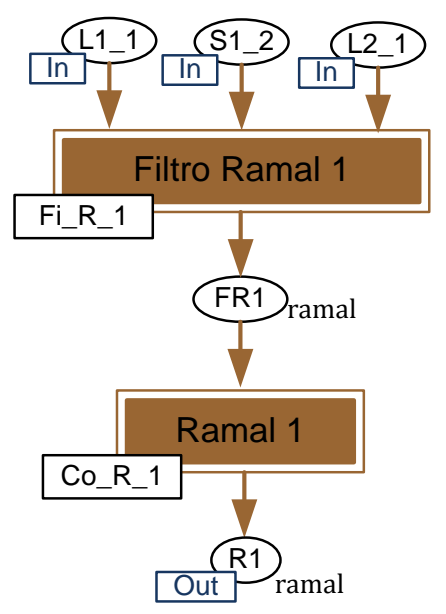

Figura 4.15 - Módulo "Ramal Telefônico 1"

A Figura 4.16 representa o dispositivo "Ramal Telefônico 1". O funcionamento desse dispositivo começa com a chegada das marcas que representam os valores dos tópicos: Sensor1, Linha1 e Linha2 aos sockets de entrada: "S1_2", "L1_1" e "L2_1", respectivamente. Dependendo desses dados, o ramal telefônico realiza as conexões entre a linha telefônica 1 ou 2 e o próprio ramal telefônico. Finalizado esse processo, é enviada uma marca ao socket de saída "R1" indicando qual foi o processo realizado.

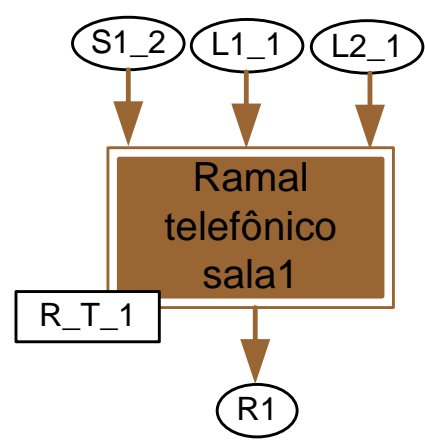

Figura 4.16 - Substituição de transição "Ramal Telefônico sala 1"

A construção dos outros componentes que constituem os dispositivos, descritos no Quadro 2, segue a mesma abordagem utilizada para desenvolver o "Ramal Telefônico sala 1". 


\subsection{ETAPA 5: MODELAGEM ESTRUTURAL DO SISTEMA DE CONTROLE}

O ciclo de funcionamento do sistema de controle projetado está representado no esquema da Figura 4.17. Inicialmente, estímulos são recebidos na forma de dados de entrada. Estes dados são: os usuários que ingressam na sala 1 e na sala $2 \mathrm{e}$ uma chamada telefônica proveniente da concessionária telefônica através da linha telefônica 1 ou da 2. Essa informação é alimentada ao módulo 'Processos' por meio das interfaces de comunicação: U1, U2, C1 e C2. Nesse módulo, são executadas as estratégias de controle definidas anteriormente (ver Etapa 2). Uma vez finalizadas as atividades de controle, obtêm-se como resultado os dados de saída, que alimentam as interfaces de comunicação R1, R2, E1 e M1. Depois que todos os dados de saída são obtidos, novamente é iniciado outro ciclo de funcionamento do sistema de controle.

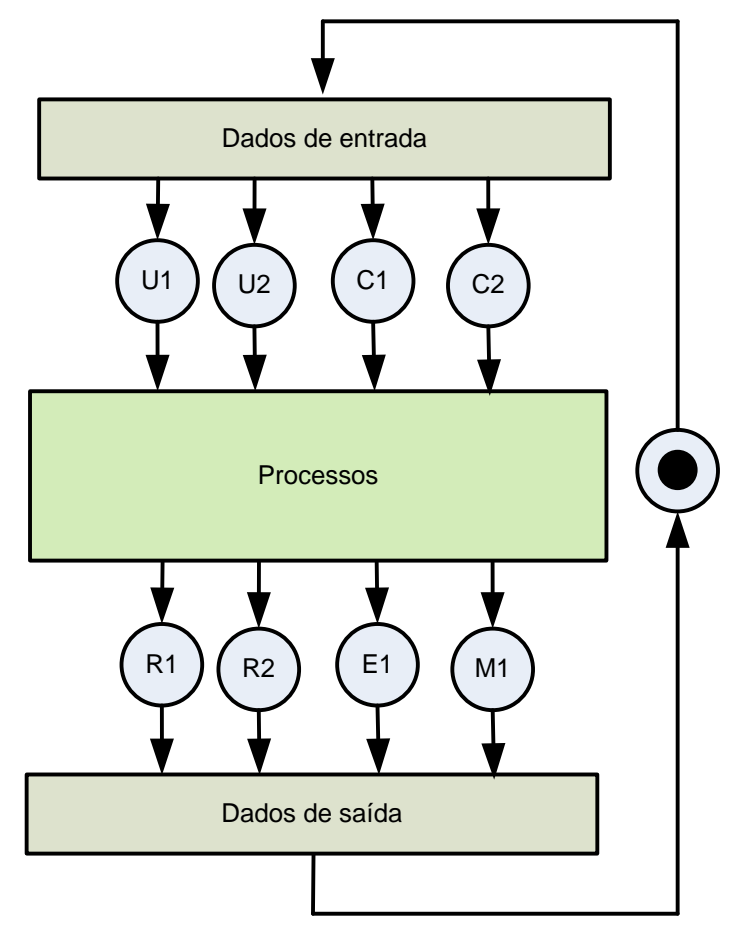

Figura 4.17 - Modelo de funcionamento do sistema de controle

Internamente, o módulo 'Processos' é constituído pelas aplicações que realizam as atividades definidas nas etapas anteriores. Na Figura 4.18 é apresentada a 
arquitetura do sistema proposto. Essa arquitetura é constituída por aplicações que interagem por meio da publicação e subscrição de tópicos de dados. As aplicações são representadas pelas substituições de transições. As setas indicam o fluxo de dados e os sockets representam as interfaces de entrada e saída de dados.

Por exemplo, o 'Sensor 1' recebe os dados de entrada pelo socket U1. Este dado é processado pelo dispositivo sensor e publica na rede de controle os usuários que ingressam na sala 1. Essa informação é agrupada no tópico Sensor1 e representada por meio de uma transição. As aplicações que necessitam desse tópico para realizar suas atividades são: o "Ramal telefônico da sala 1", a "secretária eletrônica" e o "módulo de segurança predial", por meio dos sockets de entrada S1.1, S1.2 e S1.3, respectivamente.

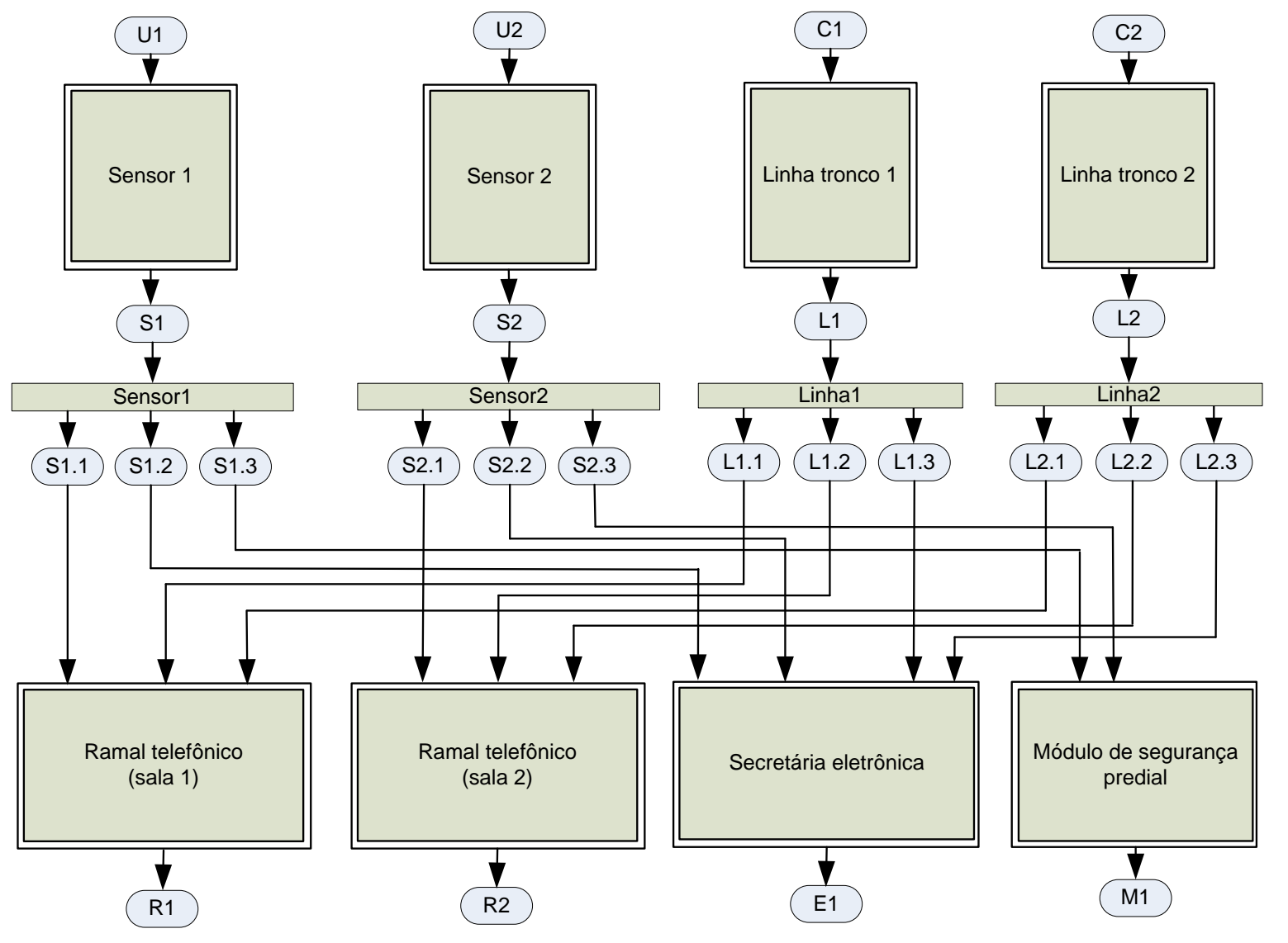

Figura 4.18 - Módulo Processos

A partir da criação e reutilização dos componentes previamente desenvolvidos, são construídas todas as aplicações que foram descritas no Quadro 2. A arquitetura 
resultante da integração dessas aplicações é modelada por meio da RPC. O modelo executável do sistema de controle é apresentado na Figura 4.19 e sua respectiva substituição de transição é ilustrada pela Figura 4.20.

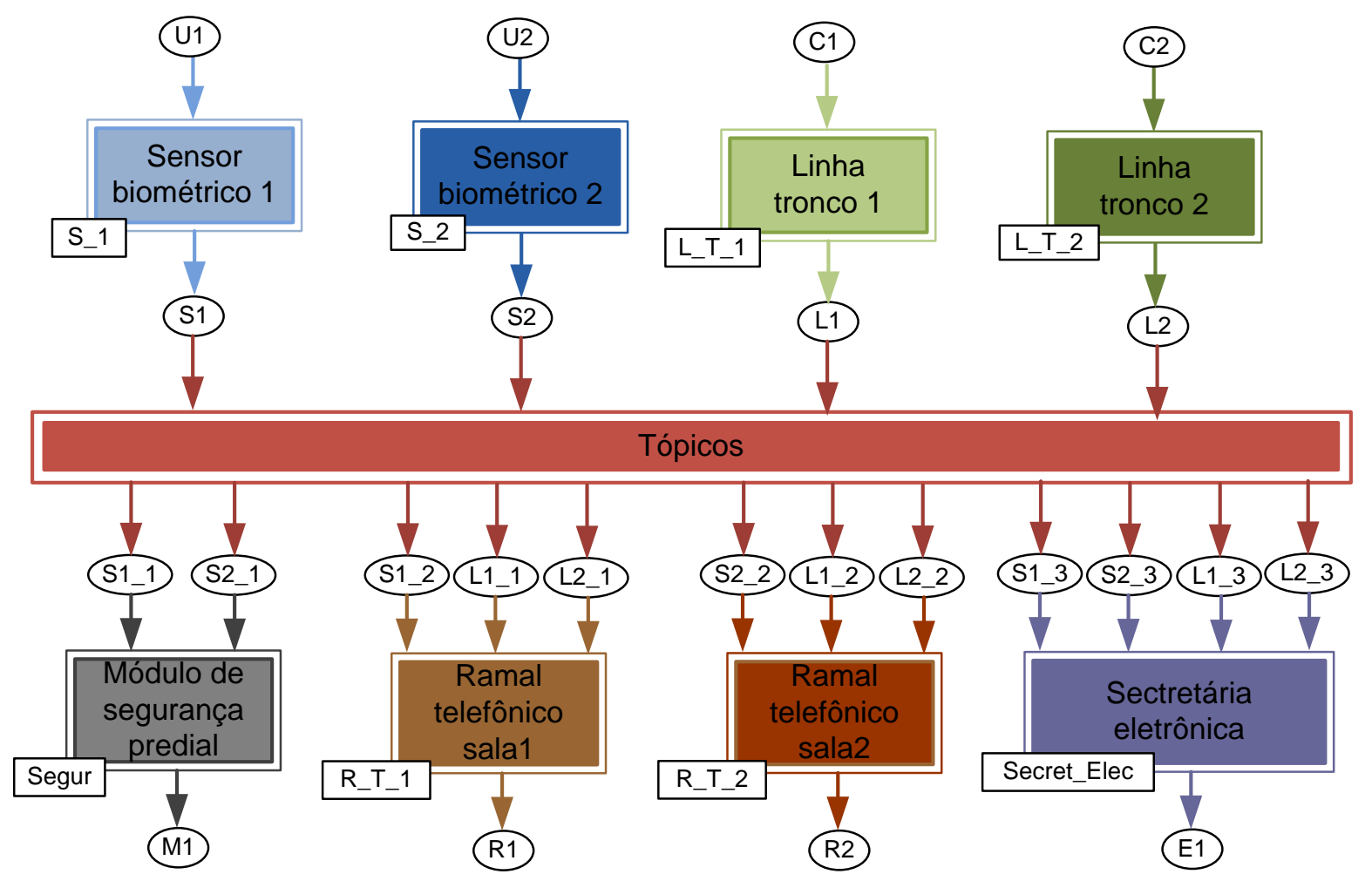

Figura 4.19 - Arquitetura do SCD

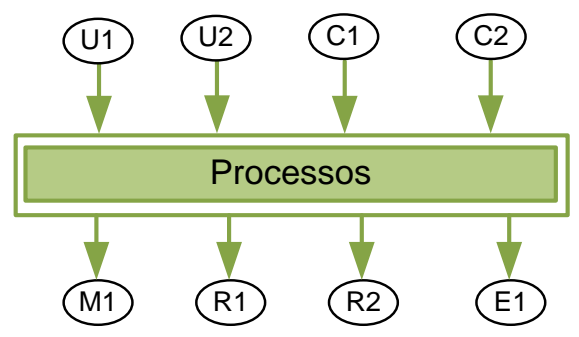

Figura 4.20 - Substituição de transição "Processos"

Observa-se que o modelo da Figura 4.21 é similar ao modelo de funcionamento apresentado na Figura 4.17. No entanto, o modelo da Figura 4.21 já é um modelo executável desenvolvido em CPNtools que pode ser simulado, e as propriedades comportamentais e estruturais do sistema de controle podem ser analisadas. 


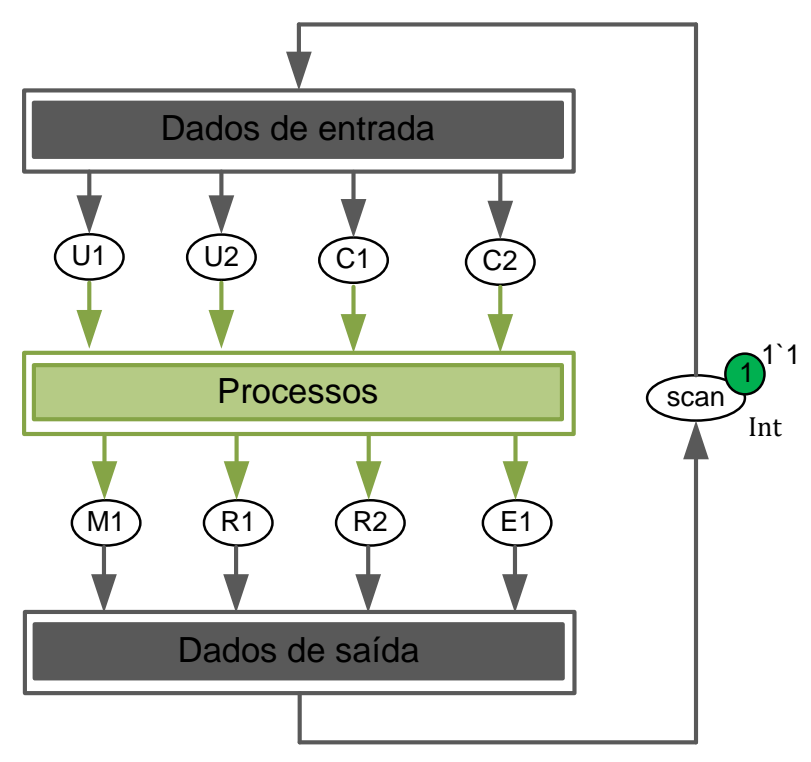

Figura 4.21 - Modelo final do SCD

\subsection{ETAPA 6: ANÁLISE DOS MODELOS}

Os modelos funcionais do sistema de controle são analisados para determinar se a dinâmica do seu comportamento representa as especificações que foram geradas nas etapas anteriores. O software CPNTools (JENSEN et al., 2007) foi utilizado para a construção e simulação dos modelos funcionais. Durante a edição dos modelos, o software já indica se existe algum erro estrutural. Por meio da simulação, diferentes cenários podem ser estudados a partir de condições iniciais específicas.

Segue um exemplo das questões $(Q)$ que apareceram durante a simulação do modelo do sistema de controle e suas correspondentes respostas derivadas da análise do modelo $(R)$ :

Q1. O que acontece se um usuário não cadastrado ingressa em uma das salas?

R1. O módulo de segurança predial envia uma mensagem de alerta ao sistema de segurança predial. 
Q2. É possível estabelecer uma comunicação interna entre os ramais telefônicos da sala 1 e da sala 2 ?

R2. Não. O modelo criado não permite esse tipo de comunicação.

Q3. É possível que o SCD registre o ingresso de mais um usuário em uma das salas?

R3. Não. O modelo que representa o SCD não permite o registro de mais de um usuário em cada sala, porem esta limitação pode ser retirada por meio de uma atualização do componente representado na Figura 4.4.

As questões Q2 e Q3 e suas respostas R2 e R3 motivam futuras modificações do modelo, visando a aperfeiçoar as características funcionais do sistema, por meio da atualização dos componentes. Além da verificação das especificações previstas, o software CPNTools permite que as propriedades estruturais e comportamentais da RPC também possam ser estudadas. Os resultados dessa análise podem ser salvos em um arquivo, com informações como deadlock, vivacidade e limitação (MURATA, 1989).

\subsection{OBSERVAÇÕES}

O procedimento proposto para modelar os sistemas de controle para Els foi aplicado na modelagem de um sistema de controle constituído por um sistema de comunicação distribuído e um sistema de vigilância predial.

Este procedimento possibilitou a identificação dos dispositivos assim como as interações necessárias para estabelecer a colaboração entre os dispositivos de controle. Os modelos desenvolvidos representaram o sistema de controle em diferentes níveis de detalhe, facilitando assim, o seu desenvolvimento. A RPC possibilitou a utilização de uma abordagem orientada a componentes para desenvolver o sistema de controle. Dessa forma, a complexidade do sistema de controle foi dissolvida por meio da construção de componentes menores, os quais foram integrados para desenvolver o sistema de controle. 
Uma das limitações encontradas durante o desenvolvimento do exemplo de aplicação é a impossibilidade de representar o tempo de resposta do sistema, já que a linguagem de modelagem utilizada não captura a dimensão temporal do sistema. Assim, não é possível modelar a duração das mensagens e das atividades dos dispositivos de controle. Por exemplo, não é possível modelar simultaneamente um atuador que precisa de uma informação a períodos curtos de tempo e um sensor que disponibiliza esta informação a intervalos de tempos diferentes. Neste sentido, a utilização da RPC temporizadas pode facilitar a representação do sistema já que esta permite agregar o tempo de disparo de uma transição. Neste sentido, trabalhos futuros podem ser desenvolvidos utilizando este tipo de RP (JENSEN;KRISTENSEN,2009) para representar a dimensão temporal do sistema de controle.

\subsection{CONSIDERAÇÕES FINAIS DO PRESENTE CAPÍTULO}

Por meio do procedimento de modelagem proposto, foi possível obter as especificações dos algoritmos de controle do SCD. E, além de assegurar um adequado funcionamento em situações normais, o procedimento permite desenvolver novas funcionalidades e aprimorar as existentes. Diferentemente do trabalho apresentado em Cunha (2008), o exemplo de aplicação aqui descrito se refere à integração do sistema de telefonia projetado para duas salas com o sistema de segurança predial.

Durante as etapas de construção dos modelos, foi definido o propósito do modelo, o que se pretende conhecer do sistema que está sendo estudado e quais são as propriedades do sistema de controle que se pretende analisar. Esses questionamentos permitiram abstrair adequadamente os modelos gerados visando à obtenção das especificações do sistema de controle estudado. Nesse sentido, observou-se a importância de encontrar o nível de abstração adequado que represente as funcionalidades dos dispositivos inteligentes durante o processo de 
modelagem do sistema.

Os modelos foram simulados e analisados utilizando-se os recursos disponíveis no software CPNTools para verificar as propriedades estruturais e algumas propriedades comportamentais, tais como: estados finais indesejáveis, vivacidade e deadlock. Adicionalmente, por meio da simulação do modelo, foi possível conhecer detalhadamente as características do sistema, comportamentos inesperados e outros aspectos relevantes que nem sempre são explicitamente definidos durante a etapa de definição dos requisitos. Dessa forma, conseguiu-se estudar e aprimorar o próprio modelo e os cenários alternativos, visando a um contínuo aprimoramento do sistema de controle. 


\section{CONCLUSÕES}

Este trabalho abordou o desenvolvimento do sistema de controle do El, especificamente a proposta de um procedimento sistemático de modelagem e simulação.

Inicialmente, foi apresentada uma visão geral do El, objeto de estudo do presente trabalho. Considerou-se o El como um sistema que proporciona serviços (segurança e conforto, entre outros) a seus usuários com um melhor aproveitamento dos recursos prediais (infraestrutura, energia, água etc.) quando comparado aos edifícios convencionais. Apresentaram-se também as principais motivações que guiaram a elaboração deste trabalho e os objetivos a serem atingidos. Em seguida, foram apresentados os principais conceitos relacionados aos Els. Por fim, apresentou-se uma proposta de uma abordagem para especificar sistemas de controle heterárquicos para o controle dos Els no qual o controle global do El emerge da colaboração entre os dispositivos inteligentes.

Este procedimento adotou uma abordagem baseada na componentização para a geração dos dispositivos. Em relação à colaboração entre os dispositivos, a principal conclusão obtida foi que a introdução do paradigma $P / S$ para estabelecer a comunicação entre os dispositivos foi essencial para tratar da complexidade, devido ao grande número de interações que são necessárias para realizar o controle do El. Desta forma, foram desenvolvidos dispositivos de controle que não estão diretamente acoplados um aos outros, facilitando assim a incorporação de outros elementos sem aumentar o grau de complexidade do sistema. Quanto à construção dos dispositivos de controle, a utilização de uma abordagem baseada em componentes possibilitou o reaproveitamento dos componentes na construção de outros dispositivos, reduzindo o tempo e os custos de desenvolvimento do sistema de controle.

A RPC foi fundamental para modelar as interações entre os dispositivos por possuir a capacidade de diferenciar umas marcas das outras. Esta característica foi 
essencial para representar o processo de comunicação entre os dispositivos de controle. Alem disso, a característica da RPC em utilizar conceitos de hierarquia, viabilizou a construção do sistema de controle em diferentes níveis de abstração.

O exemplo de aplicação ilustrou as principais características da abordagem proposta. Esta abordagem possibilitou o desenvolvimento de novas aplicações de controle predial, nas quais os dispositivos inteligentes colaboram entre $\mathrm{si}$, adaptando-se dinamicamente às características dos usuários e do ambiente. $\mathrm{O}$ exemplo de aplicação, limitado a duas salas de escritórios, foi idealizado como sendo parte de um El da terceira geração (apresentado no Capítulo 2). Este ambiente predial evidenciou a necessidade de o sistema de controle em identificar os usuários e se adaptar dinamicamente a esta informação, para realizar, por exemplo, a transferências de chamadas telefônicas. O controle das instalações prediais foi realizado por meio da colaboração entre os dispositivos inteligentes, os quais geram e utilizam uma grande quantidade de dados, disponibilizados na rede de controle. Conclui-se que a utilização do paradigma P/S foi essencial para abordar a complexidade devido ao grande número de interações entre os dispositivos. Por meio do paradigma $\mathrm{P} / \mathrm{S}$, foi possível o desacoplamento dos dispositivos e 0 agrupamento dos dados em tópicos.

O desacoplamento dos dispositivos viabilizou melhoru a robustez do sistema de controle, durante a ocorrência de falhas em alguns dos dispositivos. Por exemplo, se um dos sensores apresentar alguma falha de funcionamento, a informação fornecida por este dispositivo não é disponibilizada na rede de controle, mas esta situação tem um efeito limitado no sistema de controle em relação ao comportamento global do sistema. Adicionalmente, conclui-se que o desacoplamento entre os dispositivos facilita a incorporação de novos elementos ao sistema de controle, já que estes unicamente precisam-se subscrever a um tópico de dados. A abordagem possibilitou a identificação dos elementos que integram os sistemas em seus diferentes níveis de abstração, as suas funcionalidades e as interações que ocorrem durante o seu funcionamento. Entretanto, no procedimento proposto, unicamente foram definidos dispositivos inteligentes produtores ou consumidores de dados. Com tudo, uma generalização do procedimento poderia ser realizada por meio da incorporação de dispositivos inteligentes que concorrentemente publiquem e se subscrevam a dados. 
Neste sentido, novas pesquisas podem ser desenvolvidas considerando dispositivos inteligentes com estas características.

\subsection{PRINCIPAIS CONTRIBUIÇÕES}

O problema da especificação dos sistemas de controle para o El por meio da RP tem sido estudado por diversos pesquisadores (ARAKAKI, 2004; BASTIDAS; MIYAGI; PINA, 2006; KANESHIRO et al., 2010; VILLANI, 2004). Assim, no que se refere à modelagem dos sistemas de controle, no desenvolvimento deste trabalho foram consideradas várias contribuições anteriores. No entanto, do que se tem conhecimento, durante a elaboração deste trabalho não foram encontradas propostas para modelar sistemas de controle do El que possuam uma arquitetura completamente heterárquica. Algumas propostas, como em Silva (2008), propõem a utilização de abordagens parcialmente heterárquicas, nas quais os dispositivos de controle são cooperativos e autônomos com uma estrutura de coordenação hierárquica, e em situações específicas, como em caso de falha no sistema, assumem um comportamento colaborativo. Neste sentido, as principais contribuições derivadas deste trabalho podem ser sintetizadas em:

1. Proposta de uma arquitetura para o controle do El baseado em uma distribuição heterárquica das funcionalidades do sistema.

2. Proposta de uma abordagem sistemática para especificar o sistema de controle.

No que se refere à arquitetura proposta, o controle global do El emerge da colaboração entre os componentes inteligentes. A abordagem da arquitetura desconsidera qualquer nível de hierarquia entre os dispositivos de controle. O exemplo de aplicação demostrou que a arquitetura proposta possui as seguintes características quando comparada às arquiteturas centralizadas e hierárquicas: (i) flexibilidade: facilidade de incluir novas funcionalidades por meio da troca ou atualização dos componentes que constituem os dispositivos de controles; (ii) robustez: em caso de o sistema apresentar alguma falha em um dos dispositivos, o sistema de controle pode manter certo nível de estabilidade sem comprometer as principais funcionalidades do sistema; e (iii) escalável: pela facilidade em agregar 
novos dispositivos ao sistema de controle.

Uma limitação da arquitetura proposta é a ineficiência para transmitir mensagens de grande tamanho, já que isto tornaria lenta a comunicação, podendo tornar imprevisível o controle dos dispositivos. Contudo, essa limitação não se constitui em um problema real, pois em geral, as mensagens que trafegam em redes de automação (valor de uma grandeza medida, ordem para alguma atuação etc.) possuem pequeno tamanho.

Para garantir o correto funcionamento dos dispositivos e a garantia a sua interoperabilidade, foi proposto um procedimento de modelagem que permite verificar e validar o sistema de controle. Um dos principais diferenciais do procedimento adotado em relação às abordagens para especificação dos Els (apresentadas no capítulo 2.6) consiste em que a interação entre os dispositivos inteligentes é realizada por meio da publicação e subscrição de tópicos de dados, os quais são disponibilizados na rede de controle.

Em relação às linguagens de modelagem existentes para especificar o sistema de controle, a RPC foi escolhida pelas seguintes características: (i) possuir regras básicas simples; (ii) a sua representação gráfica permite que o modelo possa ser apresentado e entendido pelos projetistas e proprietários do edifício, que geralmente não estão familiarizados com os formalismos matemáticos, e (iii) pode ser derivada em uma linguagem de programação. Adicionalmente, a RPC permite inserir atributos às marcas, possibilitando assim diferenciar uma marca da outra. Essa característica foi aproveitada para modelar a interação entre os dispositivos do sistema de controle, na qual a diferenciação das mensagens é um requisito fundamental. Esse foi um dos principais motivos que levaram à escolha da RPC em relação às RP tradicionais. Outra vantagem da RPC é a construção de sistemas complexos por meio da componentização, reduzindo assim, os custos e o tempo de desenvolvimento dos sistemas de controle. 


\subsection{TRABALHOS FUTUROS}

Nesta seção são apresentados os trabalhos que podem ser desenvolvidos a partir dos questionamentos identificados e que ainda não foram tratados. Entre estes trabalhos, podem-se citar:

- diagnóstico e tratamento de falhas: o desenvolvimento de procedimentos que considerem o diagnóstico e o tratamento de falhas. No caso de uma aplicação deixar de funcionar, alguma outra poderia executar as funcionalidades da anterior. Uma das possíveis alternativas poderia ser a atribuição de prioridade aos arcos da RP. Por exemplo, quando uma aplicação solicita um dado, e este não é enviado em um intervalo de tempo determinado, o mecanismo de diagnóstico e tratamento de falhas poderia automaticamente disponibilizar outra aplicação que forneça o dado solicitado;

- proteção da informação: estudo de métodos que garantam a segurança da informação durante a comunicação entre os dispositivos. Como as mensagens dos dispositivos são compartilhadas em uma rede de controle, torna-se necessário criar meios para proteger a informação de agentes externos que possam fazer uso indevido das mesmas;

- estudo de caso real: desenvolvimento de um protótipo que represente um estudo de caso real de um El. Dessa forma, poderiam ser estudadas as tecnologias existentes que implementam as redes de controle predial e a aplicação do procedimento proposto para especificar as funcionalidades dos dispositivos que constituem a rede de controle;

- bibliotecas de componentes: desenvolvimento de bibliotecas que facilitem a criação de novas aplicações de Els;

- tratamento de incertezas: diferentemente do apresentado em Lu, Croome e Viljanen (2009), nesta tese, o sistema de controle El considerado possui um comportamento orientado a eventos discretos, sem considerar o tratamento 
de incertezas causadas pelo comportamento humano. Nesse sentido, procedimentos de modelagem que considerem essas características podem ser desenvolvidos.

- Aplicação do procedimento de modelagem no desenvolvimento de sistemas de controle orientados às aplicações agrícolas. $O$ procedimento de modelagem proposto pode ser utilizado como suporte ao desenvolvimento das pesquisas que se realizam no Laboratório de Automação Agrícola da USP, que desenvolve pesquisas envolvendo ambientes de criação vegetal e animal. Estes ambientes apresentam algumas das características encontradas nos Els. Neste sentido, o procedimento de modelagem pode fornecer uma sistemática para a criação de modelos que capturem a dinâmica do sistema de controle e assim, analisar o comportamento destes sistemas, reduzindo a necessidade de deslocamento aos lugares para realizar os testes de campo.

- Utilização de RPC temporizada. Como apresentado no capítulo 4, uma das limitações encontradas no procedimento proposto é impossibilidade de representar a dimensão temporal do sistema. Neste sentido, trabalhos futuros podem ser desenvolvidos considerando a utilização de linguagens de modelagem que capturem a dimensão temporal do sistema de controle, como por exemplo, a RPC temporizada.

\subsection{ENCERRAMENTO}

A evolução dos sistemas de controle dos Els tem sido fundamentada pelo aumento da capacidade computacional e de comunicação dos dispositivos eletrônicos. Estes avanços tecnológicos possibilitaram 0 desenvolvimento de arquiteturas heterárquicas, as quais permitem criar sistemas mais flexíveis e com maior capacidade de adaptação às necessidades tecnológicas dos seus usuários. $\mathrm{O}$ presente trabalho foi motivado pelo reconhecimento das vantagens na utilização da arquitetura de controle heterárquica. Esse tipo de arquitetura possibilita um alto grau 
de flexibilidade do sistema de controle. Entretanto, esta apresenta certo nível de imprevisibilidade do comportamento global do sistema, originada pelo fato de que o comportamento global do sistema de controle não é o resultado da integração do comportamento das partes que constituem o sistema. Nesse sentido, o procedimento proposto procurou uma abordagem sistemática para especificar 0 sistema de controle do El, visando à redução de erros de funcionamento.

O aprofundamento da pesquisa introduzida neste trabalho poderá ajudar no desenvolvimento de sistemas de controle dos Els com um maior entendimento do funcionamento dos seus componentes e do sistema como um todo. Para concluir, como as tecnologias para Els evoluem constantemente, os seus sistemas de controle sempre serão uma área de constante pesquisa, visando à criação de sistemas que se adaptem às novas tendências tecnológicas e às necessidades dos seus usuários. 


\section{REFERÊNCIAS}

ABAWAJY, J. H. Advances in pervasive computing: Guest Editorial. International Journal of Pervasive Computing and Communications, v. 5, n. 1, p. 4-8, 2009. Disponível em:

<http://www.emeraldinsight.com/journals.htm?articleid=1782744\&show=abstract>. Acesso em: 01 jun. 2010

ALDRED, L. et al. On the Notion of Coupling in Communication Middleware. In: MEERSMAN, R. and TARI, Z. (Ed.). On the Move to Meaningful Internet Systems 2005: CoopIS, DOA, and ODBASE. Berlin:Springer, 2005. p.1015-1033. Disponível em: <http://www.springerlink.com/content/8m702qh8xvkxvr5r/>. Acesso em: 01 ago. 2009

ARAKAKI, J. Técnicas de Degeneração no Projeto do Controle de Sistemas Produtivos. 2004. 154 p. Tese (Doutorado) - Escola Politécnica, Universidade de São Paulo, São Paulo, 2004.

ARKIN, H.; PACIUK, M. Evaluating intelligent buildings according to level of service systems integration. Automation in Construction, v. 6, n. 5-6, p. 471-479, 1997. Disponível em: < linkinghub.elsevier.com/retrieve/pii/S0926580597000253>. Acesso em: 02 jan. 2008.

AUGUSTIN, I. et al. ISAMadapt: abstractions and tools for designing generalpurpose pervasive applications. Software Practice Experience, v.36, n.11, p.12311256, 2006. Disponível em: <http://portal.acm.org/citation.cfm?id=1152337>. Acesso em 15 fev. 2010.

BARESI, L.; GHEZZI, C.; MOTTOLA, L. On Accurate Automatic Verification of Publish-Subscribe Architectures. In: INTERNATIONAL CONFERENCE ON SOFTWARE ENGINEERING, 29., 2007, Minneapolis, MN. Proceeding... Washington, DC.: IEEE Computer Society, 2007. p.119-208. Disponível em: < http://portal.acm.org/citation.cfm?id=1248853>. Acesso em: 11 jan. 2008.

BASTIDAS, G. Modelagem e análise de sistemas distribuídos e abertos para automação predial. 2005. 196 p. Tese (Doutorado) - Escola Politécnica, Universidade de São Paulo, São Paulo, 2005.

BASTIDAS, G.; MIYAGI, P. E.; PINA, I. Development of an Open Distributed Approach for Building Automation. In: INTERNATIONAL CONGRESS OF MECHANICAL ENGINEERING, 18., 2005, Ouro Preto, MG. Proceeding... [S.L.]: ABCM, 2006, p.150-157.

BECKER, C.; SCHIELE, G. Middleware and application adaptation requirements and their support in pervasive computing. In: INTERNATIONAL CONFERENCE ON DISTRIBUTED COMPUTING SYSTEMS, 23.,2003, [S.L.]. Proceeding... [S.L..s.n.], 2003, p.98-103. Disponível em:

$<$ http://ieeexplore.ieee.org/xpls/abs_all.jsp?arnumber=1203539\&tag=1 >. Acesso em: 11 jan. 2010. 
BETTINI, C.O. et al., A survey of context modelling and reasoning techniques. Journal of Pervasive and Mobile Computing. v. 6, n. 2, p. 161-180, 2010. Disponível em: <http://dx.doi.org/10.1016/j.pmcj.2009.06.002>. Acesso em 12 nov. 2010.

BRAUER, W.; REISIG, W. Carl Adam Petri and Petri Nets. Informatik-Spektrum, v. 29, n. 5, p. 369-374, 2006. Disponível em: <http://www.informatik.unihamburg.de/TGI/mitarbeiter/profs/petri_eng.html>. Acesso em: 11 jan. 2009.

CANOVAS, S. R. Intregração entre Redes Lonworks e Redes IP: Aplicações, Requisitos e Soluções. 2006. 193 p. Dissertação (Mestrado) - Escola Politécnica, Universidade de São Paulo, São Paulo, 2006.

CANOVAS, S. R. M.; CUGNASCA, C. E. Implementation of a Control Loop Experiment in a Network-Based Control System With LonWorks Technology and IP Networks. IEEE Transactions on Industrial Electronics, , v. 57, n. 11, p. 38573867, Nov. 2010. Disponível em:

$<$ http://ieeexplore.ieee.org/xpl/freeabs_all.jsp?arnumber=5409582\&con=yes\&userTy pe=inst>. Acesso em 20 Dez. 2010.

CLARK, G.; MEHTA, P. Artificial intelligence and networking in integrated building management systems. Automation in Construction, v. 6, n. 5-6, p. 481-498, 1997. Disponível em: <http://linkinghub.elsevier.com/retrieve/pii/S0926580597000265>. Acesso em 01 fev. 2008.

CHEN, H.; FININ, T.; JOSHI, A. An ontology for context-aware pervasive computing environments. The Knowledge Engineering Review, v. 18, n. 3, p.197-207, 2003. Disponível em: <http://portal.acm.org/citation.cfm?id=991806>. Acesso em 06 jun. 2010.

CLARKE, E. et al. Formal methods: State of the art and future directions. Journal ACM Computing Surveys (CSUR), v. 28, n. 4, p. 626-643, 1996. Disponível em: <http://portal.acm.org/citation.cfm?id=242257>. Acesso em: 01 fev. 2008.

COOK, D.; AUGUSTO, J.; JAKKULA, V. Ambient intelligence: Technologies, applications, and opportunities. Pervasive and Mobile Computing, v. 5, n. 4, p. 277-298, 2009. Disponível em:

<http://linkinghub.elsevier.com/retrieve/pii/S157411920900025X>. Acesso em 01 fev. 2010.

CORSARO, A. et al. Quality of service in publish/subscribe middleware. In:BALDONI R. and CORTESE G. (Ed.). Global Data Management. [S.L.:S.n.], 2006. v. 5, p. 122. Disponível em:

$<$ http://citeseerx.ist.psu.edu/viewdoc/download?doi=10.1.1.96.5691\&rep=rep1\&type= pdf>. Acesso em 01 jan. 2008.

CUGOLA, G.; MARGARA, A.; MIGLIAVACCA, M. Context-aware publish-subscribe: Model, implementation, and evaluation. In: IEEE SYMPOSIUM ON COMPUTERS 
AND COMMUNICATIONS, 2009, Sousse. Proceeding... [S.L.:s.n.], 2009. p.875881. Disponível em:

$<$ http://ieeexplore.ieee.org/xpls/abs_all.jsp?arnumber=5202277\&tag=1 >. Acesso em 10 jan. 2010.

CUNHA, R. A. Aplicação de técnicas de inteligência artificial para o gerenciamento dinâmico de dipositivos de um PABX distribuído, desenvolvido com a tecnologia LonWorks. 2008. 122 p. Dissertação (Mestrado) - Escola Politécnica, Universidade de São Paulo, São Paulo, 2008.

DEBONI, J. E. Z. Modelagem Orientada a Objetos com a UML. [S.L.]:Futura, 2003. $240 \mathrm{p}$.

DILTIS, D. M.; BOYD, N. P.; WHORMS, H. H. The evolution of control architectures for automated manufacturing systems. Journal of Manufacturing Systems, v. 10, n. 1, p. 79-93, 1991. Diponível em:

<http://linkinghub.elsevier.com/retrieve/pii/0278612591900498>. Acesso em 23 jan. 2009.

ELLIOTT, C. Intelligent buildings. Intelligent Buildings International, v. 1, n. 1, p. 75-81, 2009. Disponível em:

<http://www.ingentaconnect.com/content/earthscan/inbi/2009/00000001/00000001/ar t00006>. Acesso em 10 mar. 2010.

EUGSTER, P. T. et al. The many faces of publish/subscribe. Journal ACM Computing Surveys (CSUR), v. 35, n. 2, p. 114-131, 2003. Disponível em: <http://portal.acm.org/citation.cfm?id=857078>. Acesso em 10 mar. 2010.

FEIJÓ, R. H. B. Uma arquitetura de software baseada em componentes para visualização de informações industriais. 2007. 87 p. Dissertação (Mestrado) Engenharia Elétrica, Universidade Federal do Rio Grande do Norte, Natal, 2007.

FENKAM, P. et al. Evaluation of a publish/subscribe system for collaborative and mobile working. In: IEEE INTERNATIONAL WORSHOPS ON ENABLING TECHNOLOGIES: INFRAESTRUTURE FOR COLLABORATIVE ENTERPRISES, 11., 2002, Proceeding... Washington DC.: IEEE Computer Society, 2002. p.23-28. Disponível em: < http://portal.acm.org/citation.cfm?id=715956>. Acesso em 10 mar. 2010.

FLAX, B. M. Intelligent buildings. Communications Magazine, IEEE, v. 29, n. 4, p. 24-27, 1991. Disponível em: < http://ieeexplore.ieee.org/search/searchresult.jsp?newsearch=true\&queryText=flax+B .M>. Acesso em 01 jan. 2007.

GIMENES, I.; HUZITA, E. Desenvolvimento baseado em componentes: Conceitos e Técnicas. [S.L.]: Ciência Moderna, 2005. 304 p.

GRONBAEK, K.; KROGH, P. G.; KYNG, M. Intelligent Buildings and pervasive computing - research perspectives and discussions. In: CONFERENCE ON ARCHITECTURAL RESEARCH AND INFORMATION TECHNOLOGY, 2001. 
Proceeding... Aarhus:[s.n.], 2001. p.33-39. Disponível em: $<$ www.daimi.au.dk/ cfpc/publications/files/Intelligentbuildings.pdf >. Acesso em 10 jan. 2007.

GU, T.; PUNG, H.; ZHANG, D. A service-oriented middleware for building contextaware services. Journal of Network and Computer Applications, v. 28, n. 1, p. 118, 2005. Disponível em: <http://portal.acm.org/citation.cfm?id=1053031>. Acesso em 12 fev. 2009.

GUNASEKARAN, A. Agile manufacturing: a framework for research and development. International Journal of Production Economics, v. 62, n. 1-2, p. 87105, 1999. Disponível em: <www.citeulike.org/group/854/article/1539419>. Acesso em 13 fev. 2009.

HELAL, S. et al. The gator tech smart house: A programmable pervasive space. Computer, v. 38, n. 3, p. 50-60, 2005. Disponível em:

<http://www.computer.org/portal/web/csdl/doi/10.1109/MC.2005.107>. Acesso em 12 fev. 2010.

HIRATA, T. Processo de avaliação de componentes de software fornecidos por terceiros baseado no uso de modelos de qualidade. 2008. 147 p. Dissertação (Mestrado) - Escola Politécnica, Universidade de São Paulo, São Paulo, 2008.

HUANG, Y.; GARCIA, H. Publish/subscribe in a mobile environment. Wireless Networks, v. 10, n. 6, p. 643-652, 2004. Diponível em: <http://portal.acm.org/citation.cfm?id=1035681>. Acesso em 12 fev. 2010.

HUR, S.; KIM, D.; PARK, G. Building automation system via LonWorks and Linux based personal computer. Automation in Construction, v. 15, n. 4, p. 522-530, 2006. Disponível em:

<http://linkinghub.elsevier.com/retrieve/pii/S092658050500097X>. Acesso em 12 fev. 2010.

JABLONSKI, A.; KLEMPOUS, R.; LICZNERSKI, B. Diversified approach to methodology and technology in distributed intelligent building systems. Computer Aided Systems Theory-EUROCAST 2003, p. 174-184, 2004. Disponível em: <www.springerlink.com/index/txurcudj4v20026r.pdf>. Acesso em 12 fev. 2010.

JANCZURA, C. Modelling and Analysis of Railway Network Control Logic using Coloured Petri Nets. 1998. 255 p. Tese (Doutorado) - School of Mathematics, University of South Australia, Austrália do Sul, 1998.

JENSEN, K. Coloured Petri nets: basic concepts, analysis methods, and practical use. [S.L.]:Springer Verlag, 1996. 234 p.

JENSEN, K.; KRISTENSEN, L. M.; WELLS, L. Coloured Petri Nets and CPN Tools for modelling and validation of concurrent systems. International Journal on

Software Tools for Technology Transfer, v. 9, n. 3-4, p. 213-254, 2007.

Disponível em: <http://citeseer.ist.psu.edu/viewdoc/summary?doi=10.1.1.116.8898>. Acesso em 15 jan. 2009. 
JENSEN, K.; KRISTENSEN, L. Coloured Petri Nets: Modeling and Validation of Concurrent Systems. Nova York: Springer-Verlag, 2009. 384 p.

JORGENSEN, J. B. Coloured Petri Nets in UML-Based Software DevelopmentDesigning Middleware for Pervasive Healthcare. In: WORKSHOP AND TUTORIAL PRACTICAL USE OF COLOURED PETRI NETS AND THE CPNTOOLS, 4., 2002. Proceeding... Aarhus:[s.n.], 2002. p.61-80. Disponível em:<http://citeseerx.ist.psu.edu/viewdoc/summary?doi=10.1.1.90.900>. Acesso em 10 abr. 2009.

JORGENSEN, J. B.; TJELL, S.; FERNANDES, J. M. Formal requirements modelling with executable use cases and coloured Petri nets. Innovations in Systems and Software Engineering, v. 5, n. 1, p. 13-25, 2009. Disponível em: <http://www.citeulike.org/user/Grobi/article/4029444>. Acesso em 20 jan. 2010.

JUNQUEIRA, F.; MIYAGI, P. E. Modelagem e simulação distribuída de sistema produtivo baseados em rede de Petri. Sba: Controle \& Automação Sociedade Brasileira de Automatica, v. 20, p. 1-19, 2009. Disponível em: $<$ http://www.scielo.br/scielo.php?pid=S0103$17592009000100001 \&$ script=sci_arttext>. Acesso em 01 jan. 2010.

KANESHIRO, P.J.I. Modelagem de sistemas de proteção técnica contra incêndio em edifícios inteligentes através de rede de Petri. 2006. 129 p. Dissertação (Mestrado) - Escola Politécnica, Universidade de São Paulo, São Paulo, 2006.

KANESHIRO, P. J. I. et al. Modeling of Distributed Control System in Intelligent Buildings Based on Colored Petri Net. Latin America Transactions, IEEE , v. 8, n. 5, p. 589-596, 2010. Disponível em:<http://ieeexplore.ieee.org/xpls/abs_all.jsp?arnumber $=5623513 \& t a g=1>$. Acesso em 01 jan. 2011.

LEE, C.; HELAL, S.; LEE, W. Universal Interactions with Smart Spaces. IEEE Pervasive Computing. v. 5, n. 1, p. 16-21, 2006. Disponível em: <http://portal.acm.org/citation.cfm?id=1115742>. Acesso em 14 jun. 2010.

LIU, K.; YAO, R. Guest editorial: Understanding pervasive intelligent spaces using semiotics. Intelligent Buildings International, v. 2, p. 3-4, 2010. Disponível em: $<$ http://www.ingentaconnect.com/content/earthscan/inbi/2010/00000002/00000001/ar t00001; jsessionid=270ova3ukmdh2. alexandra >. Acesso em 28 jun. 2010.

\section{LOPES, F. CES - Um Mecanismo Genérico de Composição de Eventos para}

Sistemas Sensíveis ao Contexto. 2008. 88 p. Dissertação (Mestrado) Departamento de Informática e Matemática Aplicada, Universidade Federal do Rio Grande do Norte, Natal, 2008.

LU, X.; CLEMENTS CROOME, D.; VILJANEN, M. Past, present and future mathematical models for buildings. Intelligent Buildings International, v. 1, n. 1, p. 23-38, 2009.Disponível em: 
$<$ http://www.ingentaconnect.com/content/earthscan/inbi/2009/00000001/00000001/ar t00003>. Acesso em 28 jun. 2010.

MATSUSAKI, C.; SANTOS FILHO, D. F. Modeling of Distributed Collaborative Control Systems of Production Systems. In: ABCM SYMPOSIUM SERIES IN MECHATRONICS, 2., 2006. [S.L.]. Anais... [S.L.]:ABCM, 2006. p.345-352.

MATSUSAKI, C. T. M. Modelagem de Sistemas de Controle Distribuídos e Colaborativos de Sistemas Produtivos. 2004. 154 p. Tese (Doutorado) - Escola Politécnica, Universidade de São Paulo, São Paulo, 2004.

MIYAGI, P. E. Controle programável: Fundamentos do controle de sistemas a eventos discretos. São Paulo: Edgard Blucher, 1996. 194 p.

MIYAGI, P. E. et al. Petri Net approach for modelling system integration in intelligent buildings. Journal of the Brazilian Society of Mechanical Sciences, v. 24, p. 341350, 2002. Disponível em: < http://www.scielo.br/scielo.php?pid=S010073862002000400015\&script=sci_arttext>. Acesso em 04 jan.2007.

MURATA, T. Petri nets: Properties, analysis and applications. Proceedings of the IEEE, v. 77, n. 4, p. 541-580, 1989. Disponível em:

$<$ http://ieeexplore.ieee.org/stamp/stamp.jsp?tp=\&arnumber=24143\&userType=inst $>$. Acesso em 05 jan. 2007.

NAKAMOTO, F. Y. Projeto de sistemas modulares de controle para sistemas produtivos. 2008. 158 p. Tese (Doutorado) - Escola Politécnica, Universidade de São Paulo, São Paulo, 2008.

PREKOP, P.; BURNETT, M. Activities, context and ubiquitous computing. Computer Communications, v. 26, n. 11, p. 1168-1176, 2003. Disponível em: <http://dx.doi.org/10.1016/S0140-3664(02)00251-7>. Acesso em 10 jan. 2008.

PRESSMAN, R. S. Engenharia de software. São Paulo: McGraw-Hill, 2006. 711p.

PUJO, P.; BROISSIN, N.; OUNNAR, F. PROSIS: An isoarchic structure for HMS control. Engineering Applications of Artificial Intelligence, v. 22, n. 7, p. 10341045, 2009. Disponível em: <http://dx.doi.org/10.1016/j.engappai.2009.01.011>. Acesso em 05 fev. 2010.

RAMADGE, P. J. G.; WONHAM, W. M. The control of discrete event systems. Proceedings of the IEEE, v. 77, n. 1, p. 81-98, 1989. Disponível em: $<$ http://ieeexplore.ieee.org/xpls/abs_all.jsp?arnumber=21072>. Acesso em 05 jan. 2007.

REISIG, W. Primer in Petri net design. [S.L.]:Springer-Verlag, 1992. 448 p.

RIES, L. Uma plataforma para integrar dispositivos eletrônicos em ambientes pervasivos. 2007. 81 p. Dissertação (Mestrado) - Faculdade de Informática, Pontifícia Universidade Católica do Rio Grande do Sul, Porto Alegre, 2007. 
SARAMAGO, M. Integração de Dispositivos Inteligentes Utilizando Conceitos de Domótica Direcionados a Automação Hospitalar. 2002. 119 p. Tese (Doutorado) - Faculdade de Engenharia Mecânica, Universidade Estadual de Campinas, Campinas, 2002.

SHARPLES, S.; CALLAGHAN, V.; CLARKE, G. A multi-agent architecture for intelligent building sensing and control. Sensor Review, v. 19, n. 2, p. 135-140, 1999. Disponível em:

<http://www.emeraldinsight.com/journals.htm?articleid=876286>. Acesso em 02 jan. 2009.

SILVA, R. M. D. Modelagem de Sistemas de Controle de Edifícios Inteligentes Considerando a Ocorrência de Falhas. 2008. 183 p. Dissertação (Mestrado) Escola Politécnica, Universidade de São Paulo, São Paulo, 2008.

SILVA, R. P. Suporte ao desenvolvimento e uso de frameworks e componentes. 2000. 262 p. Tese (Doutorado) - Computação, Universidade Federal do Rio Grande do Sul, Porto Alegre, 2000.

SILVEIRA, M. R. D.; COMBACAU, M. Supervision and control of heterarchical discrete event system. Revista Controle \& Automação, v. 17, n. 1, p. 9, 2006. Disponível em: <www.scielo.br/pdf/ca/v17n1/a01v17n1.pdf>. Acesso em 05 jan. 2010.

SIMÃO, A. Aplicação de análise de mutantes no contexto do teste e validação de redes de Petri coloridas. 2004. 310 p. Dissertação (Mestrado) - Instituto de Ciências Matemáticas e de Computação, Universidade de São Paulo, São Carlos, 2004.

SOFTEX. Campinas. Perspectivas de desenvolvimento e uso de componentes na industria brasileira. Disponível em:

<http://www.softex.br/observatorio/ noticias/noticia.asp?id=1362 >. Acesso em: 10 outubro, 2009.

SOMMERVILLE, I. Engenharia de Software. $8^{\text {th }}$ ed. [S.L.]: Addison Wesley, 2007. $568 \mathrm{p}$.

TRENTESAUX, D. Distributed control of production systems. Engineering Application of Artificial Intelligence, v. 22, p. 971-978, 2009. Disponível em: $<$ linkinghub.elsevier.com/retrieve/pii/S0952197609000797>. Acesso em 10 jan. 2010.

VILLANI, E. Modelagem e Análise de Sistemas Supervisórios Híbridos. 2004. 334 p. Tese (Doutorado) - Escola Politécnica, Universidade de São Paulo, São Paulo, 2004.

VILLANI, E.; MIYAGI, P. E.; VALETTE, R. Modelling and analysis of hybrid supervisory systems: a Petri net approach. $1^{\text {th }}$ ed. [S.L.]: Springer Verlag, 2007. $224 \mathrm{p}$.

WANG, S.; XIE, J. Integrating Building Management System and facilities 
management on the Internet. Automation in Construction, v. 11, n. 6, p. 707-715, 2002. Disponível em: <http://dx.doi.org/10.1016/S0926-5805(02)00011-0>. Acesso em 03 jan. 2007.

WEISER, M. The computer for the 21st century. Scientific American, v. 265, n. 3, p. 94-104, 1991. Disponível em: <http://wiki.daimi.au.dk/pca/_files/weiser-orig.pdf>. Acesso em 03 jan. 2007.

WONG, J.; LI, H. Development of intelligence analytic models for integrated building management systems (IBMS) in intelligent buildings. Intelligent Buildings International, v. 1, n. 1, p. 5-22, 2009. Disponível em: $<$ http://www.ingentaconnect.com/content/earthscan/inbi/2009/00000001/00000001/ar t00002>. Acesso em 03 jan. 2007.

WONG, J.; LI, H.; WANG, S. Intelligent building research: a review. Automation in Construction, v. 14, n. 1, p. 143-159, 2005. Disponível em:

<http://dx.doi.org/10.1016/j.autcon.2004.06.001>. Acesso em 03 jan. 2007.

XIE, C.; PU, J.; MOORE, P. A case study on the development of intelligent actuator components for distributed control systems using LONWORK neuron chips.

Mechatronics, v. 8, n. 2, p. 103-119, 1998. Disponível em:

<http://dx.doi.org/10.1016/S0957-4158(97)00043-3>. Acesso em: 03 jan. 2007.

ZHOU, M.; DICESARE, F. Petri net: synthesis for discrete event control of manufacturing systems. [S.L.]: Springer, 1993. 256 p. 


\section{Anexo 1}

\section{METODOLOGIA DA PESQUISA}

Este trabalho adotou a metodologia de desenvolvimento das pesquisas na área de rede de Petri citada em Jensen (1996). A Figura A.1 sintetiza o ciclo de desenvolvimento nesta área.

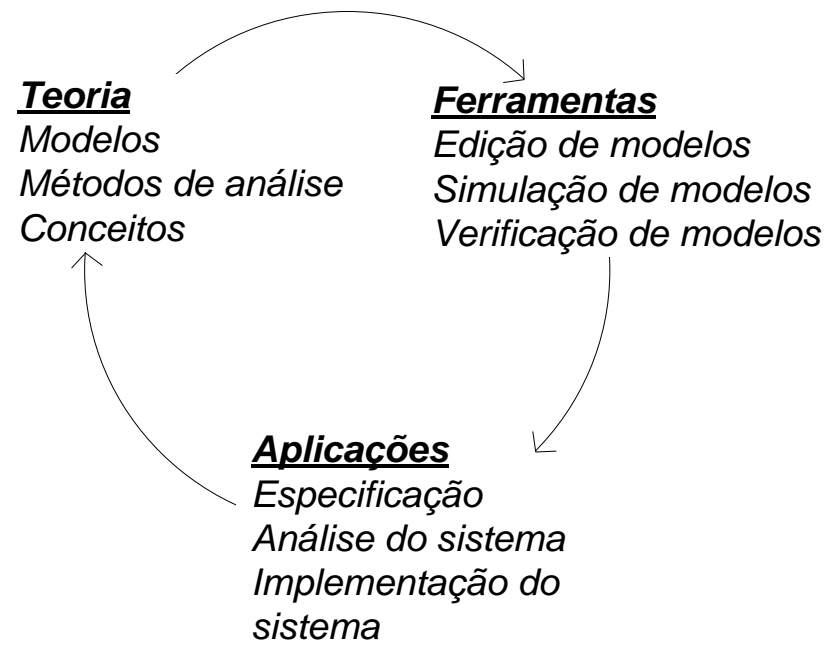

Figura A.1 - Ciclo de desenvolvimento de metodologia com rede de Petri. (Adaptado de Jensen (1996))

Esta abordagem evidencia uma forte inter-relação entre teoria, ferramentas e aplicações, estando os três aspectos integrados no processo de desenvolvimento de um método e contribuindo sinergicamente para os processos de desenvolvimento associados a cada um deles. É uma abordagem de engenharia que, considerando os aspectos formais associados à definição do modelo e das técnicas de análise aplicáveis, utiliza as aplicações como "motor" de desenvolvimento para ferramentas de suporte à aplicação do modelo. É uma fórmula plenamente bem sucedida pelos diversos trabalhos desenvolvidos relacionados às redes de Petri. A Figura A.2 sintetiza as principais referências do presente trabalho em termos da metodologia de pesquisa apresentada. 


\section{Teoria}

Modelagem de sistemas

a eventos discretos

$R P C$

Ferramentas

Edifícios Inteligentes

\section{Aplicacões}

CPNTOos

Sistemas de controle

de Edifícios

Inteligentes

Figura A.2 - Ciclo de desenvolvimento considerado nesta pesquisa 


\section{Anexo 2}

\section{Tecnologia LonWorks}

LonWorks é uma tecnologia que inclui a infraestrutura de hardware e software para a operação de uma rede de comunicação de um sistema de controle denominada Local Operating Network ( $L O M$ ). Trata-se de uma tecnologia aberta de controle distribuído que possibilita a interoperabilidade. $O$ protocolo de comunicação utilizado, denominado LonTalk (ANSI-709.1) implementa as sete camadas do modelo de referência da ISO (International Organization for Standarization) e foi projetado para aplicações que envolvem funções de sensoriamento, controle, monitoração e identificação (CUNHA, 2008).

São permitidos seis meios físicos de transmissão de dados: cabos de energia elétrica, par trançado, cabo coaxial, infravermelho, radiofrequência e fibra ótica. A parte principal de uma rede LonWorks é um circuito integrado de nome "Neuron Chip", o qual atua como um nó da rede, incluindo o hardware de comunicação e o protocolo LonTalk. O gerenciamento da rede de comunicação é distribuído nos dispositivos (nós). Cada nó tem seu próprio programa aplicativo, de acordo com a sua função, e se comunica com os outros nós por meio do protocolo LonTalk. A associação LonMark estabelece padrões e certifica dispositivos de controle interoperáveis (CANOVAS; CUGNASCA, 2010).

Os subsistemas básicos que compõem uma rede LonWorks são:

- processadores "Neuron Chip";

- transceivers, que permitem a conexão aos distintos meios físicos de transmissão;

- módulos de controle LonWorks, que incluem o "Neuron Chip", tranceivers e memória externa;

- roteadores, que servem de encaminhadores entre as diferentes sub-redes e/ou meios de transmissão; 
- interfaces de rede de comunicação, por meio das quais podem se interconectar outros elementos baseados no protocolo LonTalk, tais como computadores, Controladores Lógicos Programáveis (CLP) etc.;

- ferramentas de instalação, configuração e diagnóstico, tanto dos nós como das redes de comunicação;

- ferramentas de desenvolvimento de aplicações, compilador, depurador etc.

Os nós podem se dividir em dois grandes grupos funcionais:

- nós de controle com memória e capacidade de processamento; e

- nós transdutores de sensores e/ou atuadores.

Este último grupo de nós possui a função de ler os valores adquiridos dos sensores, enviando-os por meio das variáveis de rede aos nós que necessitem de tais informações. Similarmente, um nó atuador pode simplesmente ativar uma saída em resposta a uma ordem enviada pelo nó de controle. Essa distribuição é necessária em razão do número limitado de entradas/saídas físicas de cada nó e, em muitos casos, não é possível integrar em um único nó as funções de sensoriamento, atuação e controle.

A Figura B.1 mostra um exemplo de uma rede LonWorks de um sistema contra incêndio, no qual se podem notar os seus principais componentes: sensores (pressostatos, sensores, estações manuais), atuadores (bomba contra incêndio, bomba secundária contra incêndio (jockey)), dispositivos de controle (terminais de monitoração e controle, painel de controle), canais de comunicação, roteadores e gateways. Nessa figura, a bomba contra incêndio, as estações manuais e o painel de controle se comunicam por meio de uma rede do tipo par trançado; o roteador permite a comunicação com a rede powerline, que utiliza a rede elétrica como meio de transporte dos dados que interliga a bomba jockey, o pressostato e o multisensor. O gateway permite a comunicação com a rede externa do tipo TCP/IP que está conectada aos terminais de monitoração e supervisão. 


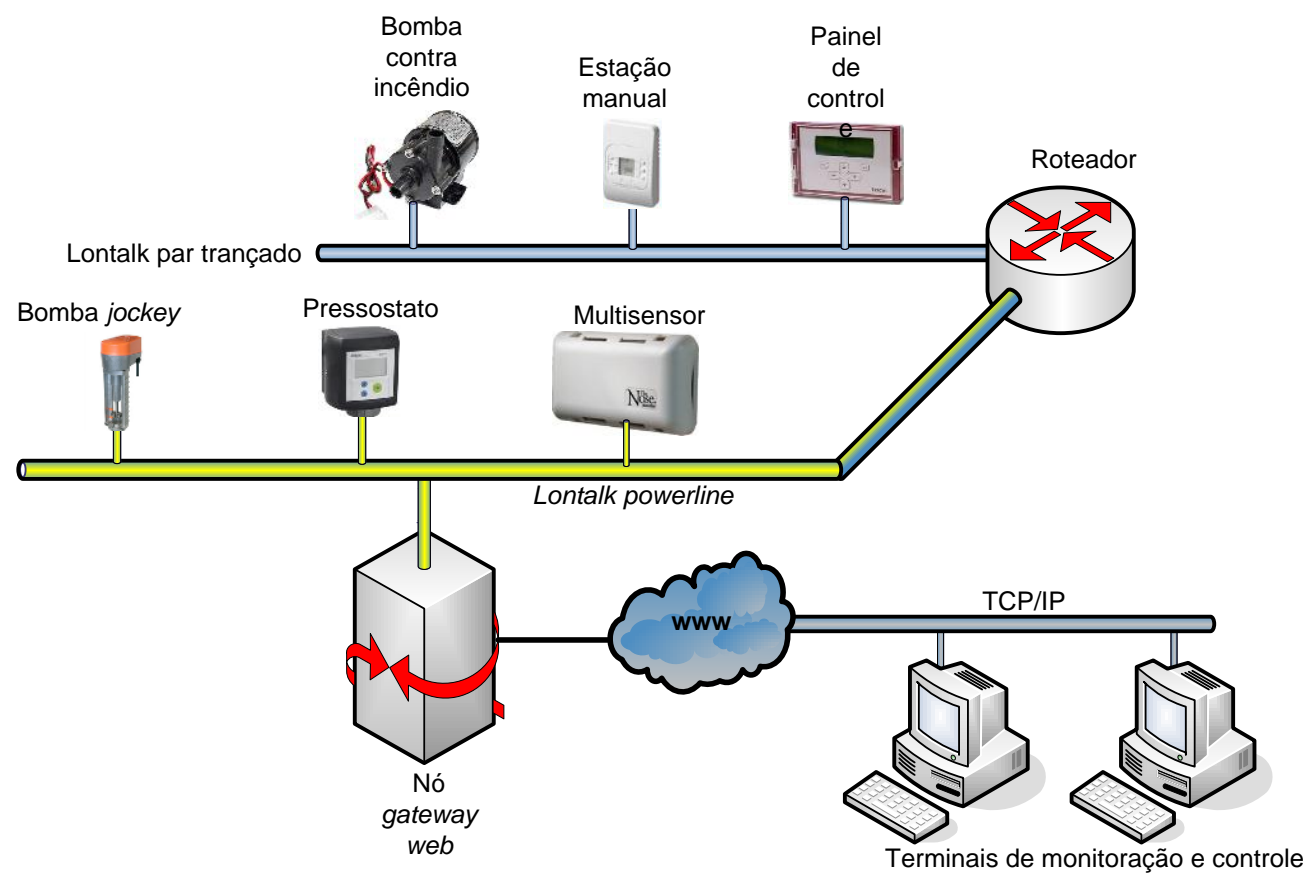

Figura B.1 - Exemplo de uma rede LonWorks típica (KANESHIRO et al., 2007) 